\title{
SMALL FRUITS
}

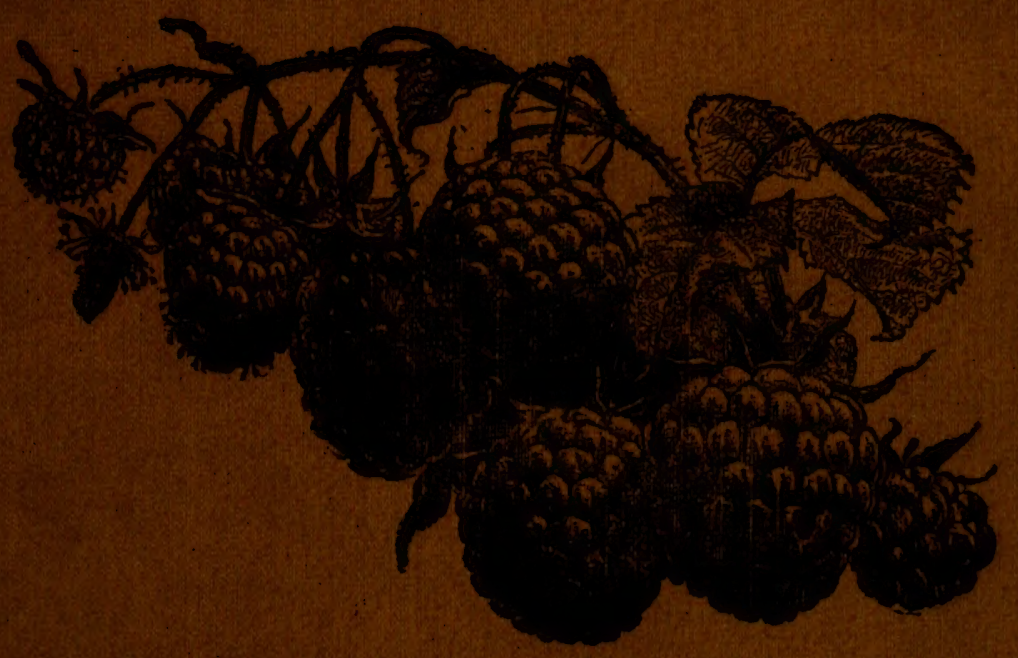

SB 381

.465

Copy 1

WILLIAM H.HILLS 


\section{LIBRARY OF CONGRESS, SB381

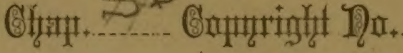

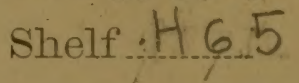 \\ UNITED STATES OF AMERICA.}








\section{SMALL FRUITS:}

\section{Their Propagation and Cultivation, Including the Grape.}

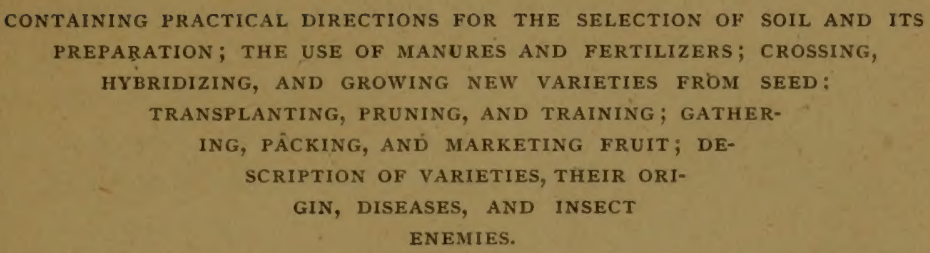

Ellustrated with Numerous Eengrabings.

BY

WILLIAM H. HILLS, FRACTICAL HORTICULTURIST, PLAISTOW, N.H.

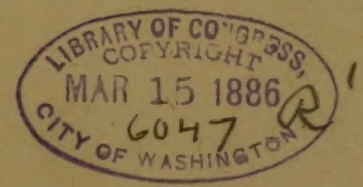

BOSTON :

CUPPLES, UPHAM \& CO., AGRICULTURAL PUBLISHERS.

r886. 
CoPYRIGHT, 1886 ,

BY W. H. HILLS.

All rights reserved. 


\section{PREF A CE.}

I have been induced to present in the following pages practical directions for the propagation and cultivation of small fruits, partly because a few friends, to whose judgment I have been accustomed to defer, advised it; partly to answer the numerous questions that are being constantly addressed to me orally and by letter; and partly because I hoped thereby to encourage the more general dissemination and use of fruits.

There are many merchants, mechanics, professional men, and men of leisure, owners of small tracts of land in the country or suburban villages, who are anxious to learn something of the best varieties, and the different methods of growing them in the private garden. It has been my aim to furnish a hand-book containing just the kind of information required by this class, and also for more extensive cultivators in the field.

No attempt has been made to dress the subject in fine language and well rounded periods, or to do more than to give the best practical directions in the most compact form, thus bringing the work within the means of all who may wish to cultivate fruits for their own tables with their own hands. Whoever wishes to grow fruits for the market will not fail to consult the works of such men as Downing, Barry, Fuller, and Roe, each of which should have a place in the library of every one making any pretensions to horticultural knowledge. Some of the more elaborate works, however, embrace matter of little or no interest to the novice, while others are too expensive for general circulation.

This brief treatise will be found to contain all that is essential to success at trifling cost, but is not intended to supersede the labor of others. Most of the so-called "Guides " and "Instructors" are little more than advertising catalogues, in which new varieties are puffed, 
and old standard sorts decried or totally neglected. Believing that all varieties of merit should be retained, I have endeavored to avoid fulsome praise of the new, on the one hand, and undue detraction of the old, on the other. Both the faults and excellences of varieties have been frankly stated, hoping that disappointments and needless expense on the part of the beginner may thereby be avoided.

The collection of information as to the origin of varieties has caused me no small amount of labor. Due credit has been given to those by whose skill and care superior new fruits have been produced. If I have occasionally hit a humbug, no apology will be made for the offence.

The book is mainly the result of not large but long personal experience and observation, to which is added information drawn from some of the most reliable and intelligent horticulturists in the country. It has been written in odd moments, and will be found neither perfect nor complete.

About one third of the volume is devoted to grape culture, a subject not usually embraced in works treating of small fruits. A few copies of the essay on grapes were originally printed in pamphlet form, and received the commendation of President Wilder, Charles Downing, and other eminent horticulturists. That essay has been revised and enlarged, so as to adapt it to the present state of knowledge. I trust it may be found of some value.

If those who nay take the trouble to read what has been here presented shall find therein the information they are seeking, the writer will feel amply rewarded for the labor its preparation has cost.

WILLIAM H. HILLS.

Plaistow, N. H., May 19, 1885. 


\section{SMALL FRUITS:}

THEIR PROPAGATION AND CULTIVATION.

As the practices and opinions of fruit-growers differ so widely, anything that may be written on the subject is likely to be severely criticised, and the criticisms in many instances srill undoubtedly be just and pertinent. My aim will be simply to make the process of growing small fruits, both for the market and family use, so plain and practical that the novice will need no other guide.

I shall not occupy the limited space allotted me with directions for enltivating the barberry or the huckleberry, but confine myself mainly to those species and varieties usually found under cultivation. I shall make no attempt to write up the history of our small fruits, regarding it of no importance whether Pliny, Virgil, or Orid spent their leisure hours in the berry "patch," or even knew anything at all about the best varieties.

I began the cultivation of the strawberry more than thirty years ago, at a time when the Hovey's Seedling, Boston Pine, Hooker, Virginia Scarlet, and Cutter's Seedling were the leading varieties, all of which, except the Hovey, have disappeared from the lists of varieties cultivated or named. In size, beauty, productiveness, and quality, some of these were at that time thought wonderful; and though most of them are not now to be uamed in comparison with the best sorts of to-day, yet they were so much superior to the wild berries gathered in boyhood, that they made an impressinn upon the mind never to be effaced. Since that time I have ner $r$ lost my interest in this and the other small fruits, but have h.rd uncler cultivation at times some 
nfty varieties, adding new and rejecting old sorts from year to year, so that many of the candidates for popular favor have been fairly tested.

\section{A NEW DEPARTURE.}

A new departure was made in 1806 , by one Michael Keen, a cclebrated English gardener, who introduced the "Imperial," which he grew from seed, and subsequently, from seed of the Imperial, what was long known as "Keen's Seedling:" This was a wonderful fruit for the time, being large, productive, and of good flavor and habit of growth; but it did not succeed in this country, and was soon supplanted by more hardy sorts. The London Horticultural Society, in 1821, had executed a colored plate of this strasperry (not a very rare thing now), indicating its high appreciation of its merits.

The success of Keen excited scores of others to attempt the growing of better varieties from seeds, and from that time to the present, seedlings have been numerous. Little was done in this country, except in imitation of English practices, till about 1834, when Mr. C. M. Hovey prodnced and introduced what has since been kuown as "Hovey's Seedling," a fruit hardly surpassed by the best varieties of the present time.

Little or nothing was generally known in this country, at the time when the Hovey appeared, relative to the seruality of the strawberry. The wild plants were all perfect flowering, or staminate, and the effect of cultivation in producing pistillate varieties had attracted but little notice. Mr. Longworth, of Ohio, was among the first to take a decided stand on this question, and the war on the subject was long, if not bloody. Mr. Longworth marle a standing offer-if history is not at fault-of one Jundred clollars, to any one who would produce a perfect berry from a pistillate plant, unless the same was fertilized by a staminate variety. No claim was ever made for the money, and the correctness of his position is now generally conceded by all intelligent pomologists.

The great success attending the production of seedling strawberries lias ineited those engaged in the business to try and improve other small fruits by similar methods, and with almost equally farorable results. This has been accomplished by sow- 
ing and resowing seeds of the best varieties under cultivation, by transplanting to the garden plants of the choicest wild berries, and by crossing and hybridizing, a process that will be hereafter described.

The result is, that we now have raspberries, blackberries, grapes, and currants, nearly equal in size and quality to the finest foreign sorts, and greatly surpassing them in hardiness and general adaptation to our climate. The progress made seems more rapid every year, as the methods are better understood, and it is to be hoped that the ideal berry will soon be produced.

\section{SMALL FRUITS NEGLECTED.}

It would seem that no orner or lessee of land for a term of years would omit to plant out on his place a rariety of small fruits, sufficiently abundant to supply his family during their entire season. There should always be a surplus for the liberal entertainment of friends, - always numerous in the berry season, - and for preserving in various ways for winter use. The first cost of plants would be but a trifle, - no more than a meerschaum pipe, a bux of cigars, or a gallon of whiskey, -and they are so rapidly propagated that the sale of surplus plants may be made a source of some income.

When urging farmers to plant out small fruits, we are frequently told that there is an abundance of wild berries in the neighboring fields and pastures, to be had for the mere picking. Now, while there may be wild berries of an inferior quality in some localities, it is more of ten the case that the supply is limited to one or two kinds, and these are only attainable by making rambling journeys over brush and brake. There is nothing like a continuous supply during the small fruit season.

It is often claimed that wild frnits-strawberries and the likeare superior in flavor to cultivated varieties. 'This is a great mistake, arising in part from lack of familiarity with the best cultivated sorts, and in part from an uncultivated taste. I have seen persons who preferred the flavor of the wild, foxy grapes of the swamps to that of the best foreign variety grown under glass.

The wild strawberry is not usually picked as soon as colored, as frequently occurs in case of those under cultivation, but 
remains on the vines till perfectly ripe, and in its best conclition. But the arerage wild strawberry will be found as poor in quality as it is inferior in size and appearance. Place the two on the fruit-stand or table, side by side, and no one would hesitate in making a selection. We now have plenty of varieties superior in all respects to any obtainable without cultivation. More fruit, of larger size, superior flavor, and of almost any variety, can be grown on five square rods, rightly managed, than can be found wild on any farm of ordinary size in the country. A few rods devoted to this purpose will afford health, satisfaction, and pleasure, and by enlarging the area from time to time, as experience is acquired, may, in many localities, become a source of profit. Special knowledge and skill will be useful in this business, as in any other, but the clegree of skill and knowledge required is no greater than for the successful treatment of any farm crop.

Who ever saw a wild strawberry that would equal in size the smallest variety now under cultivation? Just take a ramble over fields and pastures, where you formerly gathered the berries now remembered with so much pleasure, gathering and testing the best fruit to be found, and it will prove to be almost uniformly small, sour or insipid, and worthless. Who ever thinks of eating wild strawberries, that has the improved varieties under cultivation? Children, even, will hardly stop to pick such fruit, if growing directly in their path. The wild berries are as abunclant in their season as formerly, yet they are never seen in market, and, if offered for sale, would be rejected at once. Oceasionally one has been found better than the rest, and transferred to the garden, like Cutter's Seedling, and disseminated more or less widely, but I know of no rariety now uncier cultivation that originated in that way. Yet, as birds are scattering the seeds of the best sorts far and near every year, the discovery of valuable seedlings in uncultivated localities would be no surprise, and the wide-awake fruit-grower is always on the lookont for all such chance seedlings.

TO THE NOVICE.

To the inquiry, often made, as to where to locate in the small fruit business, I would say in answer, as near to the people as 
possible. Your success will depend largely upon the distance you are from market. Small fruits cannot be grown profitably ten miles from the consumer, except on the line of some railroad, in which case a distance of twenty or thirty miles will make a difference of only an hour or two in time.

There are numerous villages, large and small, furnishing good opportunities to those near by for doing a safe and profitable business in growing fruits. In the vicinity of summer resorts, fresh fruits net a higher price than can be realized from commission men in large cities, where competition is sharp. If marketed by the grower, there is no expense for freight, or per cent. to be deducted by the middle-man. The large manufacturing towns afford good markets. Mechanies, factory operatives, and shop-girls spend their money freely when the times are brisk, and the boarding-houses consume fruits in large quantities. Get as near to such a town or village as you can. If within a mile, you will have a great advantage over one five miles away. You can watch the market, and rush your berries when there is a demand, and hold them back when there is a glut.

There are always many visitors from the cities to near-by fruit-farms, persons who like to take their fruits fresh and fragrant from the vines, even at an extra price, rather than stale from the huckster's stall. The man engaged in growing small fruits must not only cultivate his berries, but also his business, by selling only the best, lionestly and tastefully put up. In this way he will soon acquire a reputation, and secure the patronage of a desirable class of customers.

But the beginner should enter upon the business expecting to meet with many discouragements, such as hard winters, late spring frosts, drouths, destructive insects, overstocked markets and consequent low prices. It must be borne in mind, however, that others will meet with like discouragements and quit the business, leaving the coast clear for those who are more persistent. If the beginner consults his own interest, and grows only the best varieties in the best way, and puts his fruit upon the market in the most attractive form, he is sure to succeed. Of such fruit there is never an over-supply. 


\section{SOII AND ITS PREPARATION.}

Small fruits may be successfully grown on almost any soil which is in suitable condition for the ordinary field and garden crops. Land well prepared for corn, potatoes, or any of the root crops, will insure, other conditions being favorable, a profitable yield of strawberries, raspberries, blackberries, currants, or gooseberries. It is true that some fruits require a strong soil and high cultivation, while others will succeed admirably on rather light, sancly, or gravelly land, with comparatively little care. The extremes, loose sand and heavy clay, should of course be avoided. The slip-shod sloven will do well to inquire for and plant out the varieties last named only. The more careful cultivator will select a plot such as he would prefer for garden regetables, and prepare it in a similar manner.

To say that small fruits must be planted on soil plorred or trenched eighteen, twenty, or twenty-four inches deep, and receive an application of ten, fifteen, or twenty cords of fine old manure to the acre, is only to frighten the novice out of his wits, or, at least, out of any idea he may entertain of growing small fruits at all. It is not denied that surprising results may be attained by adopting such methods, but the returns will not justify the outlay.

This statement is made after having tested nearly all the various methods recommended. In one instance the ground was trencher with a spade two feet deep, and well fertilized to that depth with fine old manure. Strawberry plants were set in beds containing three rows each one foot by eighteen inches, with walks of two feet between the beds. All runners were cut as soon as they appeared, and each plant formed a stool as large as a well cultivated bill of beans. The result was simply wonderful. As many as twenty-seven fruit stocks were counted on one plant of the Wilson, and the yield was undonbtedly a quart to a plant in many instances. But it did not pay; the expense was too great, - not less than $\$ 300$ per acre. I have grown as fine berries, and nearly as large a crop, with half the manure, on land plored less than a foot deep. But it must be admitted that under the treatment first named the plants continued to yield well one or two years longer than under the latter.

Remunerative crops are not likely to be repeated under the 
usual methods of cultivation for more than two or three years, and many take one full crop only ard then turn under the plants, growing some other crop on the land for a year or two before planting again to berries. The practice of frequently renewing the plot, as young plants give the finest fruit, will be found most profitable and satisfactory.

It is not intended here to encourage poor cultivation under any circumstauces, but only to combat the wild and extravagant statements of a few writers who do much to cliscourage the general cultivation of small fruits. A circular recently received, with a highly-colored picture of a strawberry bearing the name of the writer, contains the statement that the soil, after being dug or plowed, should be "spread over with at least three inches of thoroughly rotted stable manure." 'This would require about eighty-five cords to the acre, varying in cost from five to eight dollars a cord, according to locality. Here we have an outlay of from four hundred and trenty-five to six hundred and eighty dollars per acre for manure alone. If this pet berry, christened in the name of the modest disseninator, requires such extraordinary treatment, it will be well for purchasers to leave it altogether in first hands.

Some varieties require good strong soil and high cultivation, and if the best treatment cannot be given them they had better be left severely alone. As a rule, it will he safe to give all kinds the best care possible. Do not spread over and half cultivate too large an area, but plant less and cultivate better, remembering that it is the inferior fruit that gluts the market, and that there is never a surplus of the best. A good sancly loam will be found suited to a greater number of varieties than any other. Whatever the soil selected may be, it will pay to have it thoroughly prepared mechanically before the plants are set. This would consist in deep plowing, cross plowing, cultivating, and harrowing. A sub-soiler run in the furrow of the common plow, loosening and lifting, but not bringing to the surface the lower strata, will tend to ensure the crop against a protracted drouth, such as of ten happens at the season of ripening. There is little danger of working land too deep.

If these operations are preceded by the application of a suffcient quantity of stable manure, it will have become well mixed with the soil by the time the planting out is completed. 
PLANTING ON SOD.

As a rule, never plant small fruits on sod land if it can be avoided. Still, if such land is plowed up early in the fall, when covered with grass or clover, the socls will become well decayed by spring, and may be worked fine with the Acme, or one of the wheel harrows. The soil may thus be made mellow four or five inches deep, without disturbing and bringing to the surface undecayed herbage. The roots of plants on such land will strike down into the decayed sods and make themselves quite at home. If an application of manure is spread broadcast on the land before plowing, all the better.

The great danger in planting such land with strawberries would arise from the white grub, so common in sod land, often proving very destructive to the plants.

\section{DRAINAGE.}

Whatever the character of the soil selected for small fruits, care should be exercised that no water stands over or around the plants in winter. A heavy rain will often occur after the ground has frozen in the fall, filling depressions, and sometimes covering a large level plot completely with ice. This is sure to prove fatal to the plants frozen in and excluded from the air. Outlets should be seasonably provided for the escape of surplus water from all low places, and even on level plots it is safer to plant in beds slightly raised, to aroid this danger. Where there is a slope to the land, which will almost always be the case, the width of the bed may be greater, and the elevation less, in proportion to the fall.

On all wet lands under-draining of some kind must be attended to or the plants will be thrown out by frost, and this should be clone, of course, before the plants are set. Tile for this purpose will be found the best, cheapest, and every way the most satisfactory. Where rocks are abundant and must be removed at all events, they may be utilized for this purpose; but the flow of water in stone drains is liable to become obstructed, while tile drains, properly laid, never fail. The depth at which tiles should be laid ought never to be less than three feet. The expense of excavation will be much less than for more shallow drains when stones are used. Any one about to put in 
drains of any lind will find it for his interest to cousult some one of the valuable works on that subject before any expense is incurred, thereby avoiding many mistakes and much unnecessary labor.

A plot well drained with tile is not only comparatively safe from sudden floods in summer and fall, but will be in condition to work much earlier in the spring-a matter of no small importance when new plantations are to be made.

\section{MANURE AND FERTILIZERS.}

The kind and quantity of manure required will depend somewhat upon the character and condition of the soil. For light, sandy land, a compost of one third peat or muck containing a large per cent. of regetable matter, one third clay or strong clay loam, and one third stable manure, will make a valuable compost for any of the small fruits. Ground bone mixed with unleached wood ashes-one part bone and two parts ashesdampened with water at the time of mixing, and allowed to beat for a few days, will make one of the best fertilizers for working into the soil at the time of cultivation. The mixture should be shovelled over on the stable floor once or twice, and more water and a little gypsum added to check too high a degree of heat.

Some contend that old manure is indispensable. This has not been my experience. A Kiemp manure spreader will fine any manure, and give it an even distribution. If spread by hand, a disk harrow will cut and cover it in a satisfactory manner. Fine old manure will act at once, and, for top dressing old beds-as it can be more evenly spread-is much to be preferred. Coarse manure in rotting down will shrink one half in bulk, and in its fine condition we usually apply twice as much of it, and this, in connection with the fact that it is more soluble, gives it a deservedly high reputation. But no one expects a crop of fruit till a year, at least, from the time of setting the plants, by which time, and long before, green manure will have become decayed and available.

Liquid manure will produce immediate and wonderful results, but, unfortunately, few have the facilities for applying it. When used it should always be in a dilute form, as otherwise it will 
prove not only unavailable as plant food, but injurious if not destructive.

In making a plantation of small fruits, the condition of the land selected should be carefully considered before deciding what kind and amount of plant food to apply. A fertile soil, under ligh cultivation, will give a good crop with very little or no manure, while a starving soil must be liberally fed to insure profitable results. As a rule, the poorer the land the more manure will be required; and the more manure, the larger the crop.

If special fertilizers are used, compost them with more bulky manures. The two will be better when mixed than either alone. The strawberry is not only a gross feeder, requiring large applications of plant food of some kind, but it will pay to have it in the best condition, and at the right time.

The fruit buds of the strawberry, and so of other small fruits, are formed in summer and autumn, and no application of manure in spring will increase their number, although it may increase the size of the fruit. There is no better time to apply manure to the strawberry-bed than immediately after the picking season, or early in autumn. A late application in spring will be of comparatively little benefit. To obtain the largest crop of fruit, we must have vigorous and healthy plants, and these must be grown the previous season.

Some varieties, under high cultivation, are inclined to make a very rank growth without a corresponding yield of fruit, while others have a dwarf habit. The hlackberry, for example, on rich, heary land, makes a rampant growth, and for this reason the less stimulating manures should be used. On the other hand, the Wilson, and some other varieties of the strawberry, are of a dwarfish habit, and will bear Peruvian guano and other nitrogenous fertilizers. Thus the cultivator will find occasion for constant observation and study.

SEASON FOR TRANSPLANTING STRAWBERRIES.

The spring is undoubtedly the best time to set plants in the latitucle of New England, but, with a little extra care and risk, it may be done in mid-summer, or as soon after as new plants from runners become well rooted. The time will depend upon 
the weather and the condition of the ground, whether wet or dry. I have made plantations as early as July, and obtained nearly a full crop of fruit in less than a year. Where plants must be obtained from a distance, and are several days on the way, the risk is greater, and more losses will occur; but if they are only to be moved from one part of the field to another, there need be but few failures. If the new plants are rooted in small pots-a method described elsewhere-they may be transported long distances, and set out at any time before the middle of September, and will yield a partial crop the next season.

If runner plants from the bed are to be set in the fall, whiclr may be done from August to October, a time should be chosen when the ground is moist, or during a rainy season, in which case very few will fail to take root and become firmly established before winter. When set late, the plants will not always become well rooted, and are liable to be thrown out by frost and destroyed.

When set in spring, let it be as early as possible,-as soon as the ground can be properly worked. April is preferable to any other month, but they do well in May. At this seasonApril-the land is cool and moist, the days are not long, and there is an absence of drying winds and scorching suns. It is at about this time that the plants are in a semi-dormant condition, and, being but half awake, they receive less shock than if transplanted after.vigorous growth has begun.

Plants set as early in spring as is here recommended will give a moderate quantity of fruit within three months, if the flower buds are allowed to remain. But fruiting plants will not make a very strong growth, and it is better to pinch off all fruitstalks, and trim off all but the centre leaves at the time of transplanting.

Where a mixture of varieties is suspected, sufficient fruit may be allowed to set as a test of purity, and all spurious plants at once removed. The racancies thus caused will be filled by runners in a few weeks, and the grower will have the satisfaction of knowing that his plants are unmixed and true to name. The reputation of a dealer depends upon the purity of his stock, and he should make a study of foliage so as to be able to detect any mixture at a glance. No two varieties have the same habits of 
growth, and when the peculiar characteristics of a plant are once fixed in the mind, all spurious sorts can be removed at any time.

Old beds of strawberries are often situated in proximity to where a new bed is to be formed, and in such cases tufts of plants can be cut out with a spade, and removed to the newly prepared bed. If in spring, fruit may be obtained in a few weeks. As trenches will be required to receive plants removed in this way, and as they are bulky and heary to handle, this method can only be recommended for small plots, where the stock plants are near at hand, and fruit is desired at the earliest possible moment.

\section{POTTED PLANTS.}

The amateur is often anxious for a strawberry-bed in bearing at once, and cares very little about the expense. This demand from persons who are in a hurry, has led to the practice of rooting plants in small earthen flower-pots, and such plants can be furnished at about double the price of those that are allowed to strike root in the ground.

The method adopted is to fill the pots with rich soil or fine compost-the better the material the sooner the plant will fill the pot with roots - sink the pot in the ground, under the young plant, and fix the plant in position by placing on the runver a small stone, or covering it with dirt, to prevent displacement by the wind. It will take about three weeks, under farorable circumstances, for the roots to fill the pot, when the runner connecting it with the old plant should be cut. The pot may be left undisturbed for a week or two longer to allow the plant to become well established as an independent institution. If the weather be dry during this time, one or two applications of water, pouring it directly into the pot, will be of service.

As soon as plants have become well rooted, they will be in the best condition for planting out in their new quarters. If allowed to remain long in the pots, they become almost worthless, owing to lack of room for their roots to develop and expand. They are cramped and dwarfed, like a Chinaman's foot, and seldom if ever recover. These plants are in the condition known to plant-growers as "pot-bound." On examination, it will be found that the roots next to the pot have turned black, 
and are in fact dead. The best way to restore such plants is to turn them out of the pots and wash all the soil from their roots, removing entirely those that are dead, and plauting out in fresh soil. It must be apparent that such plants are greatly inferior to those that have simply taken root in the ground, yet unscrupulous dealers sometimes impose upon their customers by filling orders in spring with plants that have been kept over winter in pots.

For the reason here given, dealers only pot plants in limited numbers, and of leading varieties, not knowing what and how many will be called for, and not wishing to injure their stock, or incur unnecessary expense. Hence potted plants should be ordered early, never less than three or four weeks in adrance, to secure a supply of well-rooted plants of the varieties wanted.

It should be borne in mind that plants grow, but cannot be made to order. They should always be turned out of the pots when shipped, and the balls of dirt containing the roots packed in damp moss, leaving the foliage fully exposed to light and air, and in this condition they may be transported almost any distance without risk.

Fig. 1 represents, better than language can describe, the method of growing potted plants. 'The marks of cancellation

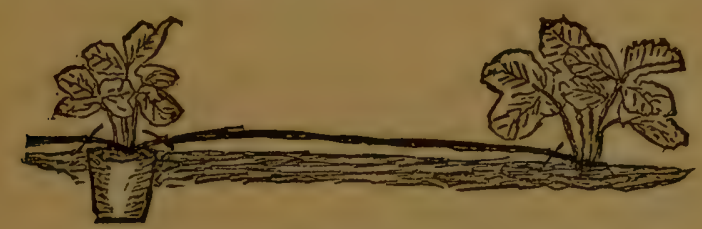

Fig. 1.

show where the runner should be cut when the plant has filled the pot with roots.

There is not much to be gained by setting runner plants in autumn, as they will not give a full crop the next year; but even a sinall crop may be better than none, and it is sometimes more convenient to transplant at that season.

TRANSPLANTING STRAWBERRIES.

The land being ready, the next thing in order will be to set the plants. Let the rows for field culture be as long as possi- 
ble, so that the horse and cultivator can be conveniently used to keep the ground loose and clean. The hand hoe may answer for small plots in the garden, but need only be used immediately around the plants on large plantations. If the plants are to be grown in "matted rows," - the most common practice-they should be four feet apart. Matted rows a foot wide will do to talk about, but they are seldom seen. A single row of fully developed plants will spread at least a foot, and matted rows are seldom less than two feet wide. This will leave only two feet for the horse and cultivator. Where plants are to be kept strictly in hills, or narrow rows, three feet apart will be a suitable distance.

Plants are usually set one foot apart in the rows, but varieties that send out numerous runners may just as well be set two feet. This should be the distance when set in spring, or where the multiplication of plants is an object, as in case of some new or valuable variety. If the land be rich, it will be fully stocked with plants by fall. The runners may be trained in all directions, where plants only are wanted, and covered with soil at each joint, to keep them in place and hasten rooting. Runners push before the parent plants have fully ripened their fruit, and after picking is over, make rapid growth. The new plants only are of any value for making new beds; old plants are worthless.

When plants are to be moved from one field to another, proceed as follows: Lift the plants with a garden-trowel; remove all but two or three of the centre leaf-stalks and the fruit-stalks, if any, with shears or a sharp knife; straighten out the roots, and cut them back one third their length; sprinkle the plants, if a dry day, and take them to the field or garden in a covered basket, or in a pail with their roots immersed in muddy water. Use a garden-trowel for opening the holes, and always set by a line. If the weather is dry, let an active boy open the holes and drop out the plants, a second boy fill the holes with water, while a third sets the plants, being eareful to have the crorwns just even with the surface. Spread the roots in all directions, and press the soil firmly over them. It would seem as though no mistake could be made in performing a process so simple, yet it will take one man, on an average, to watch three boys, and make 
sure that the work is properly and faithfully done. The roots will be crowded into the hole in a mass, sometimes with their ends pointing up instead of down; the plants will be set so shallow that nearly half of the roots will be out of the ground, or so deep that only the leaves can be seen, or, worst of all, so lonse that they are in danger of being blown out by the wind. I speak of boys, but they are no worse than men. In fact, a man is more intractable than a boy, just in proportion as bis skull is

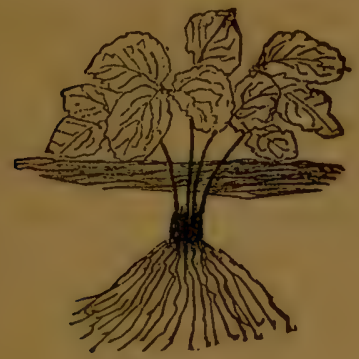

Fig. 2.

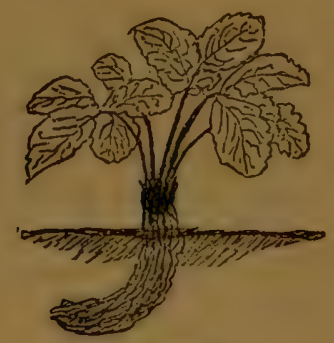

Fig. 3 .

thicker. Once more let me say to every boy and man : Set strawberry plants with their crowns just eren with the surface of the ground; spread their roots as much as possible, and press the soil firmly over and around them.

It is hoped that the illustrations here given will make the matter perfectly plain. Fig. 2 represents a plant set too deep: the crown will decay, and the plant die. Fig. 3 shows a plant set so shallow that the roots are not fully covered. They are left in a matted mass, and unless the plant is re-set it will be worthless. Fig. 4 represents a plant that had its roots shortened, and properly spread when transplanted, and gives a good illustration of how the work should be done.

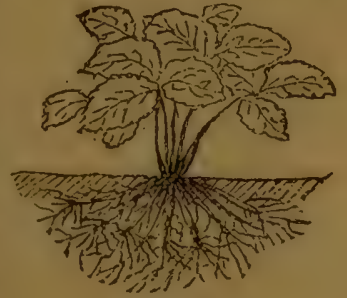

Fig. 4 .

In field culture I like the method of growing strawberries in narrow rows in preference to matted rows, or, what is still worse, matted beds. One objection to the matted row or bed system is, that it is impossible to keep the grass and weeds sub- 
dued. The plants very soon become so thick that the hoe cannot be used, and hand weeding on a large plot is out of the question. The result is, that any attempt to give clean culture must be abandoned, the grower taking one or two inferior crops of fruit, when the vines are turned under with the plow.

President Wilder says, - "For garden culture, I like the method of planting in rows three feet apart, with plants one foot in the row, allowing each to make from two to four shoulder runners, and no more, for the first season. These, by autumn, will constitute a thrifty row of strong-bearing plants, and will produce more than the common matted beds. For field culture, I would plant in rows four feet apart, and a foot apart in the row, and where wide beds are allowed, it will be found of great benefit to pinch off all superfluous runners, so as to have none but strong plants. Some varieties require to be grown in hills, and to have the rumners cut off as soou as they appear-such as the Sharpless, Bidwell, and Triomphe de Gand. Parker Earle, an extensive grower of small fruits at the West, says, - "Let as many runners grow as will make a narrow matted row: cut the balance, keep the middles clear all the time." E. P. Roe, author of "Success with Small Fruits," says,_- I am satisfied that the method best adipted to our Eastern and Western conditions is what is termed the 'narrow-row system,' believing that it will give the greatest amount of five fruit with the least degree of trouble and expense. The plants are set one foot from each other in line, and not allowed to make runners. In good soil they will touch each other after one year's growth, and make a continuous bushy row."

In garden culture, plants may be set in beds-not raised beds -of three or four rows each, the rows eighteen inches apart, and the plants one foot apart in the rows. Leave walks at least two feet wicle between the beds for convenience in hoeing and picking. There will be no occasion for stepping on beds thus set for any purpose. Cut all fruit-stalks, and, if to be grown in hills, all rumers as they appear. Kieep the ground mellow, allow no weeds to grow, and mulch in case of severe drouth. Such a bed will remain productive, if top-dressed annually for five or six years. 
THE NUMBER OF PLANTS REQUIRED FOR AN ACRE.

Many orders are given for plants and trees without making an estimate of the number required. The order may be for more or less than are wauted, thereby subjecting the purchaser to unnecessary expense in one case, or to the trouble and delay of sending a second order in the other. Late orders are always to be avoided, as the stock of a variety may be exhausted, and if not, the plants are liable to be of an inferior quality.

'The following table will be found convenient:

Number of Plants, Trees, etc., required to Set an Acre.

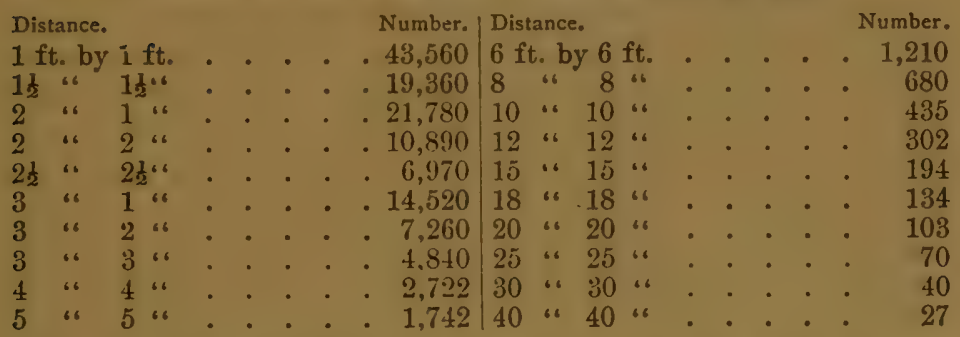

In case it is proposed to set at distances not given in the table, it will only be necessary to multiply the wiclth of the rows in feet by the distance of the plants apart, and divide 43,560 , the number of square feet in an acre, by the product.

Example. Plants set three feet by six would each occupy an area of eighteen square feet, and 43,560 divided by 18 gives 2,420 , the number required to set an acre.

\section{STRAWBERRIES. WHAT TO PLANT.}

It would be impossible to name any one variety as superior to, and for all purposes more valuable than, any other. The question is often asked, What is the best strawberry? and the answers given by good judges are quite varied. In fact, there is no one kind superior to all others under all conditions. Soil, location, cultivation, and other circumstances have so much to do with success or failure, that we cannot be sure, in advance, what variety or varieties it is best to plant out. On one plot a certain kind will lead in productiveness and profit, while only a few rods distant the soil and situation may be so 
unlike that the same variety will be a total failure. The beginner may derive much aid by consulting those extensively engaged in the business of growing small fruits, though he cannot safely rely upon the experience of others, but must experiment for himself. If growing for his own private use, he will consult his own taste as to quality; but if for market, he must cater to suit the demands of the purchaser.

\section{MUST BE ADAPTED TO TIE SOIL.}

While some varieties seem peculiarly adapted to a rather light sandy soil, others require that which is strong and heavy, and still others appear indifferent, doing equally well on any soil. One kind will give perfectly satisfactory returns grown in hills, matted rows, or by the slipshod method, while another will fail in the absence of high and clean cultivation, and unless grown in hills on congenial soil. Liberal manuring, deep working of the land, mulching, and irrigation will insure success in the dryest season. If plants are thus treated, the soil will be found filled with their roots as deep as cultivation extends. A like examination of plants on a shallow soil will show roots too short to render the moisture below available. Some varieties require deeper soil than others.

The following extract from the report of the New York Experiment Station for 1883 is in point: "A plant of the Triomphe de Gand strawberry, the roots of which we washed out August 13 , had roots extending nearly vertically clownwards to the depth of twenty-two inches. The horizontal roots were few and short, the longest being traceable but six inches. 'The greater part of the roots extended nearly perpendicularly downwards, and nearly all of the fibrous roots were found directly beneath the plant."

It will be seen that the rarieties to be selected will depend almost entirely upon the object in view. For the home garden the quality should be first considered. The plant should be hardy, healthy, and fairly productive, the fruit of at least medium size, of good form and color, and in its general appearance attractive. With such varieties as the Downing, Cumberland, Herrey Davis, Jersey Queen, Minor's Prolific, Mount Vernon, Sharpless, and Wilder, or any other judicious selection from the early, medium, and late varieties, any one may enjoy a full supply 
of the most beantiful, luscious, and healthful fruit for more than a month. That it comes before any other fruit is ready for the table renders it all the more welcome and valuable.

For the market, varieties must be selected that will "crop heavily," that are large and "showy," and that are firm enough to bear "handling." As purchasers are seldom guided by the palate, the fruit must be such as will " take the eye ;" the quality is of but little account. It is to be regretted that the public taste is so defective as not to demand fruit of the highest excellence. Fortunately there is no longer any excuse for placing upon the market inferior berries. There are now many varieties, each of which has combined in a high degree almost every desirable requisite of a first-class fruit; yet none are perfect. The ideal variety has not yet been produced, although there are plenty of them described in the catalogues.

ORDERING NEW VARIETIES.

Purchasers should be cautious in ordering new varieties at exorbitant prices. Every year brings out a batch of new strawberries, "price $\$ 2$ per dozen, $\$ 10$ per hundred." The mails are filled with beautiful colored plates of single plants, and sections of rows loaded with fruit in all stages of development-" perfectly splendid." Why, a plot ten feet square of such plants wonld supply a large family with fruit for four weeks, when it would be time for the introduction of some new candidate for favor greatly superior to the last.

These new kinds are purchased of the originator, and controlled each by a single dealer, by whom they are parcelled out to other dealers to be sold at a stipulated price for a suecified time. This "syndicate" puff and push the variety as long as the price can be kept up, and until it has become widely disseminated, when all at once it proves to be a fruit of little or no value, inferior to many of the old standard sorts. If the amateur could only keep cool a year or two, he would not want the much lauded variety at all, and thus save his money.

On a careful comparison of two lists of strawberries offered for sale by New York horticulturists, largely engaged in selling small fruits and plants-one published in 1862 , and the other in 1882, naming sixty-four and forty varieties respectively-I find 
only one variety, the Wilson, retained of the former list after a period of twenty years. This shows how rapidly old varieties are supplanted by those of recent introduction. We have better varieties now from which to select than at any time in the past, but the long list should be greatly abridged, and all inferior sorts discarded. In selecting fruits, either for lome use or for market, it is best to rely mainly upon a few standard sorts, leaving it for the amateur to hunt through a bushel of chaff to find a grain of whent.

SUBSTITUTIONS.

Some dealers claim a right to substitute other kinds of plants and trees for those ordered, whenever they can offer an excuse for so doing. The only excuse in most instances would be, that they have not in stock, and never had, half of the varieties advertised in their catalogues. Early in the season, when there is plenty of time to procure plants from other dealers, they are likely to fill the order, but later resort to substitution. Here is a sample of what one dealer claims a right to do:

IT IS IMPOSSIBLE FOR ANY NUSERYMAN to keep up his assortment of all kinds, and it is so with us, and we must claim the privilege, when out of some sorts, to put in others equally as good for the section of the country the order comes from. We believe that in nine cases out of ten we can select a better assortment for either market or family use than what is generally called for. We can, however, make out most any assortment, if allowed to put in sorts that we have not got among our larger trees, with a smaller size, or those " in the bud," we making up the difference in size and price with more trees, or any other stock you may name.

And here is another :

SUBSTITUTION. - In case where my stock of certain varieties is exhausted, as may happen late in the season, it is the general custom to substitute a variety equally as good, or better, and as near like it as possible, in time of ripening, quality, ete. It should be stated in the order, therefore, if it is desired that this should not be done.

Could anything be more absurd? Mark the modesty of the first author, when he claims that in nine cases out of ten he 
knows better what his customers want than they know themselves.

Many orders are made up largely of new varieties, the parties giving them having been in the small-fruit business for years, and possibly may have grown more plants than the dealer ever saw. He wishes to keep up with the times by testing everything new, and gives his order for one thousand of the Ne plus ultra. The dealer is short of that variety, and sends as a substitute the Big Booby (named for the originator, and badly mixed), that being a bit of a drug on his hands, but, in his estimation, just the thing to "fill the bill." The would-be purchaser may have already tested the substitute, and be on the point of plowing under an acre or two of that variety, having found it perfectly worthless.

But, says the plant man, "It should be stated in the order, therefore, if it is desired that this should not be done," or, in other words, place at the top, bottom, and sicles of your order this caution: $N . B$. Please do not substitute the old choke pear for the Seckel, nor the common field strawberry for the Sharpless.

The catalogue from which the last extract was made contains this very proper announcement: "We would be pleased to see our customers and others at any time, except on the $S_{A B B A T I x}$ : on that day there will be no admittance to our grounds, and no business transacted" - from which we may fairly infer that the author is not only a conscientious but also a pious man. When, however, we ask of this man bread, he claims a right to give us a stone; or if we ask a fish, he is ready to give us a serpent.

No man has either a legal or moral right to fill an order, except by following it literally; and the better way is, where any deviation is made, to reship the plants at once.

OVER-PRAISED FRUITS.

There is often a war of words among fruit-growers relative to the quality of clifferent fruits, and as to the rank to which each is entitled. This is sometimes the result of prejudice, or an interest which different parties may have in pushing the sale of a new rariety. The entire stock of "a new thing" is often purchased by an euterprising clealer in plants at an extravagant 
price, and it is a matter of interest for him to "unload" as soon as possible. It is not strange that the description of such a fruit, coming from a person deeply interested in its sale-sometimes unscrupulous-often turns out to be high-colored, fabulous, or a downright, bold-faced lie. I want to strike out of the last sentence all after the word "be," and insert in place thereof the words "too highly praised." The description by the originator is often so extravagant as to be amusing. Here is a specimen: "The Jersey Queen. The largest and most luxuriant plant we have ever seen; appearing to thrive under any and all circumstances; easily grown, making vigorous runners, never burning or blighting its foliage, invariably bearing the largest fruit, of fine form and first quality; coloring evenly, and perfectly brilliant and beautiful; fine in texture, solid and firm, yet melting, high-flavored and luscious. The very best of all to carry and keep. The crop under high culture, in both quantity and quality, and under neglect and abuse, has astonished every one acquainted with its performance. With the terrible drouth prevailing, it neither faltered or failed in any respect, but appeared as thriving and luxuriant as in more favorable seasons. The most trying circumstances do not seem to affect it, as under the action of the severe frost of 1878 , in the most exposed situation, when every other in its vicinity was nearly destroyed, it seemed but slightly affected, as it bore the largest and finest crop ever seen upon our grounds." I have here given only about half of what the originator has to say in praise of the Jersey Queen, yet enough to show that, if true, it is far superior to any other variety ever offered to the public. The only reason why this variety has not driven all others out of cultivation is, that there are a score of other kinds just as highly praised.

But there is an honest difference of opinion as to the merits of rarieties, that is entitled to greater respect. Soils, locations, fertilizers, and other conditions, have an important influence on the quality of all fruits. Vintners in all wine-making countries fincl that there is a great difference in the quality of wine made from the snme variety of grapes gromn in vineyards only slightly remote from each other. This difference cannot be accounted for by the vine-grower. It may be the result of a combination of circumstances apparently so trifling that no one of them 
seems important. The same is true of other fruits as well as of the grape, and this may account for the great diversity of opinion as to the rank of certain varieties, among equally good judges. In one instance a fruit is grown under the most favorable conditions, and in the other the conclitions are all adverse. Grapes in California, where grapes almost equal to our best hothouse varieties grow spontaneously, have been found to contain fifty per cent. more sugar on the mountains than in the valleys. This may be orving, in part, to the fact that on elevations the season for ripening is longer, such localities being comparatively exempt from frost.

There can be no doubt that the quality of all small fruits may be improved, or injured, by the amount and kind of plant-food applied to the soil. And there is a wide field open in this direction for experiment and observation. As all the elements of plant nutrition are now conveniently accessible, through dealers in chemicals and chemical fertilizers, it would not seem difficult to arrive at some definite and important results relative to this subject.

\section{RAPID PROPAGATION.}

The grower is often anxious to increase to the utmost a valuable, scarce, or high-priced variety, and it is possible to obtain fifty or one hundred runner plants from a single stock-plant the first year. In order to attain this object, careful attention and judicious management will be required. First in order will be a thorough preparation of the land at least a foot deep-two feet would be better-by the use of a spading-fork or plow, cultivator and harrow. A heavy application of fine old stable-manure, or compost, should be worked into the soil, and if this can be done the autumn previous to planting out, all the better. Peruvian guano, if it can be obtained before it has been " doctored," or some chemical fertilizer containing a large per cent. of nitrogen -for it is plants and not fruit that we are working for-may be applied with advantage. Aroid the use of green manure, as its action is slow and we are in a hurry, and for the reason that it is liable to fill the land with the white grub (lachnosterna fusca), the larve of the May-bug, June-bug, or dor-bug, as it is often called, so destructive in the strawberry-patch.

Set the plants as early in spring as the condition of the soil 
will admit, in rows six feet apart, and the plants at least four or five feet distant in the rows. Let all runners grow, training them so as to cover the ground. No weeds should be tolerated. Make slight depressions beneath each joint of the rumners, pressing down the young plant and reighting it with a small stone, on covering it with earth, to prevent displacement by the wind. If a little fine manure, or fertilizer of some sort, is placed under or around the plant, it will cause a stronger and more rapid growth. Irrigation, or frequent watering with dilute liquid manure, will also aid in the multiplication of rumers, and plants unsurpassed in quality. A good stock of any new strawberry may in this way be obtained in a few months.

\section{NEW VARIETIES FROM SEEDS.}

The perfect strawberry must be of the best quality, large, productive, of good color and form, and firm enough to bear handling and transportation. The plant must be vigorous, healthy, hardy, not easily injured by cold in winter, or scorching suns in summer, and every way the habit of the plant must be good.

A berry not ripening evenly and coloring to the point is objectionable, as it is inconvenient to pick, and unsalable. It is hard to convince the buyer that a berry having a white tip is fully ripe. This is a fault of the Sharpless, Kentucky, Bidwell, and most of the very large varieties. Some of the largest and best kinds have the fault of being ill-formed, or coxcomb shaped. The old Iron-Clad, as pictured, is one of the worst of this class; and the Sharpless is of ten so imperfectly formed that many think, and not without reason, that its name is Shapeless.

Experiments in growing seedlings are very interesting, and may prove very profitable. In case of small fruits, results are arrived at early-in from one to three or four years. The process consists simply in sowing seeds of the best berries of the best varieties. Never sow seeds of inferior fruit. Plants raised from the best are inclined to revert, and will usually produce fruit inferior to that of the parent. If one seedling in a thousand proves superior in all respects, the experiment may be regarded as a success.

To outain seeds, select the berries when perfectly ripe, crush 
them with the hand or otherwise, and free them from the pulp. This may be done by washing, as the seeds will readily settle, while the pulp will float, and may be drained off. The seeds may be preserved in sand, or in the ordinary paper seed-bags, and stored in a cool, dry place till wanted; or they may be sown at once in boxes, or in the open ground. Care must be taken that the seeds are not too deeply covered, say not more than one fourth of an inch. Press the soil firmly over the seeds, and and be watchful lest the soil becomes dry before they have germinated. The young plants will begin to show themselves in a few weeks, and must receive careful attention. If sown in midsummer, they will encounter the dryest and hottest weather, when watering and partial shading will be sometimes inclispensable.

If started in boxes, they may be transplanted to the open ground as soon as a few leaves have pushed, giving them suitable distance to develop and form robust plants. Watering and shading at this time are very important, and must be continued until the young seedlings have become well established. For shading a few plants-seedlings of any kind-I have found nothing better or more convenient than small flower-pots. These are inverted over the plant in the middle of the day, but removed at night and in damp, cloudy weather. As the bottoms of such pots are perforated, the plant has sufficient air, and they are not disturbed by the wind. The cost of pots is at present so small as to be no objection to their use.

Where many seedlings are grown, a low frame consisting of a narrow board may be formed around the bed, and screens made by nailing laths to narrow strips of board, so as to leave open spaces about equal to the width of the lath. These screens placed over the bed of seedlings will afford the requisite shade, as the constant movement of the sun will prevent its rays from striking upon a plant more than a few minutes at a time.

Plants treated as here recommended, if successfully wintered, will give fruit the next season when only a year old; but a longer trial will be required to determine whether any will prove of real value.

In planting out these tender seedlings, select soil prepared with extra care in the most favorable location. If you propose 
to start a strawberry "boom," and go into the "Jumbo" and" "Big Booby" business, all the conditions must be most favorable. Especially avoid a plot for a bed of seedlings liable to be covered by standing water, or sheets of ice in winter, as either will be sure death to the plants. Both the bottom and surface drainage should be perfect. A mulch of straw, not too heavy, and a few evergreen boughs over all, will carry the plants safely. through.

The directions here given will be a sufficient guide to those who may attempt the production of new varieties by hybridizing or crossing-a process fully described below.

\section{HYBRIDIZING AND CROSSING.}

In every flower, in its natural state, we find what are known to botanists as stamens and pistil. These are the male and female organs, and seeds, when present, are the offspring or true fruit. Under cultivation the stamens often diminish in.

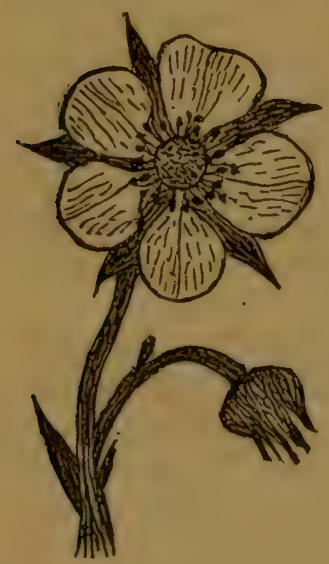

Fig. 6.

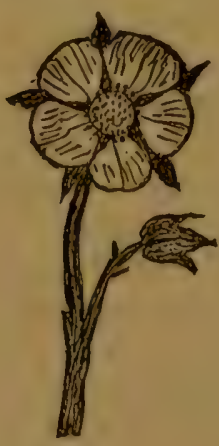

Fig. 7

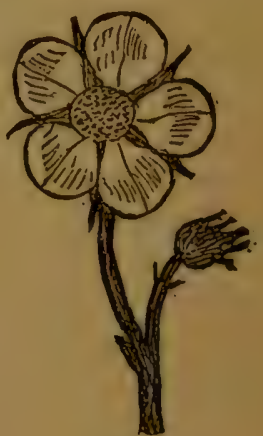

Fig. 8 .

number, are very imperfectly developed, and sometimes are en-. tirely ahsent. As an illustration, I here give a very good representation of the strawberry flower of each class.

Fig. 6 represents the perfect flower as we find it growing wild, having the pistil and the stamens fully developed. Fig. 7 shows the flower with the stamens imperfectly developed, and: 
Fig. 8 represents the flower with the stamens entirely wanting. Plants having the perfect flower, as in Fig. 6, will give a full crop of fruit, as they are self-fertilizing, and those having no staneus, as in Fig. 8, will give no fruit unless fertilized by other plants. Where the flowers are imperfectly developed, a partial crop may sometimes be obtained. Fig. 6 represents what are variously known as staminate, perfect, bi-sexual, or hermaphrodite flowers, and Fig. 8 a pistillate flower. The pistil is that part of the flower which enlarges when fertilized, and forms what is usually called the fruit, but by botanists the stigma ; unfertilized, there will be no development and no perfect fruit. It will be seen that at the top of the stamens in the perfect flower there is an enlargement which is known as the anther. This is filled with and scatters over the pistil an exceedingly fine dust called pollen, by means of which the flower is fertilized, and perfect fruit follows.

Now, as no fruit cau be obtained from a pistillate variety, unless its flowers are fertilized by pollen from some perfect flowering sort, it follows, of course, that the two rarieties must be planted out near euough togethes to insure that result. Fortunately pollen is exceedingly light, and is carried by the wind and insects from flower to florrer, and fertilization will be effected at a distance of twenty feet or more. In planting, set the staminate rarieties, so that the prevailing winds at the fruiting season will carry the pollen over the pistillate bed.

It is obvious that if a pistillate and staminate variety are set sicle by side, remote from any other, cross fertilization will occur, and the seed of the pistillate variety will produce a plant and fruit unlike either parent, but having some of the characteristics of both. In this way thousands of new varieties are easily grown, some of which may prove superior to either parent, and better than any other known sort. The method of crossing the strawberry when one is a staminate and the other a pistillate requires no skill, but may be performed by any boy of intelligence, simply by planting the two side by side. The seeds from the pistillate plant should be sown, as the staminate plant will be self-fertilized, and its seedlings may be quite like the parent.

Any one will see that two pistillate varieties caunot be crossed, 3 
as neither has the power to fertilize the other. But two staminate kinds may be crossed; - the method, however, requires more care, and is attended with more uncertainty. The stamens of one variety must be removed as soon as the flower expands, and the pistil dusted with pollen from the other. Remove all the flower-buds from the plant to be fertilized, except those experimented with, to prevent self-fertilization, or the stamens may be removed with pointed scissors from all the flowers on one plaut, when it may be treated as a pistillate variety.

I have endeavored to make this subject plain, as it is important that it may be fully understood. A majority of the new strawberries introduced from year to year are the result of crossing, either artificially or through the agency of wind or insects. We are often told that a new strawberry is a " chance seedling," found growing in a bed of the Crescent, it may be, but surrounded by plants of the Charles Downing, or some other perfect flowering kind, showing that it is as truly a cross as if more carefully effected.

Before leaving this subject, a few hints may be useful to those intending to try the experiment of producing some new and valuable variety. Success will depend more upon a judicious selection of varieties to be crossed, than upon skilful manipulation. It would not be wise to cross two varieties of very poor quality, thougin they might possess some other desirable characteristics. So of two varieties that were unproductive, lacking in firmness, of poor color or form. The aim should be to counteract any fanlt of one variety by using as the other parent a kind as near perfect in that particular as possible.

For example: The James Vick is a staminate variety, said to be immensely productive, but inclined to run too small. Why not cross this with the Jersey Queen, a pistillate sort, of very large size, fine flavor, good form and color, but in some localities not very productive?

Why not try a cross of the Windsor Chief (pistillate) with the Hervey Davis? They are both of good size and habit of growth: the color of the Chief rather dark, the quality a little off unless perfectly ripened, and not very firm. The Davis is firm, of a beautiful color, and excellent in flavor.

Try a cross of Jersey Queen or Hervey Davis-both of excel- 
lent quality-with the Crescent, a variety wonderfully productive and persistent in growth (it will beat twitch-grass, white clover, and sorrel, in a game for life, three times out of five), but not quite good enough to suit a critical taste.

I have named only crosses between pistillate and staminate varieties as being more easily made; but the suggestion will apply to crosses of staminate sorts.

The query is often propounded by the novice, Why grow the pistillate varieties, when they require to be fertilized with some perfect flowering kind in order to secure a crop? The answer is, There are among them some of the best, most beautiful, and, when fertilized, most productive varieties ever produced.

The different staminate and pistillate varieties may be planted for field or garden culture in rorrs as indicated below, the marks "P" and "S" showing which are pistillate and which staminate sorts. It is not to be understood that ouly two rows of pistillate plants can be fertilized when flanked by a row of staminates on either side, as five or more rows would do equally well. Seeds taken from these centre rows may be sown with the certainty of obtaining a new cross variety.

$\begin{array}{ll}\text { Plot 1. } \Rightarrow \begin{array}{l}\text { S. Wilson. } \\ \text { P. Crescent. }\end{array} & \text { P. Crescent. } \\ \text { S. Wilson. }\end{array}$

$\begin{array}{ll}\text { Plot 2. } & \text { S. Downing, Sharpless, or Cumberland Triumph. } \\ \text { P. Manchester. } \\ \text { P. Manchester. } \\ \text { S. Downing, Sharpless, or Cumberland Triumph. }\end{array}$

$\begin{array}{ll}\text { Plot 3. } & \text { S. Bidwell, or Sharpless. } \\ \text { P. Jersey Queen. } & \text { P. Jersey Queen. } \\ \text { S. Bidwell, or Sharpless. }\end{array}$

S. Mt. Vernon, or Kentucky.

$\begin{array}{ll}\text { Plot 4. 志 P. Champion. } & \text { P. Champion, } \\ & \text { S. Mt. Vernon, or Kentucky. }\end{array}$

The crosses here suggested are only intended as a hint to the beginner, and not as the best that can be made. Some sur- 
round a pistillate variety with a number of staminate sorts as fertilizers. This, of course, would give a great variety of seedlings, but it would be diflicult to tell who was the father of the different children. Plants may be potted, and, when in flower, the crossing performed artificially by transferring the pollen from one flower to the pistil of the other by means of a small camel's-hair brush. This may be done in a green-house or conservatory, at a season when all plants outside are in a dormant state. The process is exceedingly interesting, as showing how the laws of nature may be made to subserve the purposes of man, when guided by intelligence.

. I have treated this topic more at length, as "the books" usually make but brief allusion to it. On another page, where a clescription and the origin of the varieties are given, it will be seen how many of our best fruits have been thus produced.

\section{PIANTS FROM A DISTANCE.}

Plants that have been long packed are often received unexpectedly, before we are ready to set them ont. The land may not have been fully and properly prepared, or, owing to recent heavy rains, or storms still raging, the land may not be in suitable condition to work. We may be without suflicient help to plant out large lots at once, or other engagements may render it inconvenient or impossible. What is to be done? Shall we clouse the plauts in water, and let them remain for days in the package? Not a bit of it: yet this is the most common practice. Carefully unpack at once, being sure that the labels are all right. If the plants were packed in sphagnum, the best of all materials, damp, but not wet, with their leaves exposed to the air, they should be in prime condition though out of the ground for a week. If found quite dry, they may be spread upon the bottom of a cool, damp cellar, and lightly sprinkled with water, and the roots covered by a cloth. But it is usually better to select a damp, shady place, on the north side of a fence, grove, or building, and open a trench sloping to one side, and spread out the plants so that the foliage, when the roots are covered, will be just above the surface. They should never be covered in bundles, as the soil in such case will only come in contact with the outside roots, while it sleould touch every rootlet. 
When a single layer of plants has been spread in the trench, cover the roots with fine fresh soil, then another layer of plants, and so on till all the plants of one variety are nicely covered. The whole should then be firmly pressed down with the foot. This is called "Leeling in." Let the roots be so corered that all air will be excluded, and each variety marked with a substantial stake. Such plants are as safe as if set in the field permanently, and if not disturbed, will at once send out fibrous roots, and push a fruit stock, flower, and grow all summer. It may be well to throw a few erergreen boughs over such plants for a few days when first heeled in, especially if the weather is dry and windy. Plants treated in this manner have kept in the best condition with me for several weeks, and I should prefer to treat plants arriving in bad condition in this way rather than to set them ont at once. They very soon become well furnished with working roots, and are in a condition to make a vigorous growth. There need be no hurry. Get your land in good order, and wait for a cool, lowery day.

\section{PLANTS BY MAIL.}

The best and cheapest way of ordering and filling small orders is by mail. Four pounds can be sent in one package, any distance, at one ceut an ounce. Such packages are likely to reach their destination sooner than when sent by express, and if properly put up, will arrive in good order.

For mailing, select plants of medium size,-which are always the best,-and remove all but the centre leaves. Straighten out the roots, and spread them upon a thin layer of moss; cover them with the moss, and roll all up together. This will bring all the roots in contact with the moss, and prevent drying, or the generation of heat and consequent decay. The package should first be rolled up in oiled paper, with the leaves exposed, with strong manilla paper ontside, securely tied, and plainly directed. Such a package is good for a journey of five hundred miles. Failures almost always arise from too much moisture.

\section{SHIPPING PLANTS.}

Strawberry plants, to be sent as freight or by express, should be packed in boxes made with open slats on the top and sides. 
I prefer not to put them in bundles unless moss is mixed with the roots before tying up. If packed in the box 11 layers alternating with damp sphagnum, the roots at the centre or bottom, and the leaves exposed to air and light, the plants may be sent almost any distance without injury. Pack closely, so that the contents of the box cannot be displaced by rough handling.

The box should be strongly made, and neither too large nor too small, and it is better to have them made specially for the purpose. All packages must be carefully directed, giving the name and residence of both seller and purchaser, and the date 1 when shipped. This last direction will be found important. Express messengers dare not r'etain a package long when the date on the label is evidence of their neglect.

\section{CULTivation.}

When a plot has been properly set with plants, the next important thing will be to cultivate and care for them. Unless the land is unusually clean, the cultivator should be run between the rows the first season as often as once in ten days, followed by the hand hoe and weeder. If the land is stocked with the seeds of white clover, sorrel, conch-grass, and purslane, it will require a persistent effort to keep the weeds in subjection. Elsewhere will be found a description of some of the most useful implements for this purpose. All disturbance of the roots by cultivation should cease after the first of September.

\section{CUTTING RUNNERS.}

This work, like that of picking the fruit, will tax the muscles of the back severely, but no more than that of weeding and transplanting. Quite a number of implements have been invented for cutting strawberry runners, but $I$ have seen none of auy practical value. The runuers are very strong, and any machine, like a cultivator with knives or revolving disks attached to the outsicle frame, are as likely to pull up the parent plant as to cut its runners. There is this additional objection : such knives or wheels run into the soil so deep as to cut too many of the horizontal roots of the plant. A narrow hoe that will pass betreeu the plants, ground sharp, will do most of the work, and require but little stooping. Large shears may be 
conveniently used to finish the work, as they pull the plants less than a knife. Since the dogs have exterminated the sheep in New England, the old sheep-shears may be utilized for this purpose.

\section{MULCHING.}

Mrulching consists in covering the plants in autumn with straw, sedge from low meadows, hay from salt-marshes, leaves, sawdust, spent tan, or long, strawy manure. Evergreen boughs are an excellent winter protection, but are not always available, and do not meet all the requirements of a mulch. Corn-butts are sometimes recommended, but unless cut short are too heary, coarse, and arkward for convenient application and removal. There are other materials that may be used as a mulch, and the grower will be likely to select such as are most convenient and least expensive.

The object of a mulch is not simply to keep the plants warm, or, in other words, to prevent fatal injury by frost, for the foliage of the strawberry is not usually sensitive to the cold, but also to prevent the frequent freezing and thawing of the ground in fall and spring, by which the plants are lifted, and the roots broken and exposed to sun and wind. Mulching should be removed in spring from directly over the plants, and carefully arranged around and under them till after the fruit has been picked. If in sufficient quantity to corer the spaces between the rows, it will keep the ground from becoming dry and parched, smother the weeds, and prevent the fruit from becoming soiled and spoiled by violent showers and protracted rain-storms. Soiled berries are of very little value. It is true that the fruit can be washed, but it must be at the expense of its flavor and keeping quality, as well as its appearance on the fruit-stand and table.

The objects of mulching having been given, any one will be able to decide at once what available material it will be for his interest to employ. The objection to leaves is, that it will be found impossible to keep them in place. 'The strong winds prerailing in fall and spring, when protection is most important, are sure to drive them into windrows under some neighboring fence. There is the same objection to oat and barley straw, unless reighted in some way. Evergreen boughs cannot be 
used conveniently for protecting the fruit from sand. Sawdust and tan-bark are only a little less objectionable than sand itself, as the fine dust from either is sure to be blown and spattered upon the berries, and will be found quite as diflicult to remore. Due caution should be exercised as to the amount of mulching applied. Little more than enough to shade the foliage and ground is required, while too much is liable to exclude air entirely, and smother the plants. Straw not cleanly threshed, and grass or sedge that have matured their seeds, will fill the rows with plants as objectionable as any other weeds. I think hay from the salt marshes preferable to any other material as a mulch for the strawberry bed, as it is suficiently heary to retain its place over and around the plants, it never fills the ground with weeds, and the small per cent. of saline matter which it contains is certainly no detriment to the plants or soil.

Some have adopted the practice of throwing soil over stranberry vines with the spade or plow in autumn, remoring the covering early in spring : but this, while it may give protection, does not answer any other purpose for which a mulch is applied. It does not aid in keeping the fruit clean, but the opposite; aud it has no tendency to prevent the ground from becoming parched in time of drouth. A furrow each side of a row of strawberry plants, opened late in autumn, so near as to cover the foliage, must expose their roots to the action of frost, greatly to their injury.

Mulching has a tendency to retard the flowering of the plants, and the ripening of the fruit; but this, instead of being an objection, is sometimes an advantage, as a few days' delay in flowering may prevent injury by late spring frosts.

INSECTS.

The White Grub (Lachnosterna fusca).

This well known grub works beneath the surface, enting the roots almost to the crown of the plant, thereby causing it to wilt and die. When the matted bed or row system is practised, their mischief is not so apparent, as the plants are cromded, and the loss of a few of them is not noticed; but when grown in hills, every plant destroyed makes a bad break, which cau be 
filled only by training a runner so as to fill the racancy, or transplanting from other beds.

The grub is sure to follow the row from one plant to another, destroying everything in its path. The place to look for it is not beneath the plants that are dead, but at the roots of those that are just commencing to droop under the midday sun. On land where they are plenty, the strawberry patch should be examined often. Dig out the grubs with a garden trowel or hand weeder, and crush them with the foot, or feed them as a tidbit to the poultry. The application of fire bushels of salt to an acre, and working it well into the soil some days before the plants are set, may tend to repel the grub, but I do not believe salt can be used in suflicient quantity to kill them, without clestroying the plants. Aroid the grub by planting on land that has been occupied by some hoed crop for at least two years.

\section{The Strawberry Leaf-roller (Anchyloptera fragaria).}

This is another insect that proves very destructive to the strawberry crop in some sections of the country, especially at the West. It is not known to be common in New England at present, but is liable and likely to spread orer all sections where the strawberry is grown. Fig. ó gives a correct representation of the worm and moth. The larva, $a$, is shown of the true size, but the moth is enlarged, as seen by the lines, $b$, below. Mrs. Treat says there are two broods each year, the first one completing their transformations on the leaf about the first of July. The second brood enter the ground, where they

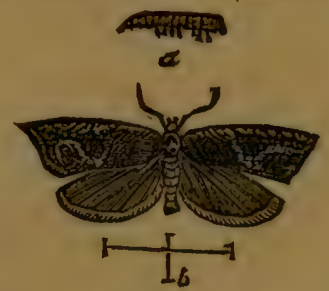

Fig. 9. change into the pupae, and remain until the next spring. The name is given to the worm from its habit of rolling itself up in the leares, which are held together by silken threarls, while the pulpy portions are eaten out. The insect is thus securely packed away, so that no application to the rines can reach it. Some recommend mowing off and burning the leaves as soon as the fruit is gathered, and others plor the plants under, and set new beds at a distance. Scattering stram lightly over the bed and burning it off will not injure the plants. but will destroy 
both the insects and their eggs. Plants should never be ordered from sections where the worm abounds.

INJURY BY FIROST IN SPRING.

It is not an uncommon occurrence to catch a late frost just when strawberry plants of the earliest varieties are in flower. This is sure to result in a partial or total destruction of the crop. All at once we find ourselves at the mercy of the weather, after having taxed our skill to the utmost in our efforts for success. We look over our fields, a day or two after a frost, only to find the incipient fruit black and blighted, and realize fully that

“'The best-laid schemes o' mice an' men

Gang aft a-gley."

The injury is sometimes so slight as not to be apparent for a time, the fruit not being killed, but only touched at the apex, causing imperfect development,-the formation of " buttons," as they are called. Such varieties as have long fruit stems and hold their flowers high above the foliage, are especially liable to injury. Among these may be named the Sharpless, Crystal City, Captain Jack, and Kentucky. The later-flowering sorts, and those having only short fruit-stalks, well protected by leaves, are more exempt from injury.

Can anything be done to ward off the mischief that threatens in all frosty sectious? The anstrer is : First, select an elevated tract of land, as little subject to frosts as possible, where winds are unobstructed, in preference to that which is low and level. It is well known that frost is not so likely to form where there is a free morement of air. Second, make yourself familiar with the habit of growth of the different varieties, and choose those having short fruit-stalks, well protected by leaves. 'Third, if the plot is not large, smoke may be made to drift orer the bed, so as to prevent all injury. This, if seasonable arrangements are made to light up, is not attended with much labor or expense. Sawdust, fine shavings from a planing-mill, dampened a little, leather chips from a shoe-factory, weers, or any waste material about the farm, may be used. This is not mere theory, as instances are not rare where the strawberry crop and tender garden plants have been successfully protected in this way. But a 
slight degree of heat is required, and smoke is always charged with more or less heat.

Still another method may be adopted, where provision to meet the foe is made in advance. A very light mulching of straw or hay will effectually protect the flowers, if applied when danger of frost occurs. If kept stacked on the field where it is likely to be wanted, it may be scattered over a large area in a short time. Of course it will be necessary to remove it from over the plants as soon as the cold wave'has passed.

I have occupied more space with these suggestions than may seem necessary to those who are situated in localities exempt from frost, feeling certain that many of the failures attributed to other causes by the unobserving are the result of injury after the flower petals have expanded. A bed of the Sharpless on my own ground, last season, that was white with flowers, gave not a single basket of fruit, having been killed by the frosts of the 30th and 31st of May. As the flower-petals are not always affected, the novice is not usually aware of the injury that has been done, but the incipient fruit turus black in a day or two, showing the full extent of the mischief.

FIELD NOTES.

Notes carefully taken in the field, from time to time, and recorded, will become very valuable afterwards for reference. The date when each variety flowers, ripens, and the length of time that it continues in bearing, should be jotted down. The following memoranda were made on the 11 th day of June, and contained information not to be found elsewhere, showing the relative hardiness of different varieties of the strawberry, and their liability to injury by spring frosts. The letters " $\mathrm{S}$ " and " $\mathrm{P}$ " indicate which are staminate, and which pistillate.

Captain Jack. S. Hardy, but a poor grower. Leaves darkgreen, and small. Flowers perfect, and badly exposed to frost. A poor show for fruit on rather light soil.

Champion (Windsor Chief). P. Hardy foliage, as dark and healthy as in mid-summer. A good but not rampant grower. Leaf-stalks longer than the fruit-stems. Flowers, only a few of which are open, well protected by leaves.

Charles Downing. S. Hardy. Plant strong and uninjured. 
The leaves are above the flowers, giving protection in case of frost. Abont one half the flowers are open. A good show for fruit.

Continental. S. Foliage half-hardy. The flowers half open. Leaf and fruit-stalks short. A poor show for fruit.

Crescent. P. Flower small, not entirely destitute of stamens, but requires a fertilizer for a full crop. Plants hardy and healthy, but not stroug. Flowers half open, and well protected. Well set for fruit. A sure cropper on any soil.

Crystal City. S. Folinge strong and healthy. Fruit and leafstalls high. Flowers exposed. Nearly out of flower. Well set with fruit, but it seldom fulfills its promise. One of the earliest. The crop is liable to be spoiled by frost.

Cumberland. S. Foliage strong and healthy. Flowers large and perfect. Well set for fruit. Flowers early.

Downer's Prolific. S. Leaf and fruit-stalks tall. Leaves a light green, but healthy. Indications of only a small crop.

Forest Rose. S. Only balf hardy. A poor grower, and poor show for fruit. Fruit-stems higher than the leaf-stalks, leaving flowers exposed. Soil poor. Might do better on stronger land.

Glendale. S. Plant strong, healthy, and hardy. Comes through the winter uninjured. Leaves yellowish-green, and higher than the flower-buds. But few flowers open. One of the "iron-clads."

Fentucky. S. Foliage dark and healthy. Rather late in flowering. Flower and leaf-stalks tall, but the flowers are not badly exposed.

Lenning's White. S. A poor grower on light land. Foliage of good color. A poor crop indicated.

Miner's Great Prolific. S. Color of foliage light green. Forms a thick matted row. Winters splendidly. Leaf and fruitstalks of medium height. Flowers well covered by leaves. Well set for fruit. The name should not be abridged.

Nicanor. S. Foliage small; plant looks feeble. Flowers small, early, and badly exposed.

Pioneer. S. Foliage yellowish-green; looks sick. Fruitstalks higher than the leares. A poor prospect for a crop. 'May do better on stronger soil.

Prouty. S. Forms a thick matted row. Healthy and hardy. 
Comes through the winter unharmed. Flowers protected by the leaves. Very productive.

Sharpless. S. Flower-stalks very high. Leares large and glossy. The strongest grower of all. Flowers large, and badly exposed. Winters well. Prospect of a heavy crop. Later notes show that the fruit was entirely clestroyed by frost.

Wilson. S. Foliage dark and healthy. Has wintered unharmed. Fruit-stems taller than leaf-stalks, leaving the flowers that open early almost entirely exposed. Well set for fruit.

From these notes, auy one can select varieties that are hardy, healthy, and productive, and that may be safely planted on frosty land, thereby avoiding disappointment and loss.

$$
\text { a }
$$

SIZE OF BERRIES.

Apparently fabulous stories are often told relative to the size of berries. It is useless to give measurements in describing different varieties, as the size of any variety will depend upon the soil, exposure, locality, and general treatment it receives at the hands of the cultivator, and often upon some cause clifficult to explain. A berry that would be classed as small, when grown under ordinary conditions might be made to rank as large in the hands of an expert.

The classification is usually as follors : Small, medium, large, very large. Just what is a small or a large berry has never been settled, all such terms being used in a relative sense. Small strawberries among fruit-growers and dealers in plants are unknown. No such thing will be found in any of the catalogues. Look over the catalogue of the American Pomological Society, where every variety described is thought worthy of general cultivation; and of forty-one varieties named, no berry will be found classed as small, and in the copy before me, only three as medium.

Specimens of the Sharpless are often found growing in matted rows, with nothing like high cultivation, measuring five or six inches in circumference. It is not rare to hear of them eight and even nine inches. It is undoubtedly the largest of all strawberries, and usually takes the prize at the fruit-shows when size is the criterion. Bidwell, Cumberland, Jersey Queen, Mriner's Prolific, Mouareh, and Shirts, are all classed as very large; and 
while some of them may arerage nearly, if not quite, as large as the Sharpless, yet they never show single berries equal to the best of that variety.

\section{ExHIBITION FRUIT.}

Almost every fruit-grower is ambitious, at times, to produce specimens of unusual size for exhibition, or as a present to some friend. This may be done by selecting one of the large varieties, preparing the bed with special care, manuring heavily, mulching, watering frequently and freely when required, cultivating in hills, and removing all runners as soon as they appear. The application of Peruvian guano or sulphate of ammonia in weak solution, with potash in some fo ' $\mathrm{m}$, will cause an enormous growth of both foliage and fruit. Cut out all but one or two of the strongest fruit stalks as soon as a selection can be made, and leave only two or three of the largest berries to mature on each.

It will be prudent to protect fruit thus carefully grown with a screen of mosquito cloth as soon as the berries begin to color, or some pet robin, whose nest is located on a neighboring tree, may not be particular in sampling your crop to select the smaller specimens. It should be borne in mind that plants producing their first full crop will give the largest fruit. Succeeding crops will run smaller, while the fruit will mature earlier.

\section{ACCELERATING AND RETARDING RIPENING.}

Strawberries are classified as early, medium, and late. Of course there is some difference in their season of ripening, but hardly two persons, equally familiar with different sorts, will agree in their classification. So much depends upon location, soil, and cultiration, that a berry that would be called early by one person would rank as medium with another when grown under varying conditions. I am satisfied that the time of ripening depends more upon the circumstances named than upon the variety grown.

It is always desirable to extend the berry season as much as possible, either for market or family use. This may be done in various ways: First, hy selecting those kinds that vary most naturally; second, by planting the early rarieties on light, 
warm, sandy, soil, having a southern exposure, and late kinds on heavier and cooler land sloping from the sun. In the garden, plant on the sunny side of a building, hedge, or tight board fence, for early fruit, and reverse the conditions to retard ripening. By adopting these methods, and others that may occur to the gardener, the season can undoubtedly be extended ten days or two weeks.

Allowing the mulch applied for winter protection to remain as late as it is safe to do so, thereby retaining the frost in the ground, will tend to prevent early growth and flowering; but caution must be used or the plants may be injured if air and light are excluded after the weather has become warm.

The following list contains some of the most popular varieties as usually classified :

Early.

Crystal City,

Crescent, early to late,

Downer's Prolific,

Dutchess,

Duncan,

Piper's Seedling,

Wilson.
Medium.

Bidwell,

Charles Downing,

Cumberland,

Hervey Davis,

James Vick,

Manchester,

Miner's Prolific,

Sharpless,

Wilder.
Late.

Captain Jack,

Champion,

Glendale,

Jersey Queen,

Jucunda,

Kentucky,

Mount Vernon,

Phelps's Seedling,

Prouty,

Seth Boyden.

PLANTING FOR FAMILY USE.

Farmers and other owners of large tracts of land often seem unwilling to devote any part of it to the growing of garden regetables or small fruits. This disinclination arises from a lack of interest in the subject, and also from an impression that the products of the garden are mere luxuries, and add nothing to the substantial comforts of life. Of course all such impressions are erroneous. No part of the farm will yield a better return than the garden, to say nothing of the pleasure and health to be derived from its cultivation.

The expense of a garden of one eighth or one fourth of an acre would he merely nominal, and such an area would supply a large family. At present the table of the mechanic, owning no land, is better supplied with fruit and regetables than that of 
the average farmer. This state of things need not and ought not to exist.

A plot of stramberries containing four hundred plants will give three bushels of fruit, or more than three quarts a day, fora month, and will occupy less than three square rods. Fifty raspberry plants will yield two bushels of fruit, or two quarts a day, for one month, and occupy three square rods; and fifty blackberry plants will give two quarts a day for two months, and require four rods of land, making the total area occupied ten square rods, or one sixteenth of an acre. An equal amount should be planted with currants, gooseberries, and grapes. The entire cost of plants will not exceed five dollars. This would appear to be a small outlay for an abundance of fresh berries. during a period of four months, whether they are regarded as a luxury or otherwise. Certainly no eighth of an acre on the farm planted with corn, potatues, or any of the other grain orvegetable crops, will yield so great an amount of pleasure or profit.

\section{PICKING AND MARKETING.}

In growing berries for market, arrangements must be made for suitable help in picking, packing, and shipping the fruit. On extensive plantations a large force is employed during the entire berry season, which, when strawberries, raspberries, gooseberries, currants, and blackberries are grown, following as. they do, in succession, will extend over a period of about three months. The man who engages in the small fruit business will never think of confining himself to any one kind, as in case that. should fail, his profits for the year are gone. When, however, the different fruits are grown a total failure will seldom occur.

Berry-baskets and crates must be provided before the season opens, and if ouly the strawberries were grown, they would be out of use at the end of three or four weeks, while if all the other small-fruits are cultivated, they will be required for nearly half the summer. They constitute a part of the fruit-grower's capital, and must not be allowed to lie idle eleven months of the year.

In case of pickers, it will be well to contract for the season, as it is difficult to secure a sufficient number of trusty persons for a short time, and transient pickers can hardiy be trained to. 
the business before the strawberry harvest will be past. Mucke better help may be obtained where constant employment can be given for a longer time. Pickers become expert in the business, when they will give better satisfaction to their employers and eara larger wages for themselves.

On large fruit farms, resort is had to the cities and villages for help, and temporary quarters are fitted up for their accommodation. This becomes necessary when the distance is too great to admit of returning home at night. These pickers sometimes form quite a little army, and have to he trained in their work by overseers, and governed by stringent rules. The picking is done at a certain price per basket, usually from one to two cents for strawberries, the price increasing as the berries diminish ; and the wages earned vary from one to two dollars a day.

Each picker is required to pick ripe fruit only, and that which is fit for market, confining himself strictly to the row assigned him. If, on pouring out a basket, occasionally, the fruit proves to be unripe, the picker forfeits all pay for his work ; and if, on examination, it is found that he has not picked his row clean, he is set back, and required to go over the ground again. One or tro such lessons usually suffice; but when, after repeated admonitions, a picker persists in violating reasonable rules, he is dismissed from the field.

Small stands are prorided, holding four or six quart baskets, for convenience in bringing the fruit to the packing shed. As each is brought in, the berries are inspected, and the picker receives a check for the number of baskets which it contains. Some growers redeem these checks every Saturday night, while others pay only at the close of the berry season. This practice is adopted to prevent desertions at the height of the harvest. As a loss of checks is a loss of pay, each picker must keep them with care until the day of redemption.

Some growers pick over one half of the ground each day, so that a particular section is gathered every alternate day, while others prefer to pick over the whole area every day. In the latter case the berries are simply colored, not ripe ; but they are firmer, and ship in better condition, which is all the grower cares for, except to get his money. These berries are sent 
from the suburbs or country to the city, where they pass through the hands of a commission merchant, by whom they are " jobbed out," and many of them sent back over the railroads to the country again, and sold, in some instances to the next neighbor of the man who grew them. This is called doing business.

PACKING FOR MARKET.

It was formerly the fashion to remove the calyx from strawberries when packing for market, but this practice has been abandoned for quite a number of years. The labor, when large quantities were grown, made it well-nigh impossible to put up berries in this way, and the fruit did not ship as safely or keep as well as when packed with the calyx remaining attached.

There is another practice, too common with careless growers, that must never be tolerated, if best prices are desired-that of mixing several varieties in the same basket and crate. There is such a difference in form and color of the kinds usually grown, to say nothing about the great difference in quality, that no sagacious dealer ever thinks of placing upon the market a mixed lot of berries. The difference in price between unmixed fruit nicely packed, and a mixed lot badly assorted and otherwise carelessly put up, will often amount to one half the net receipts. This is especially true at the height of the berry season, when the market is crowded, and the purchaser can make his selection almost at his own price. The best fruit, carefully handled, and packed in clean baskets, displayed upon the fruit-stand in an attractive manner, will never spoil for want of a purchaser, while the consignment of the careless shipper will be dumped into the dock. There is the same reason why small fruits should not be mixed as might be urged against a like practice with the large fruits, such as the apple and pear.

Only a few years since it was the custom to pack berries of all kinds in quart or pint boxes with covers, but now baskets are generally used. The change is attributable to several canses. The first cost of boxes is five times as great as that of baskets. As all air was excluded the fruit did not keep as well as in baskets, the slats of which are more or less open. The sides of boxes being perpendicular, gave the fruit a chance to settle, and become crushed by its own weight, while the baskets are 
flaring, so that the sides help support the fruit, and prevent its pressing directly upon that at the bottom-a matter of the greatest importance in case of distant shipment. Then, again, the form of the basket being nearly square, the corners only slightly rounded, they can be packed with greater economy of space than boxes. The price of baskets is so small-from $\$ 7$ to $\$ 10$ per thousand-that the dealer can well enough afford, when selling at retail, to let the purchaser take the basket along with the fruit, and return it or not, as may be convenient. For sevcral years I have kept no account of baskets, except in crates, as was formerly necessary with boxes, which cost, including freight, about $\$ 5$ per hundred. The practice still in rogue with slovenly retail grocers, of pouring the fruit into paper bags for delivery, in the same package with kerosene oil, codfish, and plug tobacco, is intolerable. The purchaser should insist upon having his fruit delivered in clean, new baskets, and refuse to receive it in packages that have become mildewed and filthy by long and careless use.

Berry crates for shipping purposes are made of several sizes, holding thirty-two, forty, and sixty quarts. The thirty-twoquart crate is used by nine tenths of fruit-growers. It is of a size easily handled by one person, and not likely to receive as rough usage as a heavier package. These crates cost, filled with baskets, about one dollar each. Veneer partitions, called "trays," accompany each crate, and are so constructed as to keep the tiers of baskets separate, and prevent all pressure from those above.

By the courtesy of the Messrs. Batterson \& Co., who have kindly Iouned their electrotypes for that purpose, I am enabled to present illustrations of crates, and also of berry and grape baskets manufactured by them. Their goods have been long on the market, and, so far as known, have given

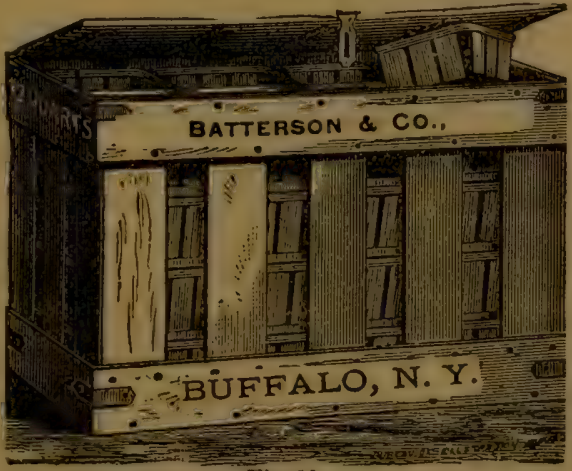

Fig. 10. 
satisfaction. It will be seen that the crates are not only strong,

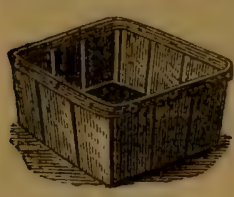

Fig. 11. but so constructed as to exclude dust, and yet admit of the requisite ventilation. There are thousands of baskets manufactured, holding less than a quart, and the temptation for some

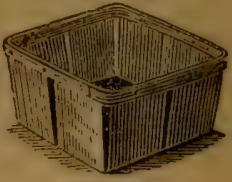

Fig. 12. growers to adopt packages of this kind is too strong for their moral sense. Thus the honest dealer is brought into competition with the cheat. The purchaser is not particular to notice the difference in size between the honest and fraudulent basket.

Strawberries and black raspberries are

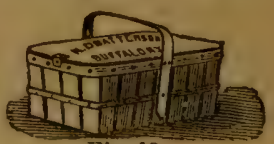
usually packed in quart baskets, but the pint basket is better for red raspberries, and some soft varieties of the strawberry, that do not "stand up" well in the larger size.

Where small fruits are grown to be shipped to a distance, seasonable provision must be made for a full supply of baskets and crates. It will take from six to ten days, on an average, for the return of crates, as consignees cannot dispose of all fruit as soon as received, and in the hurry of the season are often negligent about returning them when empty. All crates should be marked with a stencil giving the name and residence of the owner; otherwise he is liable to receive those that are inferior in return.

VARIETIES OF THE STRAWBERrY.

I shall be unable to eren so much as name many of the varieties that have beeu under cultivation within the last twenty years. To give a full list, - were it possible,-would be a waste of space that should be better occupied. Very few of those so famous a few years ago are now to be found in the catalogues, and only occasionally is one cultivated. In the following list I have included nearly all the old standard sorts, and such of more recent introduction as have been widely disseminated, and proved valuable either for market or for home use.

But few berries firm enough to bear transportation long distances are such as would be selected for the table. A berry that will rank as best for all purposes has not yet been found. 
I may not have named in the descriptive list all that may be thought entitled to a place in such a catalogue, while it might have been better to omit others that are included. In making up such a list no two fruit-growers would agree. I have made the description as brief as I possibly could and do justice to the varieties named, using very few superlative adjectives. Extravagant praise is calculated only to mislead the inquirer. An honest description will not overestimate a variety, or omit its faults.

The pistillate or imperfect varieties are so marked, and it may be understood that all others are bi-sexual, or perfectflowering. In purchasing, this knowledge becomes important, as pistillate plants will bear no fruit if set alone.

The engravings, as a rule, represent berries of the largest size, and this should be borne in mind by the novice. The cuts would please me better if they had not been overdrawn. They should have been made to represent berries of medium size.

\section{DESCRIPTIVE LIST OF VARIETIES.}

Atlantic. [Fig. 14.] New; not yet generally disseminated ; large, handsome, wellflavored, productive where it originated; good size and color ; firm, bright red; quality good. Origin, Atlantic County, N. J., with a Mr. Potter.

Bidwell. Very large, conical ; glossy crimson; firm, good; early to medium; vigorous, thrives on all soils; foliage light green, and sometimes scorched by sun in the spring; very productive.

Boyden No. 30 (Seth Boy-

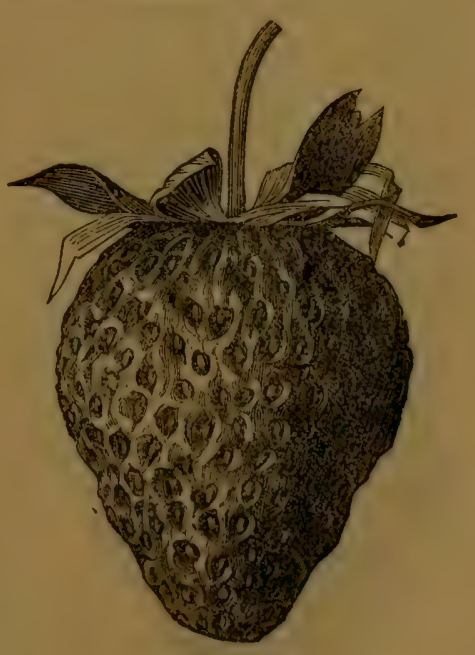

Fig. 14. den). Large, late; obtuse conical; firm, sweet. Plant in moist soil, and keep all runuers cut. Productive with good cultivation. Originated with Seth Boyden, of Newark, N.J. 
Captain Jack. Late; size medium, round; light scarlet;

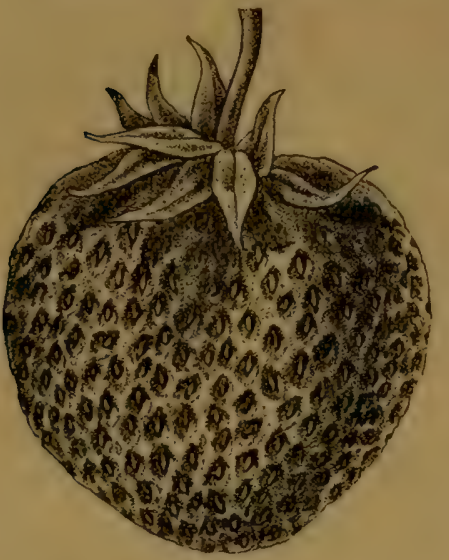
quality second-rate; firm, productive. Popular and profitable in some localities. Originated with S. Miller, of Blufton, Mo. A seedling of Wilson.

Champion (Windsor Chief). [Fig. 15.] Of good size, roundish ; dark crimson; medium to late; good when fully ripe; foliage very hardy. Plant in rich land. Originated by $\mathrm{J}$. C. Neff, of Carlisle, Penn. Pistillate.

Charles Downing. [Fig. 16.] One of the best standard varieties. Succeeds on all soils and in all localities. May be grown in hills or matted rows. Large, of good form and color, firm, productive; very good; season medium. Originated with J. S. Downer, of Fairview, $\mathrm{Ky}$.

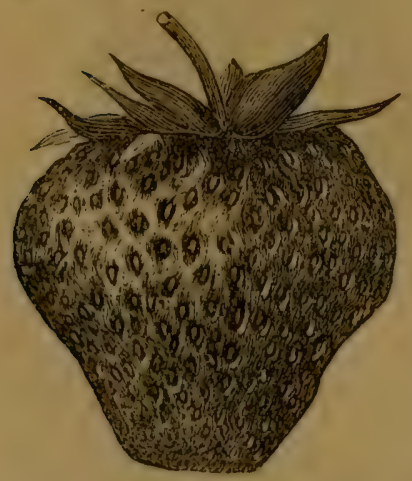

Fig. 1i.

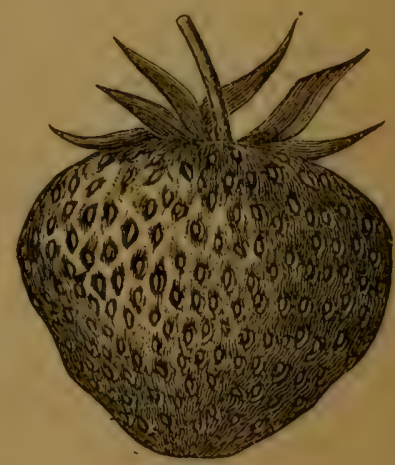

Fig. 10.

Crescent. [Fig. 17.] Medium to large; very productive; quality rather poor; moderately firm; early to late; bright scarlet; roundish conical, and more regular than in the cut; plants small, but vigorous; succeeds on all soils, and will bear more neglect than any other variety. Originated with William Parmelee, of New Haven, Conn. Pistillate.

Cumberland. Very large, regular, firm, but hardly firm 
enough for market; bright scarlet; season medium ; very desirable; quality good. Originated by Amos Miller, of Carlisle. Pa.

Downer's Prolific. Medium to large ; light scarlet; roundish conical ; rather soft; early, good; plant vigorous. Originated by J. S. Downer, Ky.

Dutchess. Round, uniform; moderately firm; fine flavor; early, but continues long in bearing; productive. Originated with D. H. Barnes, of Poughkeepsie, N. Y.

Glendale. Large, conical, late; dingy scarlet; firm ; plant vigorous and productive; calyx too large; color unattractive; quality only second-rate. Originated with Mr. Storer, of Ohio.

Great American. Large, roundish conical; firm; dark red; season medium; requires heavy soil and high culture; productive, but fails in light land. Originated with E. W. Durand, of Irvington, N. J.

Hervey Davis. New. Large, obtuse conical; bright, glossy scarlet; firm; very good; season medium; productive. Originated by J. B. Moore, of Concord, Mass. A seedling of the Wilder.

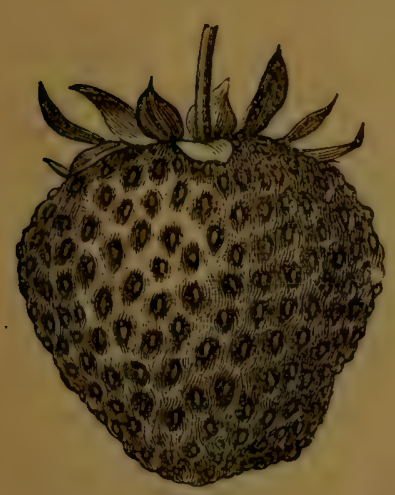

Fig. 18.

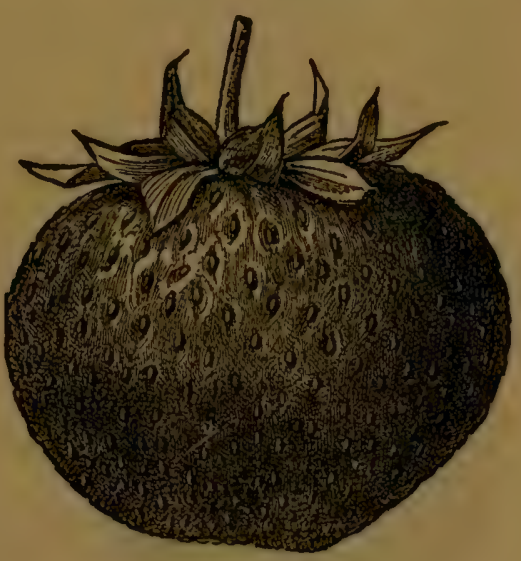

Fig. 19.

Hovey. Large, roundish, firm; bright scarlet; season medium ; very good ; vines hardy and vigorous ; moderately productive. Originated by C. MI. Hovey; of Boston, Mass. Pistillate. James Vick. [Fig. 18.] New. Medium; roundish conical; moderately firm; bright scarlet; good; very prolific; vigorous. Originated with Samuel Miller, Mo. 
Jersey Queen. [Fig. 19.] Very large; solid; roundish conical; very good; crimson; season medium. One of the best; moderately firm. Pistillate.

Kentucly. Large; late; bright searlet; roundish conical; moderately firm; prolific; fine flavor; succeeds on light soil. Originated by Mr. J. S. Downer, of Ky.

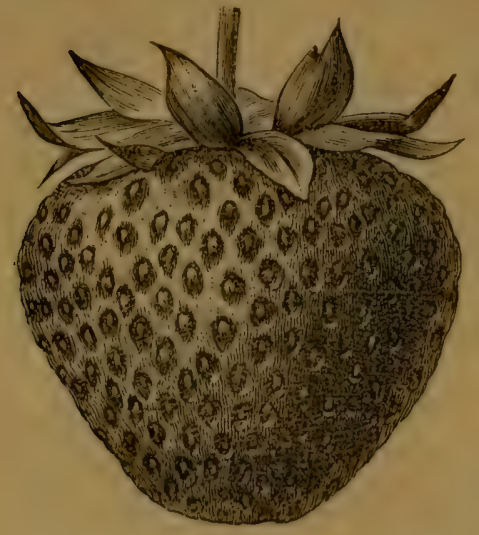

Fig. 20.

Manchester: [Fig. 20.] Large; moderately firm; scarlet; productive; obtuse conical ; season medium to late; succeeds in light soil; quality good. Leaves blight in some localities. Originated with $\mathrm{Mr}$. Jesse Beatty, of Ocean Co., N. J. Pistillate.

Miner's Prolific (Miner's Great Prolific). Very large; glossy crimson; moderately firm; roundish conical; good; a strong grower; very productive; season medium; colors unevenly. Originated with T. B. Miner, of New York.

Monarch (Monarch of the West). Very large; irregular;

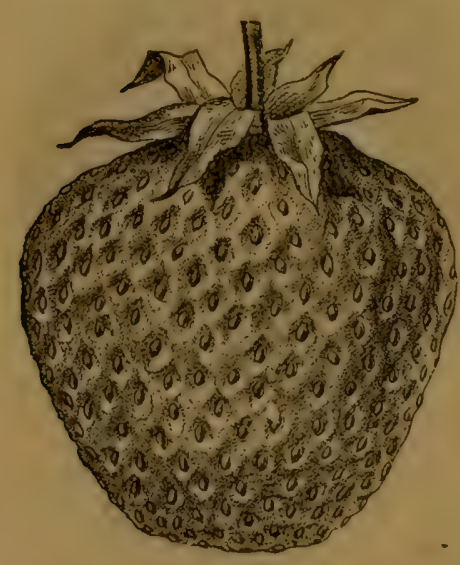

Fig. 21. plant vigorous; pale scarlet; tips white until fully ripe. Plant in hills, removing all rumners. Originated with Jesse Brady, of Plano, Ill.

Mount Vernon (Kirkwood). Large, late; light scarlet; roundish conical; moderately lfirm; good; plant vigorous and productive. Pistillate.

Mrrs. Garfield. [Fig. 21.] New. Described by the originator as a seedling of Crescent.

- Medium to large; good form, color, and quality. Season me-

dium. Plant healthy and productive. Originated with a Mr. Crawford, of Ohio. 
Pioneer. Early, scarlet, moderately firm; plant vigorous; quality good, sweet, perfumed. Originater with E. W. Durand, of Irvington, N. J.

Prouty (Prouty's Seedling). Large ; bright, glossy scarlet; long conical; moderately firm; season medium; very productive; good. Originated with Lewis, Ellsworth, Ill.

Sharpless. [Fig. 22.] Very large ; bright red, often with light tip; firm, good, productive; obtuse conical ; plant vigorous; medium to late. A most desirable variety. Originated with J. K. Sharpless, of Pennsylvania. A mammoth berry.

Triomph de Gand. An old favorite. Large, and often irregular; firm; bright crimson; sweet and rich. Requires high cultivation,

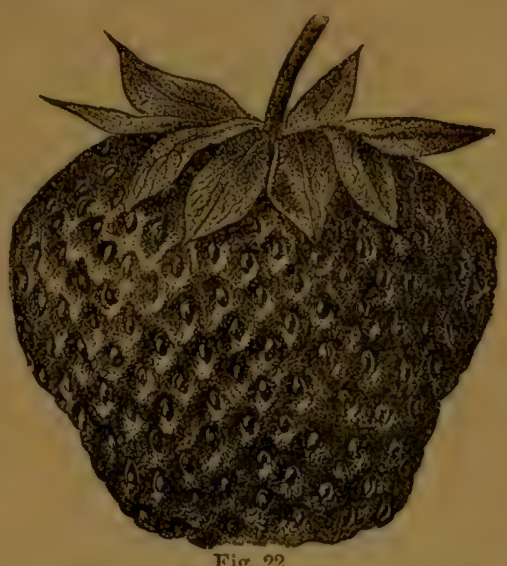

Fig. 22. and to be grown in hills. Continues long in bearing. Of foreign origin.

Wilder (President Wilder). Large; deep scarlet; roundish obtuse conical ; firm; season medium; very good. Originated with Marshall P. Wilder, of Boston, Mass.. in 1861. A hybrid of the La Constane and Hovey. Recommended for amateur cultivation.

Wilson (Wilson's Albany). [Fig. 23.] Large, but runs small at the close of the season; dark crimson; very productive ; acid ; firm ; roundish conical; early. Requires good soil and culture, and renewing of beds once in two years. A profitable market variety. Originated with John Wilson, Albany, N. Y.

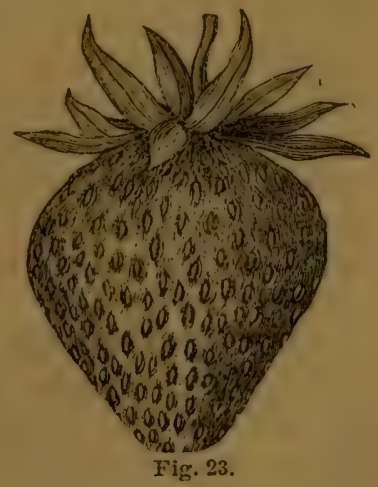




\section{A LIST FOR TRIAL.}

To those who are inclined to test other varieties, $I$ would suggest a trial of any of those named below, some of which are new, while others have a fair reputation, and prove valuable in certain localities. Those marked $P$. are pistillate.

$\begin{array}{ll}\text { Black Defiance, } & \text { Longfellow, } \\ \text { Col. Cheney, P., } & \text { Old Iron Clad (Phelps), } \\ \text { Crystal City, } & \text { Park Beauty, P., } \\ \text { Daniel Boone, } & \text { Piper's Seedling, } \\ \text { Duncan, } & \text { Primo, } \\ \text { Finch (Prolific), } & \text { Ray's Prolific, } \\ \text { Forest Rose, } & \text { Russell's Advance, } \\ \text { Green Prolific, P., } & \text { Seneca Queen, } \\ \text { Golden Defiance, } & \text { Shirts, } \\ \text { Jumbo, } & \text { Triple Crown, } \\ \text { Jucunda, } & \text { Warren. } \\ & \end{array}$

\section{RASPBERRIES.} SOIL AND PLANTING.

The raspberry is second only to the strawberry in importance among the small fruits. There are two kinds, the red (rubus strigosus) and the black ( $R$. occidentalis). The root is perennial, while the canes are biennial. Nearly all fruit is borne on wood of the previous year's growth and its branches, and, after bearing one crop, the canes die. They may be at once cut out close to the ground, new plants having in the mean time sprung up from the root to take their place. Some allow the old stalks to remain till late in the fall, and others till spring, thinking that they afford protection and support to the new growth cluring winter.

The canes are usually-not always-covered with spines more or less wicked, admonishing the cultivator and picker that the plants are to be respected, and handled with due caution. The different species are found growing wild over a large part of the western continent, and the improved varieties are the result of selection, cultivation, and crossing. 
The Black-Cap and Red species of the raspberry require somewhat different treatment, though the soil and preparation may be much alike. A good sandy loam, or clay loam, is preferable to any other, and, if somewhat elevated, the flowers will be more exempt from frost. It must be so located that standing water will not at any time accumulate and remain on the surface, especially during the winter.

Whether the plot is large or small, let the rows run lengthwise for convenience in cultivation. For Black-Caps, open furrows with a plow, six feet apart, and set the plants three feet apart in the row, which will require 2,420 plants for an acre. The red varieties may be set somewhat closer, say rows five feet and plants in the row two feet apart, or 4,356 plants to an acre. In this way hedge-rows may be formed sooner than when set at a greater distance. Some prefer to set in check-rows, four feet apart, so as to run the cultivator both ways. But the BlackCaps require more room, and the distances first named will be found none too great.

The roots should be spread out in the furrows, and carefully covered with fresh soil, making it firm over the stems, but exercising great care in placing the dirt around the germ or bud that is to form the new plant. These buds are exceedingly tender, and if broken off, some weeks will be required for new ones to form. In case of the Black-Cap, the destruction of the germ is fatal.

I use a garden line to ensure straight rows at equal distances. Choose a still, damp day for transplanting. If the weather is dry and windy, the plants may be taken to the field in a basket, mixed with damp moss, and dropped no faster than they are set. It would be well to open the furrows no faster than they can be filled.

Clean culture should follow transplanting. Let the cultivator pass through the rows as often as once in ten days, up to the last of August. Late cultivation will cause a late growth that will not mature suficiently to endure the winter. Not much fruit need be expected until the second year, and, when the rows are six feet apart, strawberries may be grown half way between, giving one or two crops, when they must gire way to the raspberries, as they will require all the space. After three or four 
years the raspberry plants will begin to fail, unless some stimulating manures are applied and worked into the soil. If this is seasonably attended to, and repeated as often as required, the plants will yield profitable crops for eight or ten years. The wide-awake fruit-grower will not forget to have new plantations in fresh soil coming forward, in the mean time, to supply the places of those that are to be rooted out.

PIROPAGATING THE RASPBERRY.

The red raspberry propagates itself rapidly by sending up numerous sprout-suckers, as they are often called, from their roots, while the Black-Cap, when allowed to grow without pruning, produces long, slender canes-too slender to support themselves in an upright position, and droop so much that by August or September the ends will be found trailing on the ground. If at this season the ends are weighted with small stones or clods to prevent their being agitated by the wind, they will take root in a few days, and form what are known among nurserymen as "tip plants." These plants are also formed on the lateral branches that push out on all sides of the main cane as soon as the tips tonch the ground. Fig. 24 represents a plant of the

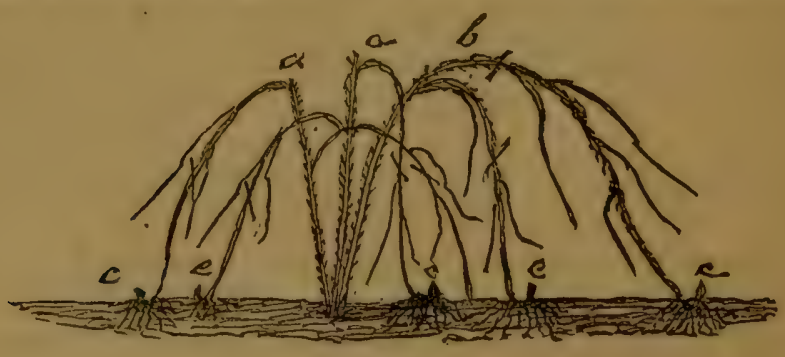

Fig. 24 .

Black-Cap raspberry that has been cut back at $a, a$, while one cane has been allowed to grow withont pruning or "piuching in," as it is usually termed, to show its habit under neglect. The branches of the central canes have been covered and taken root, as shown at $c$, and the germ of a new plant is seen at the surface of the ground. When these plants have beceme rooted, which may be easily determined by a slight pull on the branch, they may be cut from the mother plants, as shown by the marks 
of cancellation, leaving eight or ten inches of the old wood attached for convenience in haudling. When planted out, this old wood may be allowed to remain till the new plant has made sufficient growth to mark its locality. Fig. 25 shows the plant as located in its new home, $-d d$ representing the surface of the ground; $b$, the numerous roots; $c$, the bud, or germ, just commencing growth; and

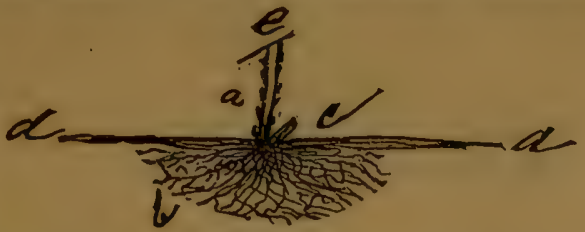

Fig. 25.

$a$, the piece of old branch that was cut at $e$. The parent plant was cut back, or pinched, when the canes were about three feet high, as shown at $a \alpha$, and the cross-marks indicate the point at which the lateral branches should be cut, to leave the plant in best form for withstanding wind and snow, and for the production of the largest crop of fruit. A plant pruned as here shown will require no stakes or trellis for support.

Fig. 26 represents a plant of the red raspberry that multiplies by suckers springing up from the roots, often in such numbers that it becomes necessary to treat them as weeds. This is always done when

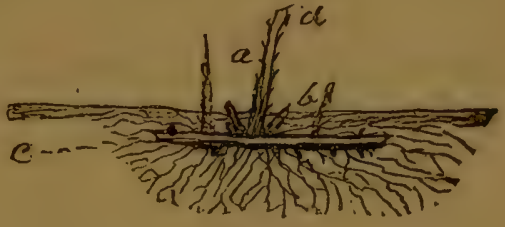

Fig. 26.

new plants are not wanted for setting or for sale.

\section{GREEN SCCKER PLANTS.}

Some varieties produce very few suckers, and it becomes necessary, when large numbers are desired, to adopt methods to encourage their growth. This may easily be done by thrusting down a sharp spade a few inches distant from the old plant in such a way as to cut its roots into pieces only three or four inches long. The roots being filled with latent buds, will send up numerous suckers forming plants of the best quality. By taking advantage of the weather, selecting a time when it is wet or cloudy, these green suckers may be successfully transplanted in summer, when five or six inches high, and a year gained in the produc- 
tion of fruit. It will be well to remove most of the leaves when transplanting green suckers, and filling the holes with water when setting will prevent excessive wilting.

It is a good practice to trim the plants as fast as they are dug, and immerse the roots at once in thick, muddy water. They may be taken to the field in a bucket, and dropped out no faster than they can be set in a freshly opened furrow. Such plants will be found better furnished with fibrous roots than when they have become older.

\section{ROOT CUTTINGS.}

Plant dealers increase their stock of new and desirable varieties with great rapidity by digging up the roots in autumn, cutting them into two or three inch lengths, and packing them in boxes mixed with damp sand or soil. They may be kept in a frost-proof cellar, or buried in a locality where neither frost nor water will reach them. Select a dry place, having a porous sub-soil, and cover the surface of the ground over the cuttings with a thick mulch of leaves or straw before freezing weather sets in. If frost and an excess of moisture are excluded, these root-cuttings will callous during winter, and emit rootlets early in spring. Before this occurs, however, the cuttings should be planted three inches apart in drills, opened in a rich, sandy loam, and covered two inches deep, making the soil firm with the back of the spade or by pressure with the foot. On no account let the soil over them become dry; neither should standing water be tolerated on the bed for an hour. A very light mulch of striw, just enough to shade the surface, but not so much as to exclude the sun's heat, will check evaporation, and prevent drying.

Let the cuttings when dropped in the trenches be immediately covered with fresh soil, as exposure to sun or wind, or placing them in contact with dry dirt, greatly endanger's the experiment. They will soon send up shoots, which, with clean and careful cultivation, will attain a size suitable for transplanting in the fall or following spring.

It should be borne in mind that the Black-Caps never sucker, and it would be useless to attempt the growing of plants from their roots. They form " tip" plants, and these, if not planted 
out in fall or spring, may be safely moved in May or June, after they have made a growth of six inches. This, however, is not recommended as the best time to set them, as their growth will be checked, and they will not make as strong plants the first year as those transplanted early in spring. The practice may be adopted in filling vacancies, or when, for any reason, spring setting has been delayed.

\section{PRUNING THE RASPBERRY.}

This important operation is often neglected, or performed, if at all, too late in the season, after the canes have made their growth, and become hard and woody. The object of pruning, or "pinching back," as it is called, is to cause the plants to form a stocky growth. well furnished with lateral branches, rather than tall, naked canes. The latter are too much exposed to high winds the force of which they cannot resist, and require stakes to keep them in place. Such canes will give but a small amount of fruit as compared with plants that have been clipped early, when two or two and a half feet high. Pinching while the plant is growing causes it to send out numerous lateral branches that will greatly increase the crop and size of fruit. Such low, bushy plants will require no stakes or wires as a support.

If the pinching is neglected until the canes become hard, but few side branches will be formed, and such as do form will not have time to mature so as to endure the winter. The process requires that each shoot should be stopped when it has reached the proper height, say two or three feet, according to the strength of the cane. As all the canes will not attain the proper height at once, it will be necessary to go through the rows two or three times during the season of growth, commencing about the middle of June. The lateral branches should be clipped when eighteen inches long. In this way the plants may be trained into a hedge-row, so as to admit of more convenient cultivation and picking of the fruit. If allowed to grow at will, cultivation and picking will be well-nigh impossible. The neglected raspherry patch soon becomes a mass of tangled brambles that no picker or cultivator would be persuaded to enter a sec- 
ond time. These directions apply specially to the Black-Caps. The Antwerps will not require pruning so early.

PRUNING OUT OLD WOOD.

As soon as the fruit has been gathered, all the old canes may be cut out close to the ground. Some varieties are very thorny, and a pair of long-handled pruning-shears will be found most convenient for this purpose; but a grass-knife, corn-hook, or sickle, will answer very well. It is not necessary that the pruning should be done at this particular season; it may be postponed till the leaves have fallen-a more leisure season-or even till spring, before leaves appear. Reasons could be given for choosing one time in preference to another, but most cultivators will be governed by what they find most convenient. The old canes, having fulfilled their mission, are somewhat in the way of pruning and cultivation; they may, in a measure, exhaust the plant if suffered to remain, and if the new wood is to be bent down and covered before winter they will be very troublesome; but if the plants are allowed to stand uncovered, the old canes may serve as a slight protection and support against drifting snows.

\section{WINTER PROTECTION.}

Many of the red raspberries, and some of the Black-Caps, are killed back to the ground when no winter protection is given. The foreign varieties are all tender, and their hybrid seedlings are not usually hardy. There are not more than two or three varieties of marked excellence that can be safely exposed to our Northern winters. The Turner and Cuthbert are seldom injured, but even these will yield larger and finer fruit when protected.

The covering of the ruspberry need not be heavy-only just enough to keep the plants in place. Many are frightened when told that the plants require protection; but the labor is not half as great as might be supposed. Soil affords the best covering, and is always at hand. The method is as follows :

First, run a furrow between the rows, to loosen the ground, and let a shovelful of dirt be thrown by the side of each plant, near its crown, so as to raise a small mound over which to bend the canes. This will prevent breaking by too short a curve. Let a boy bend the canes orer the mound, all in one direction, 
and in line with the row, and hold them while the shovellers, one on each side, throw on dirt enough to keep them down, as represented in Fig. 27 . In this way pass along the rows rapidly, and complete the covering more at leisure. The illustration shows at a glauce the method of bending down the canes, a representing the mound, and $b$ a

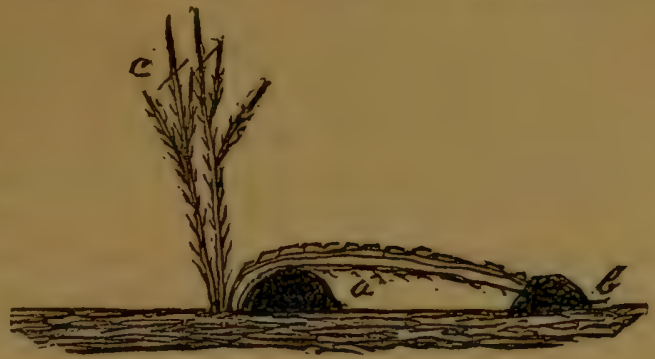

Fig. 27. shovelful of dirt thrown on the tips as a weight. The mark of cancellation at $c$ indicates the point at which the canes should be pruned to give the plant a bushy form. In the way here described a large "patch" may be gone over in a day, and no labor will be better rewarded, whether the rariety be tender or half-hardy. Slight protection will bring the plants through the winter uninjured, and ensure larger and better fruit. Some recommend turning a furrow up to the plants on either side, but this cuts and exposes the roots too much.

As soon as the frost leaves the ground in spring the plants should be uncovered and tied up to stakes. For removing the dirt from the bushes a fork is preferable to a hoe or shovel. The treatment of the rasplberry sliould be such as to secure mature wood hefore winter. For this reason the application of manure in mid-summer, and cultivation early in autumn, thereby causing a late growth, should never occur. Top-dressing after the leaves have fallen will do no harm, and the whole ground should be thoroughly cleaned before winter sets in.

\section{GROWING NEW VARIETIES.}

The raspberry, like the strawberry, may easily be grown from seeds, and this is the method where new varieties are desired. Let the fruit be gathered when perfectly ripe, crushed, and the pulp separated by washing. Always use seeds of the best varieties, and from the best specimens of that variety. Select the 
fruit from healthy and vigorous plants under high cultivation. If two varieties have been grown near each other, the seedlings are likely to be a cross, and some of them may prove superior to either parent.

The seeds are more safely planted in fall, if the operation is properly performed, and the young plants carefully protected; but they may be preserved in sand in a cool cellar until spring, and planted as soon as the ground is in suitable condition. The seed-bed should be well fertilized, finely pulverized, and so located that partial shade can be given. The young plants are exceedingly tender, and are likely to be injured, if not entirely destroyed, by hot suns when fully exposed. Boards six or eight inches wide, placed around the bed so that it can be covered by a screen made of laths an inch and a half apart, will be found couvenient, as it may be removed for cultiration, or in cloudy weather, when full light and air are desirable.

By all means plant in rows for convenience in cultivationsay in drills one foot apart-and let the seed be corered not more than half an inch deep. The soil over the rows should be made firm with the back of a spade, or otherwise. If sown in the fall, the young plants will appear early the next spring, and if in spring, they will germinate in a few weeks. The seeds of the raspberry retain their vitality for several years if kept dry and cool, and may be sent by mail to any part of the country.

Seedlings will require some care the first winter, as the rood is not likely to be sufficiently matured to bear exposure to the cold, and the roots are almost sure to be drawu out by frost and injured. Protection may be given by mulching with straw, or covering with evergreen boughs, care being taken that the mulching is not so thick and heavy as to injure the plants. Some prefer to take up the plants in autumn, and heel them in in some dry, sheltered place, to be planted again in spring into trial beds, at suitable distances for future development.

The growing of seedlings is like a lottery where most of the tickets draw blanks. Only a small percentage of the plants will prove to be of any value. Some will prove tender; others wanting in vigor, or unhealthy in growth; still others will be found unproductire, small, soft, of poor quality, form, or color, and so be soon rejected; while a few may be thought worthy of 
further trial. When all inferior to the variety from which the seeds were taken have been weeded out, the trial bed is not likely to be much crowded.

In growing seedlings, as before intimated, select as the parent a variety as nearly perfect as possible; that is, sow the seed of the best variety attainable. If you want hardy plants, sow the seeds of hardy varieties; if size is desirable, with superior flavor, color, \&c., then select from varieties possessing all these characteristics, if such are to be found.

If crossing or hybridizing is attempted-and it should not be neglected-let it always be between varieties or species of the highest merit. The method of crossing may be found in the section entitled "Crossing the Strawberry."

The flowers of some very desirable varieties of the raspberry are imperfect, and such will yield a much surer and better crop when planted by the side of other kinds as a fertilizer.

MULCHING THE RASPBERRY AND BLACKBERRY.

The practice of mulching has heretofore been confined mainly to the strawberry, to protect the plants from frost in winter, and the fruit from becoming soiled by sand. But mulching secures other valuable ends, if seasonably and properly applied. If attended to before the heat and drouth of summer, it keeps the soil not only moist, but loose, and aids in suppressing the growth of weeds. No matter how heavily rains may beat, nor how hot the sun may shine, there is never any compacting or baking of the soil under a mulch. Raise the mulch at any time, and the ground will be found loose and mellow beneath. This condition of the soil is desirable whether the season be wet or dry, while any surplus of water will leach rapidly from such a soil; instead of washing the surface, there will always be moisture enough retained for a vigorous and healthy growth of the plant.

The mulching of the raspberry, blackberry, currant, and gooseberry, or even fruit trees, large and small, will be followed by good results. The fruit will be more fully and uniformly developed, and of superior quality, the couditions being more uniform and favorable.

The raspberry crop is often ruined by a sharp drouth during 
its season of growth and ripening, especially on a sandy loam, and the same is true of the blackberry. The currant not infrequently sheds its leaves prematurely, and before the crop has fully matured. These fruits commence to ripen in July, and extend into August-a season peculiarly liable to drouth and extreme heat, and the loss from imperfect development is often very heavy. It is doubtful if irrigation, were it practicable, which it seldom is, being expensive, would answer as good a purpose as mulching.

\section{RASPBERIRIES - VARIETIES.}

Brandywine (Susqueco). Hardy, productive, very firm, bright crimson, dry and insipid. Suckers immoderately. It will ship long distances, but its popularity is on the wane. Origin unknown.

Caroline. Large, yellow. Season medium. Very good. Hardy, vigorous, productive. Thrives where Brinckle's Orange

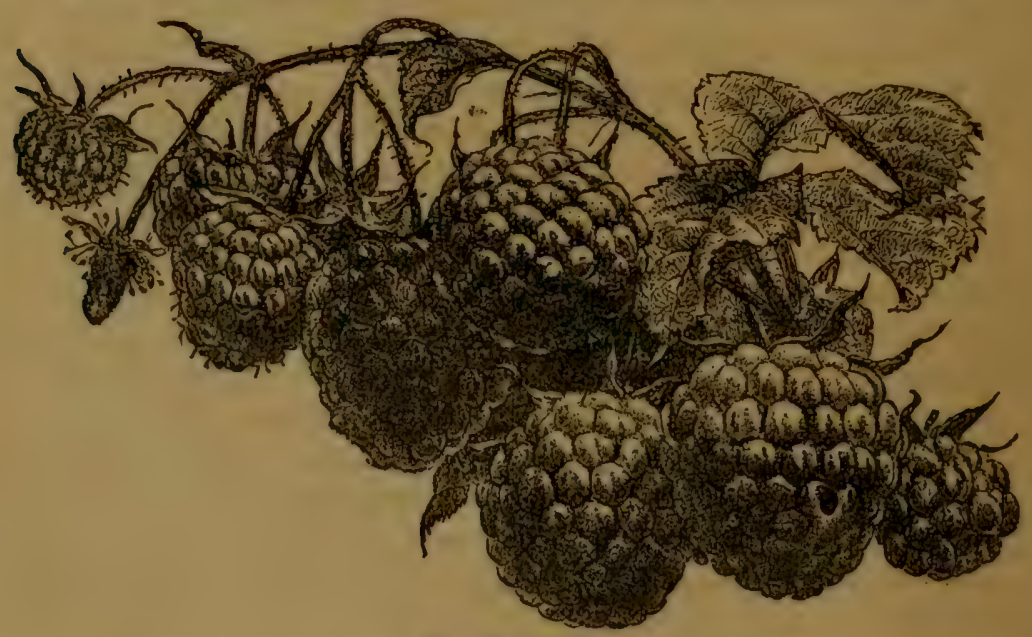

Fig. 28 (Cuthbert).

often fails. One of the best yellow varieties. Originated with E. W. Carpenter, of Rye, N. Y.

Clark. Size, medium to large; red, quality good, early. A strong, upright grower. Very productive. Half bardy. Raised from seed by E. E. Clark, of New Haven, Conu. 
Crimson Beauty. New, large, bright scarlet, roundish, conical, hardy. Very enrly, productive, and of very good quality. Originated with Dr. Stayman, of Kansas.

Cuthbert (Queen of the Market). Large, round, obtuse conical, red, hardy, and healthy. Vigorous, productive. Medium to late. The best red raspberry for general cultivation. Succeeds everywhere. Originated from seed in the garden of Thomas Cuthbert, at Riverdale, N. Y.

Franconia. Large, roundish conical, purple. Very good. Not perfectly hardy. Continues long in bearing. Origin, France, and introduced by S. G. Perkius, of Boston.

Hansell. One of the earliest red varieties. Very good.

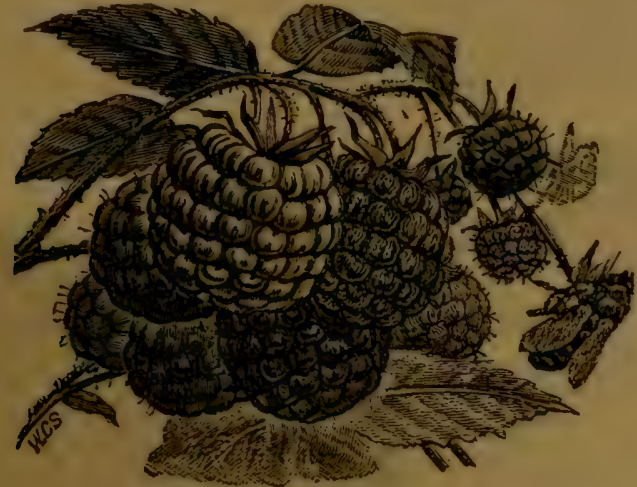

Fig. 29 (Hansell).

Medium to large. Hardy and healthy. Productive. Introduced by J. T. Lovett, of New Jersey.

Herstine. Large, obtuse conical. Red. Very good. Season medium. Canes strong, but not quite hardy. Should be picked as soou as colored, if to be sent a long distance. A hybrid of the Allen and Philadelphia. Originated with a Mr. Herstine, of Philadelphia.

Marlborough. New. Large, bright red. Firm, quality fair. Plant hardy and a vigorous grower. Productive.

Rancocas. New, early, and prolific. A strong grower. Size medium. Lacks firmness. Origin same as Hansell.

Reliance. A seedling of the Philadelphia, which it resembles in color. An improvement on its parent. Reliable for family use. 
Superb. Large, very good. Season medium. Dark crimson. A medium grower, and hardy. Productive. Crumbles in picking, and color too dull for market.

Turner (Southern Thornless.) Size, medium. Early.-Quality good. Season medium. Very productive. Absolutely hardy. One of the best for family use at the North. Originated with Prof. J. B. Turner, of Illinois, in 1833.

The following are varieties of the Black-Cap) (Rubus Occidentalis):

American Black (Doolittle). An old standard variety. Plant vigorous and thorny. Rather small. Quality good. Very productive. Season medium. Found growing wild by Leander Joslyn, of Phelps, N. Y.

Gregg. Very large. Plant a strong and rapid grower. Productive and hardy. Quality very good. Season medium to late.

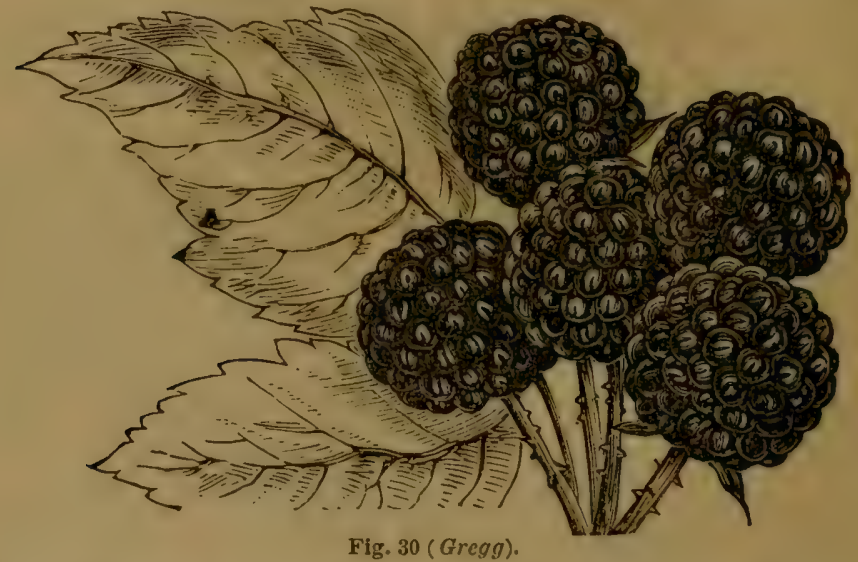

One of the most popular and profitable black raspberries in cultivation. It requires heary soil. Found growing wild on the Gregg farm in Ohio county, Indiana.

McCormick (Mammoth Cluster). Large, late, very good. Hardy, and a strong grower. Prorluctive. One of the best for market and family use.

Ohio. Size medium. Quality good. Late, hardy. A strong grower. Season medium. Productive. One of the best for evaporating. 
Shaffer's Colosscl. Very large, purple, good. Season medium to late. A rank grower, and very prolific. Owing to its unattractive color, it is not popular in the market, but good for home use, and one of the best for cauning.

Souhegan. Charles Downing said of it, "I am much pleased with the Souhegan, it being quite early, of large size, very productive, quite firm, of a deep black color, sweet flavor, and a. very promising variety for market." Plant vigorous and hardy. Originated with a Mr. Carleton, of Mont Vernon, N. H.

EXTENDED LIST OF RASPBERRIES.

Some of the varieties here given have been superseded by others supposed to be more valuable; some have merely a local value, and quite a number of them are new, and have not been widely disseminated. The cap varieties are marked thus,-C. "F" indicates a foreign origin :

Centennial. C. New, large. Flavor fine. Early. Productive.

Chapman. C. New, large, early, hardy.

Fastolff. Large, quality good, for home use, soft. F.

Florence. C. Yellow, large, good, productive, and hardy.

Fontenay (Belle de Fontenay). Large, good, late. F.

Four Sectsons Red (October Red). Large, very good.

French. Medium, very good, season medium.

Golden Thornless. C. Yellow. Superseded.

Hiland Hardy. Medium, good, early.

Hopkins. C. New. Resembles Mc:Cormick. Early, good.

Hornet. Large, very good, season medium. F.

Hudson River Antwerp. Large, quality best, season medium.

Imperial Red. Size and season medium, quality best.

K'enevett (Kenevett's Giant). Large, season medium, quality best. F.

Lost Rubies. Said to succeed on heary soil, if fertilized by a staminate.

Miami. C. Medium, season medium, quality good.

Montclair. Large, very good, season medium.

Miller's Woodland. New, large, hardy, productive.

Nemaha. C. New. From Nebraska. Large, hardy, and productive. 
Ohio Everbearing. C. Late, size medium, quality good.

Orange (Brinckle's). Large, yellow, quality best.

Philadelphia. Size medium, purplish, productive.

Pride of the Hudson. Very large, quality very good, tender.

Purple Cane. C. Size and season medium: Good.

Smith's. C. Very large, good, season medium.

Thwack. Large, purplish red, season medium, good.

Tyler. Medium, early, very good.

\section{BLACKBERRIES.}

The cultivation of the blackberry does not differ much from that of the raspberry. Unfortunately most varieties are tender, and the canes are so strong that they cannot easily be bent down and covered in winter. 'The fruit is borne on wood of the previous year's growth, and fails entirely when the canes are killed by frost.

On low land, especially if much manure is applied, the blackberry makes a rampant growth, and for this reason high land in only fair condition is preferable. The plant is naturally a strong grower, and requires more room and not as close pruning as the raspberry. Seven feet between rows, and plants four feet apart in the rows, is not too great a distance on strong soil. Strawberries, or some low-growing annual crop, may be planted half way between the rows for two years.

Pinch back the growing canes at three feet, and the laterals at two feet, and cut out the old wood, as in case of the raspberry. If the leaders are stopped at three feet, the laterals will add one or two feet more, and this will be quite high euough for convenience in gathering the fruit. The berries are often picked as soon as colorecl, and before they are fully ripe. They will improve on the bushes if allowed to remain several days, and, as a rule, twice a week will be often enough for picking. The fruit should never be exposed to the sun after picking, as it will spoil the color.

The hardiness of the Snyder and Taylor has been fully tested on my ground for a number of years. They have never been 
injured, though the thermometer has more than once dropped to twenty degrees below zero. The plants have been in an exposed location, aud have never received any protection. Summer pruning has been practised to give the plants a compact, bushy form, and prevent a late growth. In this way tencler plants can almost be changed into those that are hardy.

Blackberries will yield good crops for six or eight years, but for the last two or three years a top-dressing of manure should be given late in the fall.

A description of only a few varieties is here given :

BLACKBERRIES-DESCRIPTION OF VARIETIES.

Early Harvest. New, very early, hardy, and prolific; firm; size medium; quality very good; plant healthy ; requires good soil. Origin, Illinois.

Irittatinny. Very large and fine, plant vigorons, but rusts in many places; productive; continues long in hearing; season medium to late. Requires protection north of New York. Found growing wild in New Jersey.

Snyder. Season medium, very productive; hardy as an oak, quality very good, size medium. Valuable for a northern latitude.

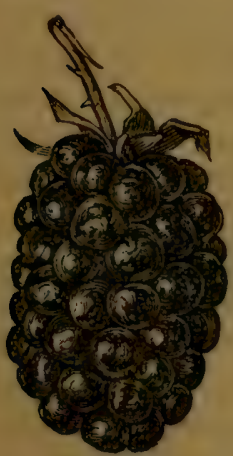

Flg. 31 .

Taylor's Prolific. [Fig. 31.] Large, very hardy and productive; a vigorous grower; sweet, and of fine flavor. Lärger and a little later than Snyder.

Wachusett. Size, medium; hardy ; very good. A strong grower; season medium to late. Requires high culture. Nearly thornless.

Western Triumph. New. Size medium; very good. Not yet fully tested. Said to be very hardy and productive. Origin, Illinois.

Bonanza. Nerr. Large, productive, hardy.

Brunton's Early. Size medium. Not entirely hardy.

Dorchester. Early, hardy, flavor fine, size medium.

Missouri Mammoth. Large, sweet. Midsenson. 
New Rochelle, or Lawton. Very large, late, tender. Stayman's Early. New. Very early, hardy, good. Slone's Hardy. Size medium, productive, hardy. Wilson's Early. Large, early, productive, tender. Wilson Junior. New. Large, early, productive, tender.

RED OR ORANGE-RUST (Uredo rubrum).

This disease attacks both the blackberry and raspberry, and in some parts of the country is very destructive, so much so that growers are forced to root out and burn entire plantations. It is of a fungus nature, and if not checked, spreads rapidly from one bush to another till all are affected. The wild plants breed the fungus, and it spreads to the cultivated varieties, some of which, such as the Kittatinny blackberry, appear to be more susceptible than others. The raspberries of the black-cap family are often affected, where the red (rubus strigosus) suffers comparatively little.

No suceessful attempt has been made to restore the plant to health after it has once become diseased. The only remedy is to dig out and burn every affected plant as soon as the rust appears. If the disease is liable to be spread by the wind, bees, pruners, and pickers, as some suppose, the importance of prompt action will be manifest.

All plants in a feeble condition, from any cause, fall an easy prey to both insects and disease. It is recommended to set plants on virgin soil, well drained, fertilized, and carefully cultivated, as tending to keep them robust, healthy, and exempt from the attacks of insects. Because no remedy has yet been discovered for rust on the raspberry and blackberry, in does not follow that nothing can be done to check the spread of it. There can be no danger of injuring the diseased plants, and experiments may be safely tried, and should not be neglected.

One writer says that after other remedies had failed, he used strong soapsuds, adding a handful of salt to a pailful of water. The plants were almost entirely covered with rust, and were spriukled thoronghly, and the application repeated after two days. In less than a week the plants were bright, and growing finely, showing no signs of the disease. Mr. A. S. Fuller says that "an application of lime, salt, or some similar substance 
may check the disease, but I know of no remedy except that of rooting up erery affected plant and buruing it." Mr. Charles Downing recommended the same course.

The rust has only occasionally attacked a single plant on my grounds, but if it should make its appearance to any extent, I would try the following preparation: Place one peck of quicklime and tro pounds of sulphur in a tight cask, and slack the lime with hot water, covering the cask with an old rug to prevent the escape of steam. After cooling off, fill up the cask with cold water, and stir the contents thoroughly. The sediment will soon settle, leaving a clear yellowish liquid at the top. If thought too strong, the lime and sulphur mixture may be reduced, using only one or two quarts to a bucket of water. Apply this to the diseased plants with a small hand force pump or syringe, and repeat the application within a week.

This has proved a most effective remedy for rust on the verbena and other green-house plants, and sulphur alone is known as a specific for rust-or what amounts to about the same thing, mildew-on the grape. It may be well to experiment with carbolic acid, or sulphate of iron, in weak solution. The cultivator should bear in mind the maxim that every wrong has a remedy, and take it upon himself to discover, if possible, what the remedy is.

\section{MULBERRIES.}

This fruit is attracting some notice at the present time, as what is known as the Russian mulberry is being unduly puffed by unscrupulous nursery men, and pushed at extravagant prices by tree peddlers equally unscrupulous. The mulberry-tree grows forty or fifty feet high, and sometimes three feet in diameter, furnishing a beautiful lawn or street tree. It is hardy, and should be more generally introduced for ormamental purposes. The white variety is well known where the silk industry has been introduced, as the leaves are used for feeding the silkworms. Except for shade, it is otherwise of no value.

All the varieties make rapid growth, and produce fruit when not more than four or five feet high. For quality the Downing 
is the best, and yields an abundance of fruit for more than three months. The berries fall as they ripen, and if the ground under the trees is not in turf, it should be corered by a clean mulch to prevent their becoming soiled.

Thousands of the Russian mulbery plants are annually sold, many of which are grown from seeds, and of course are in every grade of quality. They can be grown from cuttings as easily as the willow, and the best only should be propagated. Tree agents are taking orders for small plants at from one to two dollars each, but reliable nursery men offer them at twenty-five and fifty cents. Birds are very fond of the fruit, and it might be more extensively grown for their especial benefit.

Rev. Henry Ward Beecher says,_- "I regard it as an indispensable addition to every fruit garden; and I speak what I think when I say I had rather have one tree of Downing's ever-bearing mulberry than a bed of strawberries."

\section{CURRA NTS.}

Plants of the currant are easily multiplied by cuttings. These are made from one-year-old wood as soon as the leaves have fallen in autumn, and at once planted out in a good saudy loam. The soil must be well drained, as a surplus of water on the surface, or at the base of the cutting, will prove fatal. The currant sheds its leaves quite early, and if the cuttings are put in immediately, they will callons over and send out small roots, so as to make strong plants the next year. If to be grown in tree form, all buds below the surface should be removed before the cuttings are set. Cuttings are usually macle from six to ten inches long, but in case the wood is of some scarce and choice variety, it may be cut into lengths of three or four inches. Those having facilities for propagating under glass sometimes cut to single buds, and plant half an inch deep in boxes of sand.

When planting in trenches, set the cuttings three inches apart, and make the soil around them very firm. If many are to be propagated, they may be placed in double or triple rows, and in 
this way will occupy much less land. Only a sufficient number of buds are to be left above the surface to form a well balanced top. Some allow only a single shoot to grow the first year, in which case the branches will be higher from the ground. When cuttings of any kind are planted in trenches in autumn, they will require mulching to prevent their being thrown out by frost.

The advantage of growing the plants in tree form is that it admits of clean and convenient cultivation around and under them, while if suckers are allowed to spring up from the ground, as they will when the buds are not removed from the base of the cutting, grass and weeds are sure to take possession and hold their ground in spite of the cultivator's best efforts to suppress them. Too many of the shoots that spring up are weak and

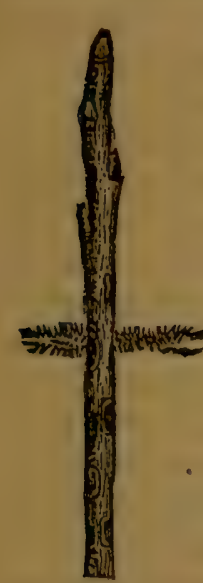

Fig. 32. worthless, and they cannot be as easily pruned out in forming the top as when trained in the tree form. Fig. 32 is a good representation of a cutting when planted in the trench, and Fig. 33 of the same when rooted. If properly made and managed, not five per cent. of such cuttings will fail.

The currant should be pruned in autumn, and the wood may be utilized for propagating purposes. It may be preserved in good condition if packed in damp sand or moss and kept during winter in a cool

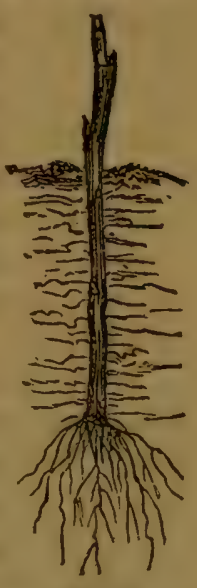

Fig. 33. cellar, to be planted out early in spring. Some propagators prune in spring, and use the cuttings as taken directly from the old plants; but a larger per cent. will fail, and those that root will make a comparatively small growth. A few evergreen boughs set on the southerly side of the rows, so as to give partial shade in summer, will enhance success.

For field-culture, plant in rows five feet apart, with the bushes four feet distant in the row. Cultivation in spring is not recommended, but if it is given early, and so shallow as not to disturb the roots, no injury will result. Mulching between the rows and under the plants will do much to suppress weeds, 
while it will keep the ground cool and moist,-a condition perfectly suited to the wants of the currant. A thorough cultivation should be given in autumn, when the plants have become dormant, working in at the time a liberal quantity of manure:

Pruning the currant consists in thinning out all immature and superfluous wood, shortening the leading shoots, and removing all decaying and mossy branches as the plant grows old. The object to be aimed at is to admit light and air, and at the same time reduce the bearing wood somewhat, thereby increasing the size and quality of the fruit.

As the currant flourishes in partial shade, it may be planted in line with rows of pear or plum trees, and yield very profitable returns. As has been before stated, it must have a generous application of manure spread broadcast annually. Ground bone and wood ashes make a good fertilizer, and even coal ashes are supposed to be of some value as a mulch, if in no other way.

The borer sometimes injures the plant, but among its insect enemies the currant-worm, known in England as the larva of the magpie moth (Abraxas agrossulariata), is most destructive. It is equally injurious to the currant and gooseberry, and such has been its ravages that the growing of these fruits has, in many localities, been abandoned. It is an imported pest, and, according to Mr. Roe, made its appearance at Rochester, N. Y., in 1857. This is the insect figured by Mr. Fuller and Mr. Roe, but Mrs. Treat, in her valuable work on "Injurious Insects," speaks of the imported currant-worm (Ematus ventricosus) as " the larva of the saw-fly, of the order Hymenoptera, called false caterpillars, as they never have less than six, sometimes as many as eight, pairs of pro-legs, while the true caterpillars never have more than five pairs."

The insects appear almost as soon as the currant and gooseberry are in leaf, and lay their eggs upon the under side of the leaves in regular rows. The books say that the worm appears in June-rather indefinite; but I am assured by an intelligent observer that they appear in the vicinity of Boston from the 12 th to the 16 th of May, the second brood about the 25 th of May, and a third from the 15th to the 20th of June. I found them full grown this year (188ã) on gooseberry bushes in my grounds, June 1. 
Fig. 34 shows the perfect insect, $a$ being the male and $b$ the female, the lines representing the size with wings expanded. The eggs hatch in from six to ten days, and the worm immediately commences feeding upon the leaves. The caterpillars increase in size rapIdly until they are three fourths of an inch long. When full grown they pass down into the ground and spin brownish 'cocoons, and assume the pupa state. They again leave the

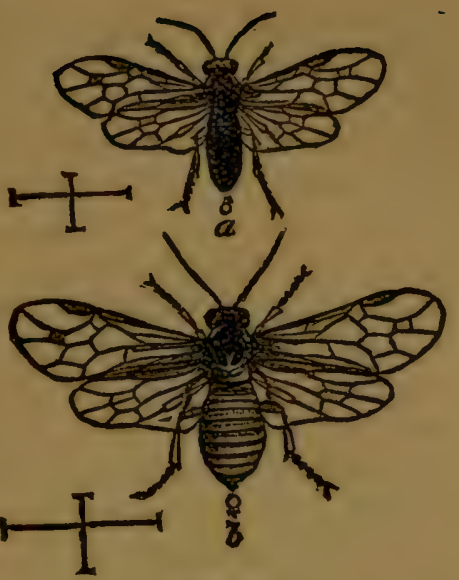

Fig. 34. ground in about two weeks in the form of perfect insects, and lay a second crop of eggs from which a second brood is hatched, which pass the pupa state in the ground, where they remain till the following spring. It is said that the fly lives about nine days. The worms when first hatched are of a pale color, soon, however, becoming green, with a black head and shining black spots on each side of the body. Fig. 35 represents the worm in different stages of development feeding upon the leaves of the gooseberry, and $b$ represents the spots on a magnified joint of the

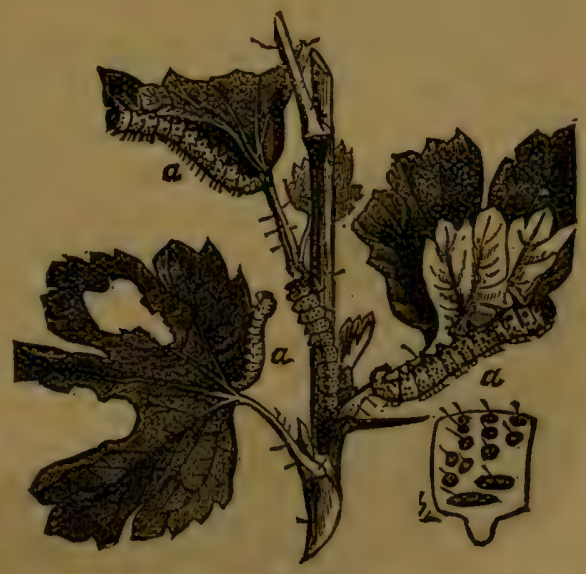

Fig. 35 .

body. The worm is not often discovered until its work of destruction attracts attention, and its work is so rapid that a plant may be entirely divested of foliage in forty-eight hours. The importance of a daily examination of currant and gooseberry bushes, at the season when the worm is likely to appear, is quite apparent. 
But if the rorm disposes of our currant crop in a summary way, it is fortunate that we are able to rid ourselves of the worm in an equally summary manner. A tablespoonful of powdered white hellebore (veratrum album) to a pailful of water, well mixed, and applied with a watering can having a fine sprinkler, will end the career of the currant-worm in a very short time. The powder may be dusted over the bushes when wet, and will prove equally effective. It should be understood that this article is a poison, and should be used with care, and kept beyond the reach of children and raluable animals. It is not as dangerous as Paris green, and as it soon loses strength it is often quite harmless when first purchased, and of no value as a destroyer of insects. Be surè to get a pure article from some reliable druggist, and keep) it excluded from the air. It is washed from the plants by the first rain, long before the fruit will be fit to use.

There are but few varieties of the currant in cultivation, and only one of any note of American origin. It is fortunate that we are not obliged to make a selection from a hundred sorts, as in case of the strawberry.

The old Red and White Dutch are very productive, and are standard varieties as to quality, but they are not equal in size to

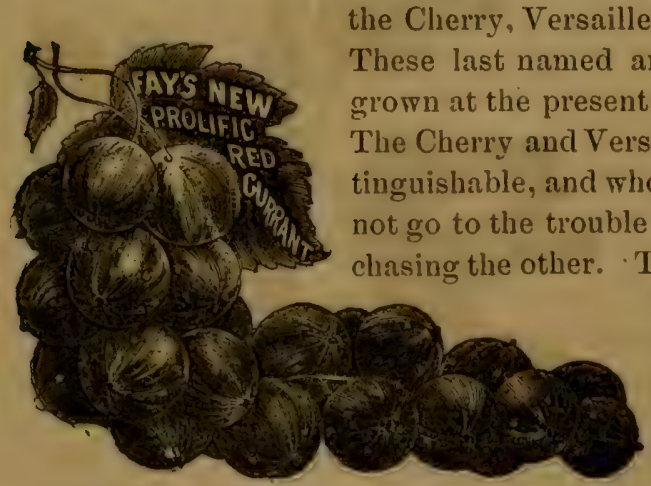

Fig. 36. the Cherry, Versailles, and White Grape. These last named are more extensirely grown at the present time than any other. The Cherry and Versailles are hardly distinguishable, and whoever has either need not go to the trouble and expense of purchasing the other. The Cherry is thought by some to give the larger berries, while the Versailles produces the larger bunches. Fay's Prolific, Fig. 36, is

a new American currant, and claimed to be twice as productive as any other variety. It is undoubtedly very promising, but the plants have always been held at too high a price to admit of its being extensively planted. Dana's Transparent is one 
of the finest white currants. The Belgian is late and continues long in bearing, and as it lengthens the season tro or three weeks it is valuable for this purpose. The Black Naples and Lee's Prolific are the only two black currants named in the catalogues, and what use any civilized being can make of either it is impossible to imagine. But the rank and musky odor of the leaves, wood, and fruit, that is so disagreeable to me, is thought by others to be delightful. Truly there is no accounting for tastes-culinary.

No fruit will pay better for the care bestowed in its cultivation than the currant. It meets with less competition in market than most other small fruits, and there is not the same occasion for haste in gathering and disposing of the crop as in case of the strawberry and raspberry. The fruit may remain on the bushes for weeks after coloring, if not stolen by the birds, and thereby be improved for all uses except for jellies, for which purpose it should be picked before it becomes over-ripe. The same is true of the grape and other fruits, and for want of this knowledge many a good houservife fails to make the jelly "come."

The currant does not require to be renewed every five or six years, as some suppose, but with proper treatment, such as pruning, cultivation, and manuring, will continue to yield good crops for a long time. The plants may be set in fall or spring. The buds push early, and if transplanting is delayed till late in May, but little growth will be made ; while if set in autumn, as soon as the leaves fall, they will become well established before the ground freezes, and be ready for an early growth.

The proper age for plants is one or trro years from the cutting. I should prefer plants of one year, if of first quality, to those of two years of second quality. There is little danger in transplanting the currant, even though the plant contains but few roots, as new roots form readily under favorable conditions. The work of setting requires less skill than with many other plants, though extra care will be well repaid, and should never be neglected. As every part of the plant will emit roots when placed in contact with the soil, there is no objection to planting the bush three or four inches deeper than it stood in the cuttingbud. 
The currant may easily be grown from seeds; but this is not advisable, except for the purpose of obtaining new and better varieties. There is a wide field for improvement in this direction. A large per cent. of seedlings will be inferior to the old standard varieties, but this should not deter us from making an effort for something better. Some bushes will be found to produce finer fruit and more abuudaut crops every year than others near by of the same variety, and seeds shonld always be selected from the best bunches of fruit produced by these plants. Wash out the seeds when perfectly ripe, and pack them away in a cool place, treating them the same as any small regetable or flower seeds should be treated. Sow them in spring as soon as the ground is in suitable condition, cover about half an inch deep, and make the soil over them firm with the back of a spade. When the seeds have been kept dry for several months, they will vegetate sooner if soaked in tepid water for forty-eight hours before planting. The seeds may be mixed with sand as soon as washed out, and placed in pots or boxes and buried in some cool shady place. They should be allowed to remain frozen up until the proper time for planting ont in spring. The young seedlings should be carefully cultivated, and transplanted the second year into trial beds for testing their value.

\section{GOOSEBERRIES.}

\section{(Ribes grossularia.)}

Having given pretty full directions for growing the currant, it will be unnecessary to say much under this head, as the conditions required for the successful cultivation of the one apply with equal force to the other. They both thrive in a strong, rather moist soil, and in a cool, half-shady location. Both demand a liberal application of manure, and protection from the same insect enemies.

The gooseberry is not as easily propagated as the currant, inasmuch as the cuttings do not strike root with the same facility. For this reasou the plants are usually increased by lavers. Layering consists simply in bending down and covering the 
branches with soil, and mulching to preserve moisture during the season of growth. In this way they root easily, and the rooted branches may be cut from the parent plant in the fall, or allowed to remain until the following spring, when they may be at once planted out.

Most varieties are inclined to form very low, almost trailing, bushes, sending out branches near the ground. As roots push wherever the wood comes in contact with moist soil, nursery men take advantage of this peculiarity of the plant to increase their stock. They have only to bank up their bushes above the intersection of the branches, when each will send out roots, and, when cut loose, form a strong, independent plant.

We have but few varieties of native gooseberries, and such as we have are much inferior to foreign sorts. Great attention has been given in European countries to the improvement of this fruit by growing new varieties from seeds, so that they can now count them by the hundred, while we have only five or six worth naming. Here, then, is even a wider field open for improvement than with the currant. There is the greater occasion for effort in this direction as the foreign varieties can seldom be successfully grown in this country, owing to their liability to mildew. We are forced, however unwillingly, to rely upon natives, poor as they are, as the seedlings of foreign sorts, though grown in this climate, have thus far proved entirely unreliable.

The American Pomological Catalogue for 1883 names only six native gooseberries worthy of cultivation,-Downing, Houghton, Mountain, Orange, Pale Red, and Smith's ; and only three from the long list of foreign sorts,-Crown Bob, Roaring Lion, and Whitesmith. These last named will only succeed in skilful hands under the most favorable conditions.

As before intimated, mildew is the great obstacle to the cultivation of the foreign gooseberry: neither the foliage nor the fruit will endure our climate. A cool, moist, half-shady situation, close pruning, high manuring, and the free use of sulphur, are the only conditions under which success is sure. Like the currant, all gooseberries delight in a spot where they are protected from the direct rays of our scorching sun and drying winds. Set on the north side of buildings or fences, or in pear 
or plum orchards, where the shade is not too dense, they seem to be at home. In such locations some of the English varieties have been successfully grown. Mr. Benjamin G. Smith, who has often been a successful competitor for the prizes offered by the Massachusetts Horticultural Society, names as the best of the English gooseberries, Woodward's Whitesmith, Wellington's Glory, Glenton Green, and Yellow Amber : and of native varieties, Downing and Smith's Seedling. 'The Houghton originated in Lynn, Mass., with Mr. Abel Houghtou. It is very hardy and productive, but rather small for a popular market sort.

Gooseberries should be set in rows five feet apart, and the plants three feet apart in the rows. If any cultivation is given in spring, it should be shallow and very early, as any disturbance of the roots at this season is thought to be injurious, and all cultivation later than August has a tendency to cause a growth of immature wood that is liable to be injured in winter. To avoid the same result, no manure should be applied in the fall until the plants have ceased to grow. Coal ashes have been recommended for currant and gooseberry bushes, and wheu mixed with about ninety-nine per cent. of wood ashes, they are undoubtedly of great value.

\section{THE CRANBERRY.}

\section{(Vaccinium macrocarpon.)}

Few fruits will better repay the enterprise and skill of the intelligent cultivator than the cranberry. It grows and thrives best on land entirely worthless for any other purpose. A natural peat-bog, wet meadow, or morass, if properly prepared, and kept clean until the vines become established, will continue productive for an indefinite period. Instances may be found of bogs planted thirty, and even fifty, years ago, on Cape Cod and in New Jersey, that still yield profitable crops.

The vines require no manure, though fertilizers have, in a few cases, been applied with apparent benefit. The gradual and constant decay of the regetable substances of which such soils are composed, with the sediment precipitated by the annual in- 
undation which the plants require, will furnish an abundant supply of nutriment for both foliage and fruit.

There are thousands of acres in sections of the country adapted to this fruit, lying worse than idle, that could be easily transformed into cranberry meadows, and made to yield a greater profit than the best upland in other farm crops. A swamp covered with alders, dogwood, laurel, water-bushes, and brambles, or almost any wet meadow, will answer for cranberries, except those where clay and drift abound. On such soil, failure is almost certain to follow the best efforts for success.

In selecting a plot for a cranberry meadow, the facilities for flowing must be carefully observed. Water is one of the first requisites. The owner of a bog having complete control of water, may feel reasonably sure of a paying crop, while his neighbor, having all the other requisites, may fail three times in four for the want of it. If the cranberry could be grown in localities exempt from frost, and where the cranberry worm is unknown, flooding the bed might be dispensed with; but peatbogs are always found in low, frosty localities, and the vine worm is as sure to find a crauberry meadow as is a Colorado beetle the potato field. If the bog is so situated that a reservoir can be constructed above, from which water can be let down suddenly, it will be of great advantage in case of early frosts in autumn.

Much has been said and written in years past about growing cranberries on high land; but all of the so-called successful experiments bave turned out failures. It would be difficult to find an instance where any one has been able to produce profitable crops on upland for a series of years. The crops have been destroyed by insects and frost. Those who wish to engage in cranberry culture, will find a tract of 'low, level ground, and an abundant supply of water, indispensable.

If the meadow or swamp is filled with water, the first work after clearing the surface will be to cut ditches through the middle and around the margin, with cross ditches at suitable intervals, so that the surplus water can be drawn eighteen inches below the surface at pleasure.

A dam will be required at the lowest point of the meadow, with flood-gates high enough to raise the water eighteen inches 
over the entire surface. A much more shallow covering of water would suffice for most purposes, but, if only a few inches deep, the vines would be frozen into the ice in winter, and, in case of freshets, the ice might lift and break the vines, and damage the meadow.

A third requisite will be a good and convenient supply of pure sand or gravel with which to cover the surface of the bog from three to eight inches deep. The depth of sand required will depend upon the depth of the peat-the more peat the more sand. In some instances as much as twelve inches has been applied, but in most cases from three to five inches will be sufficient. A meadow thinly sanded will give a crop of fruit sooner, but it will continue productive longer when the application is thicker. For this reason, some cover only two or three inches at first, and repeat the application as required. In the first instance, the sand is moved from the margin or bank to the bog on small flat cars and movable wooden tracks, if the area is large, but barrows and plank runs answer very well for small plots. The most convenient method, however, is to flow the meadow, and spread the sand evenly on the ice in winter.

Occasionally a meadow may be found that can be turned with the plow, and harrowed after it has been drained. This will save much expense in the preparation; but if the land is filled with stumps, or covered with bushes, plowing will be found impracticable, and grubbing - a much more expensive methodmust be adopted.

All elevations must be cut down, and the sods and soil used for filling depressions, so as to make the whole surface as level as possible. The brush, and all combustible substances, may be piled and burnt on the ground, while bogs and tussocks may be utilized in the construction of dikes and dams. If removed and piled on the margin of the upland, they will soon decay and become valuable for use in the compost heap and as an absorbent. Their value for this purpose will repay, at least in part, the cost of removal.

In order that the bog may be covered with water in winter to a uniform depth, it must be graded to a level, or so as to hare only a slight inclination towards the ditches. If there is much slope the upper portions could only be covered by constructing 
a high and expensive dam. The object of flowing is to protect the plants in winter, the flowers from late frosts in spring, the immature fruit from early frosts in autumn, and both plants and fruit from the ravages of the worms that injure and sometimes destroy the crop.

To prevent destruction by the vine-rrorm, or fire-rrorm as it is sometimes called, the meadow must be kept flowed in New England till near the first of June. This worm is the larva of a moth (Anchyloperca racciniana) which feeds upon the foliage, and gives it the appearance of having been scorched by fire: hence the name, fire-worm. The egg is deposited in autumn, or early in spring, on the underside of the leaf, and hatches in Massachusetts about the 20th of May. The larva is effectually destroyed by flooding the vines. The fruit-worm is also the larva of a moth, but of a species not yet fully identified. It enters the berry and eats out the inside, leaving nothing but a thin shell. Its presence is indicated by the premature coloring of the fruit.

As there are but few bogs that can be flowed at short notice, the cranberry culturist will often find his efforts baffled by insect enemies, and his hopes disappointed. In flowing for protection from insects, and spring and autumn frosts, the depth of water
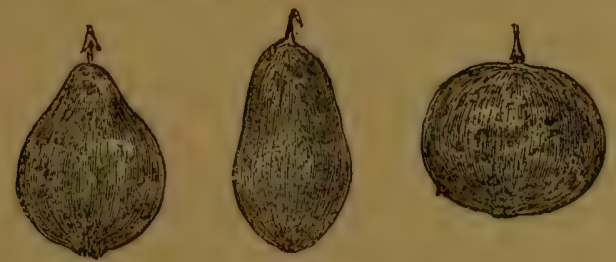

Fig. 3\%.

need be only sufficient to cover the plants. It should be borne in mind that water must not be allowed to remain on the vines when in flower for more than twenty-four hours, as it will injure the pollen, and in consequence the crop may be ruined.

SELECTING PLANTS.

- There are three varieties of the cranberry distinguished by their form as shown in Fig. 37-the bell, bugle, and cherry, the last named being the most common. On Cape Cod, where this 
fruit is extensively grown, they have two rarieties differing in size and season,- - one early, but rather small, and the other larger and later. 'The small berry is heavy, being mostly solid, while some of the larger and more showy fruit is hollow, and shrinks more in cooking. The Cape cranberry is high-colored, keeps well, and commands the highest price in market. The extra color is probably owing to climatic influences peculiar to that particular locality more than to any difference in variety. The American cranberry is larger than the European, of much superior flavor, and of a darker color.

It is very important in selecting plants to obtain those that are productive. Many bogs yield very little fruit, and that of an inferior quality, being wanting in size and color. All such plants should be rejected. It will pay to examine different meadows in the fruiting season, and make a selection of plants from such as produce large crops of the most attractive fruit. The first inquiry of the purchaser is sure to be, Are the berries large and high-colored?

\section{SETTING THE PLANTS.}

The best time for transplauting is in May or June. The rows should be straight, and some are particular to have them run both ways, and mark off the bed into check-rows, with a common garden-marker. The plants are set from one to two feet apart each way: the nearer they are set the sooner they will cover the ground.

The bed should be kept clean for at least three years, by which time the vines will have become so thick as to choke out all other vegetation. The labor of cultivation will be somewhat expensive, but when the rows are straight, a small hand cultivator or slide hoe can be run very close to the plants, and save much hand-weeding.

The vines strike root from every joint that touches the ground, and in setting, the plants are simply pressed into the sand, quite down to the peat, by any blunt implement, and the sand made firm around them. Pieces of vine, ouly a few inches long, may be planted, three or four in a hill, at each angle where the checkrows cross, and will take root and grow as well as entire plants. As the cranberry is inclined to trail, it should be set at an incli- 
nation rather than perpenclicnlarly, as it will sucker up better and sooner cover the ground. Some bogs are set in a haphazard way, without regard to distance or rows; but all such planting is likely to be followed by careless cultivation, and is properly known as the slipshod method.

But little fruit need be expected before the third year from planting, after which it will increase rapidly if all the conditions are favorable. In many experiments it has been'found that the expense and income account will just about balance the fourth year.

The first cost of preparing a cranberry bog will depend very much upon the condition in which it is found at the commencement. If covered by a growth of trees, or if filled with stumps where wood has been recently cut, the work of fitting up will be expensive. But if it is merely necessary to turn the sod with a plow, or remove it with heavy hoes made for the purpose, and if located near suitable sand deposits, the cost will be comparatively small. It is safe to say that the expense will vary from two to five hundred dollars an acre; and that, under favorable circumstances, the cultivator may reasonably expect a return of his investment in four or five years.

\section{PROFITS OF THE CROP.}

Cranberry culture, when conducted intelligently, is no longer a speculative business. In many localities it has become permanent and profitable. A good meadow, in a bearing condition, is readily worth $\$ 1,000$ per acre. A bushel to a square rod is not an uncommon yield, and a single rod has been reported as yielding more than six bushels, or at the rate of over nine hundred bushels to an acre. One hundred bushels per acre is called a good average crop. But there will be many failures in growing cranberries, as with all other fruits.

PICKING THE FRUIT.

The fruit was formerly gathered by rakes, but is now mostly picked by hand. The work is done mainly by women and children, at a cost of about fifty cents per bushel. When the rows are visible, each picker is confined strictly to his row; but if the bed has become one solid mat, plots are staked off containing 
only a few square rods, one of which is assigned to each person employed.

\section{COLORING AND CLEANING.}

Of course all fruit will be unfit for packing as it comes from the field, as there will be more or less imperfect berries, and also grass and leaves, that must be removed. The fruit is usually spread five or six inches deep on some floor in a shady place, where it remains for a few weeks to color. It should be stirred occasionally, so that all the berries may be at some time exposed to the air. When well colored they are passed through a fan-mill to remove all light substances, and finally all imperfect berries are removed by hand-picking. All sound fruit will assume a fine color by keeping, and will command a ready sale and the best prices. As it is always in clemand for exportation, there is little danger of overproduction and an overstocked market.

\section{IMPLEMEN'TS.}

It would be useless to give illustrations of, or even describe, the numerous plows, cultivators, and harrows in common use. There are so many, any one of which will do good work, that it is only necessary to risit some agricultural warehouse and make a selection. Inventors gladly send out their plows for trial, to be returned in case they prove imperfect or unsuitable.

Unless the land is so flat as to require laying up into beds, the reversible plow is preferable to a land-side. The lifting subsoiler is very serviceable for rumning in the furrow of the surface plow, loosening but not bringing to the surface the subsoil to the depth of from five to ten inches, as may be thought adrisable. This will save much labor with the spade and fork. Planting on soil made deep in either way will often protect a crop from the effects of a sharp drought in July and August, just when it is coming to maturity.

For pulverizing rough ground, and for cutting and covering coarse manure applied to the surface, there is nothing equal to the Acme and Disc harrows. If, however, the manure has been 
applied with the Kemp manure spreader, it will be in very fine condition, however lumpy it may have come from the stable.

In taking up plants of the raspberry, blackberry, etc., where the roots must be cut at a proper length, a heavy spade, ground sharp, will he required, but for loosening the soil around plants, and in spots that cannot be reached by the plow or cultivator, the digging fork is the best of all implements. If the tines come in contact with roots, they slide by without doing injury; but if the spade is used, the roots are cut at every thrust.

The pronged hoe, slide or scuffle hoe (Fig.42), and steel garden rake are all serviceable. For loosening the surface soil and desstroying small weeds, - and large weeds ought not to be tolerated,

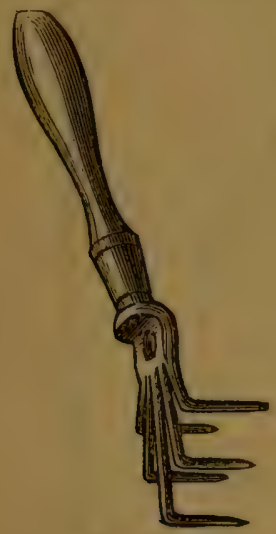

Fig. 38.

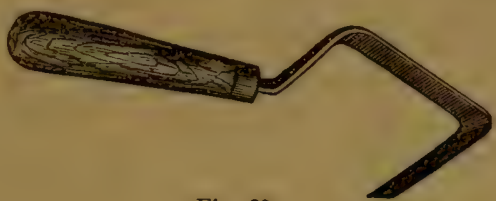

Fig. 39.

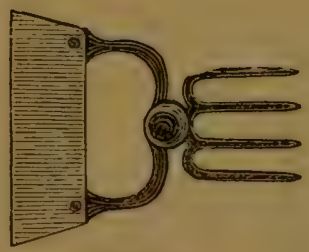

Fig. 40 .

-any one of them is preferable to the common blade hoe. When deep cultivation is not required, much more and better work can be done in the same time than with any other implements. In cleaning out weeds around small plunts, just as they are

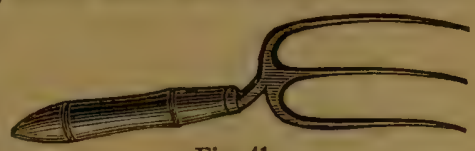

Fig. 41. breaking through the surface, the hand-weeders (Figs. 38, 39, and 40) are very effective; and in transplanting strawberry plants, the garden reel and line (Fig. 43), trowel, and strawberry fork (Fig. 41) are indispensable. Hedge shears are best for shortening the new growth of the raspberry and blackberry, and long-handled pruners to cut out the old canes. 
The enterprising cultivator of small fruits will find it for his interest to keep his workmen well supplied with the best laborsaving implements, and require that they be handled with care, and returned to the tool-room clean when not in use.

As a last word, I would say that a judicious selection of varieties, the adaptation of soil and situation, thorough cultivation, high manuring, and proper training are the secrets of success in growing small fruits.

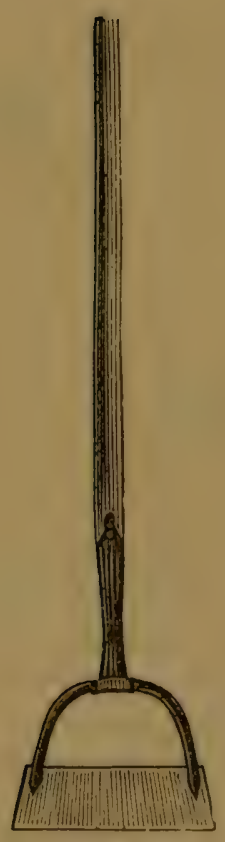

Fig. 42.

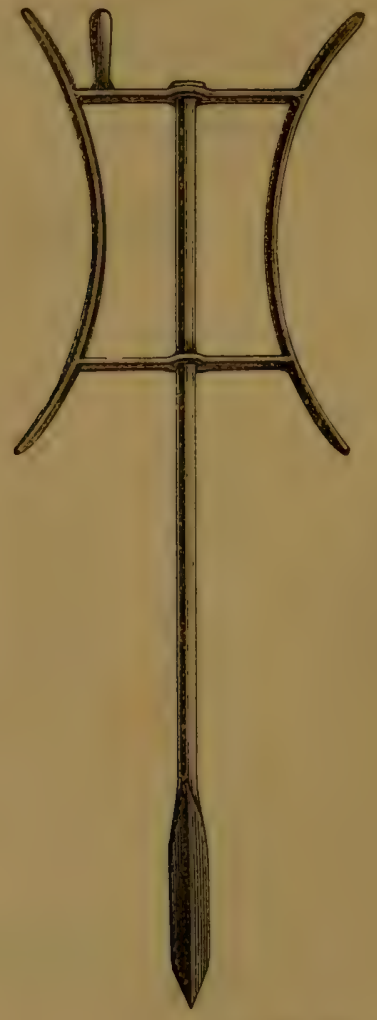

Fig. 43.

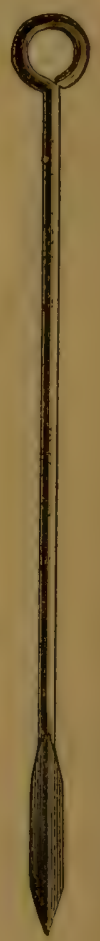




\section{GRAPE CULTURE.}

Many entertain the opinion that grapes cannot be successfully grown, except it be a single vine, here and there, in some favored locality. Certain they are that it is useless to attempt to grow grapes for market in the Eastern and Northern states. Both these notions are erroneous, having been formed some years ago, when the Isabella and Catawba were the only hardy out-door grapes to be found in the catalogues. The Isabella originated in South Carolina, and is seldom grown to perfection in the latitude of New England, and the Catawba requires too long a season. Those who judge of the possibilities from what they know of these varieties, are not up with the times. They forget, if they ever knew, that the new varieties have shortened the required season at least a month.

A knowledge of the best treatment for bringing the fruit to early maturity will aid the grower still more, and a selection of a proper soil and exposure will also tend to insure success. In favorable localities, with suitable varieties and intelligent culture, the grape crop is as certain as a crop of Indian corn. The conditions best suited to each are nearly identical. There are a few fruit-growers who are already masters of the situation, and are making the grape and the peach crop very remunerative. Inquirers and converts are rapidly incrensing.

New England is on the extreme northern limit of grape culture, and the grower, to succeed, must study and observe the conditions of success carefully. Almost any man can find spots on his farm that are practically a hundred miles north or south of his dwelling-house. For the grape, choose the spot farthest south-a warm, sandy loam, with a gentle slope, and southern 
exposure. If protected by hills or belts of timber, all the better; if not, artificial protection may be furnished by planting evergreens at intervals to break the force of winds and storms.

Heavy clay loam, and what is called strong, moist soil, are unfavorable for early maturity, and the finest quality of the grape. A soil that will absorb and retain the sun's heat is much to be preferred. There must be natural or artificial drainage.

Fruit-growing seems to have been one of the earliest occupations of man, and, although a little unpleasantness arose from the first use of the apple, it has always been an attractive pursuit since that time. There is good reason to believe that the grape was born at the same time as the apple, as Eden could not have been the model garden that it was,- - before the devil got in,-in the absence of this most delicious fruit. Noah was the first in the vineyard business, and appears to have had no scruples about sampling the wine of his own manufacture.

There is no fruit more desirable for home use, or more easily and cheaply grown, than the grape, with possibly the exception of the strawberry; but the vine has one advantage over any of the small fruit-bearing plants that require frequent renewal, when once planted it becomes a permanent institution. It will live and flourish, with decent care, to a very great age.

Many, doubtless, are deterred from attempting to grow grapes by reading the foolish directions, formerly so common, for preparing a grape border-trenching three feet deep, and the bewildering rules for pruning and training the vines. I contend that it is better to grow fruits in a "slip-shod" way rather than not grow them at all.

Vines may be planted in various localities on the farm, where they will occupy little or no valuable space, and often such spots will be peculiarly adapted to their wants. I have known of instances where the soil on the sonth sicle of ledges in the open field has been prepared, and along the sides of stone walls forming division fences, and grapes grown in great abundance. The sides of unsightly farm buildiugs may often be utilized for this purpose. True, the clusters and berries thus grown will not compare favorably in size with those produced on a carefully trained vine, and their market value would be 
less, but for home use such fruit is always acceptable, and of considerable value.

The radiation of heat from a ledge, fence, or building, will effectually protect a vine from early frosts. While nothing less than a freeze will injure the fruit, yet repeated dew frosts will affect the foliage so as to check the process of ripening; and, as we often have one or two frosty nights, followed by weeks of fine "Indian-summer weather," any available means by which we can bridge over these cold waves becomes of vital importance.

When a vine is planted by the side of a ledge, any rude trellis that will hold the fruit a few inches above the rocks is all that will be required. Of course, no skilful pomologist would think of growing grapes for the market in the way here indicated, but I want to encourage every farmer to grow at least a few grapes in some way. His sons will soon learn, and adopt the best methods.

PROPAGATION OF THE GRAPES BY BUDS.

The vines of hardy varieties are easily propagated by single buds, cuttings, or layers. Single buds are cut from well ripened wood of one year's growth in form represented by Fig. 44. This cut is so perfect that no description seems necessary. The fall and winter prunings of the vine are reserved for cuttings, and only require to be kept from

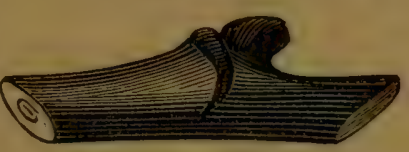

Fig. 44. drying until the season arrives for planting them out.

Cut the canes into convenient lengths, say two or three feet, tie in bundles carefully labelled, and place them on the cellar bottom. If your cellar is dry, cover with a damp cloth. Keep them as near the condition they were in when cut from the vine as possible. Some pack the wood in damp moss or sand, which prevents drying and heating. These prunings will answer equally well for one, two, or three bud cuttings.

Single buds are most successfully started under glass, in the green-bouse or a hot-bed, in February or March. Cut out the buds, as many as are wanted, and place them quite thickly in a 
box of pure sand. Cover the buds about half an inch deep, and press them dowu, so as to make all compact. These boxes

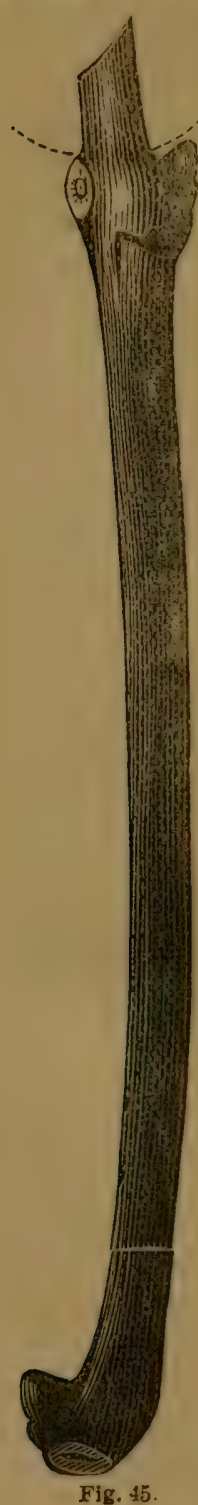
may be packed array under the benches of the house, and will require no care for several weeks, except an occasional watering, just enough to keep the sand moist. Do not expose them to much heat, as the process of root-formation, as with all hard-wooded cuttings, will be slow. If kept too warm, the heat will excite the bud into growth before roots are formed to sustain it, and when they have pushed one or two inches, and exhausted the small amount of vitality which they contain, they will perish. Any attempt to hurry a hard-wood cutting will result in disappointment. With skilful management, ninetyfive per cent. of the buds will grow, and make good plants.

As there is little or no plant-food in sand to sustain the growing vines, they should be transplanted into flower-pots, or boxes filled with good soil, as soon as they have formed roots, and turned out into the open porder as soon as the season will admit.

PROPAGATING VINES BY CUTTINGS.

Two-bud cuttings are made as represented in Fig. 45, as soon after the fall of the leaf as convenient, and planted out in any well drained sandy loam at once. Select a spot where no water will collect in winter. The base of such cuttings will callous over, and sometimes form roots before the ground freezes, and make a good growth the next year; or, the wood may be stored in the cellar, as directed above, and the cuttings planted out early in the spring. The fall is to be preferred, for the reason stated, and because the ground is in better coudition at that season of the year. Late planting of cuttings in spring is liable to prove a failure. 
In planting out two or three bud cuttings, draw a garden line the required length, and, with the back of the spade, to the line open a $\mathrm{V}$-shaped trench to receive them as represented in Fig. 46. Set the cuttings in the trench, three or four inches apart, sloping from the sun, observing that the top bud comes just even with the surface of the ground at the line. Fill the trench a little at a time, compacting the soil firmly about the cutting, especially at its base, by pressure with the foot. If the wood of

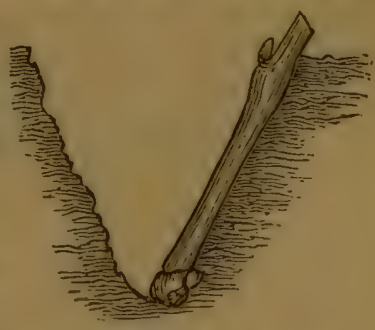

Fig. 46. which the cutting is made is in good condition, and these simple clirections are followed, a large per cent. will take root, and make plants of the best quality - as good as those sold by treetramps at $\$ 1$ each. They will be fit to plant out by the stake or trellis to which they are to be trained, in autumn or the following spring, as may be most conrenient. When cuttings or young vines are set out in the fall, the ground about them should be covered with strawy manure, or evergreen boughs, before severe weather arrives.

PROPAGATING VINES BY LAYERS.

In layering the vine, a cane of well ripened wood of the previous year's growth is chosen, containing eight or ten buds, more or less. Open a trench, as directed for cuttings, only commencing nenr the parent vine. Stretch the cane in the bottom of the trench, and fix it in place with weights or pegs. This is to be done in spring before the buds swell, and the trench is to remain open till the shoots have made a growth of four or fire inches. The young rood will take an upright direction, and the trench must be filled with care, covering the cane, and pressing the dirt down firmly. The shoots had better be tied to small stakes, from time to time, as they will often grow four or six feet high if not checked by pinching, which is recommeuded when they have attained a height of three or four feet. This will canse the shoot to "stock-up," and form a more valuable vine. Stronger plants will be obtained if every alter- 
nate bud is rubbed off at the time of layering. Fig. 47 repre-

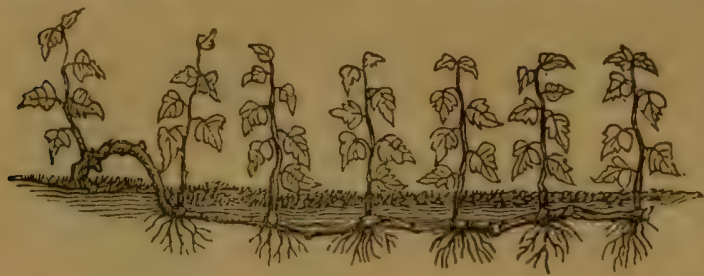

Fig. 47. sents the cane of a vine, layered as described, during the growing season, the soil being removed so as to show the root-formation. As layering seems to exhaust the parent vine, too many plants should not be attempted in one season. A layered cane may be lifted with the spade in autumn, and severed from the vine and between the buds, making as many plants as there were buds allowed to grow. Fig. 48 represents such

Fig.48. a plant after the leaves have fallen.

TRAANPLANTING THE GARßeE.

Vines may be safely set in the fall, at any time after shedding their leaves, - the earlier the better, - and in sprring as soon as the soil has become mellow and warm. If vines are received from a distance early in spring, while the ground is still cold and heavy, unpack them at once, and heel them in in some cool, shady place, and wait till the season mores on a little. Trees and plants must never be allowed to remain in the package a single day longer than is necessary, and never drench them with water while thus packed. Even if dry, it is better to trench them in, first loosening the bundle, and mixing damp soil well among the roots. Such trees or vines will be safe for weeks, if not received late, and be more Iikely to do well than when set out very early. It is always pleasant to have the birds for company when planting out small fruits.

The soil having been judiciously selected and put in good mechanical condition, vines of suitable age and size, not more than two years old, may he planted out quite rapidly. The roots of a vine, after having been set out for a few years, will be found almost entirely near the surface, unless they have been destroyed by too deep cultivation. Very few roots will be found more than five or six inches from the top. In case of a 
protracted irouth, there would be a tendency to strike down in pursuit of moisture, but usually nearly the whole system of roots will not be more than six inches deep. This is just where we want them. The vine needs the full force of the sun's heat to push on the anuual wood growth, and to ripen up the fruit in autumn.

Let the roots be cut back at transplanting to ten or twelve inches in length. The fibrous roots, about which we hear so much, are of but little or no account. Their vitality is destroyed on comparatively slight exposure. Take up a vine that has been planted a year, and the fibrous roots which it contained will hare all disappeared. They are short-lived,-annuals, like the leaves. They serve a purpose while undisturbed, but are of no value after exposure, and may as well be pruned off as to remain.

Let the canes be reduced to one, and cut that back to two or three buds. One bud is all that should be allowed to grow, but it is not safe to remove them till they hare made a growth of some inches, as they are extremely tender, and liable to be injured in various ways. Always retaiu the lowest shoot, provided it is strong and healthy.

The transplanting of trees and vines can be done by two persons, working together, much more conveniently than by one. The man with the spade removes the soil five or six inches deep, where the vine is to be planted, in a circle as large as the roots will occupy, while another prunes the roots and top, as above described. The vine is at once placed in position, with the roots radiating equally on all sides. The soil is to be at once thrown over them by the man of the spade, while the other makes all firm with his foot; and the thing is done in less time than would be required to read the directions here given. Take the vines to the field with the roots in a bucket of water, or in a basket packed in damp swamp moss. Only one need be exposed at a time, and that only for a moment. Two men who use no tobacco can set out one thousand vines in a day.

Vines may be tied up to a stake the first year, or allowed to sprawl. I prefer to tie up, becanse it is more convenient for pinching back laterals, and they are less in the way of the cultivator. Almost any hoed crop may be grown on the land for 
two or three years; but never attempt to grow two crops where you apply only plant-food for one. Some grow strawberries between the rows while the vines are making wood; but it is a practice of doubtful expecliency, as the strawberry plant is a gross feeder, and will soon exhaust the soil.

PRUNING AND TRAINING.

The aim of the propagator must be to get as strong growth as possible the first year. When the wood of the plant has become

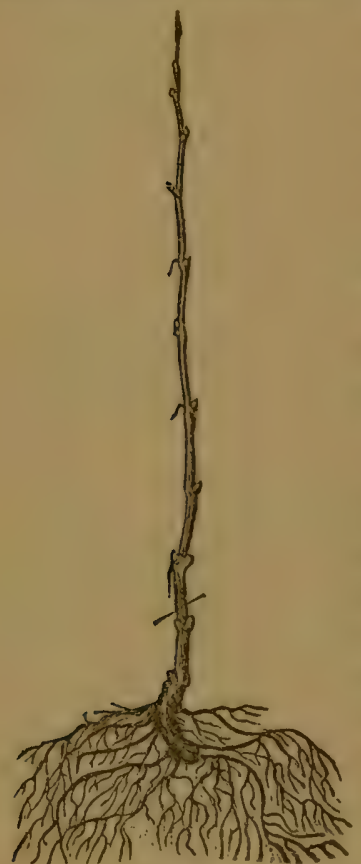

Fig. 49. mature, cut it back, leaving only two buds. Two buds are allowed to remain for safety, one of which is to be rubbed off when both start, leaving only one to grow the first year after transplanting. What is wanted is a strong root and cane at the outset; whatever system of training may subsequently be adopted. Fig. 49 will give a good idea of a well grown vine at the end of the first yeur after planting out. Repeat the cutting back till the preponderance of the root over the top is such as to give a siugle strong cane, such as the cut represents. When this is secured, whether the vine is one or five years from the bud-but not before-cut back to two buds at the time of pruning, and allow both to grow and form canes the next season.

There are numerous ways of pruning and training the vine, practised with apparently equal success by those engaged in grape culture, each following some peculiar notion of his own. To be convinced of the truth of this statement, one has only to look over the various works on this subject, published from time to time, and compare the illustrations and directions given as a guide to the novice. Many of the methods are ingenious, some simple, and others so complex as to mystify rather than enlighten or aid the amateur. 
They give us the spur method, the renewal method, and a score of others, - all well enough, perhaps, if the gardener has the ability to master them, and the time and skill requisite to carry them out in practice. It would be useless for me to describe more than two or three of the most simple methods, such as may be easily understood and adopted by any one of fair intelligence. It is presumed that the gentleman of wealth will employ an expert, and intrust the business wholly to him. I am not writing specially for that class, but rather for thousands of farmers and mechanics, orving small tracts of land, where they may grow a succession of fruits for the entire year.

To recapitulate, Fig. 48 represents a small vine, grown from a single bud, cutting, or layer, in the autumn of its first year, after the leaves have fallen. A plant grown from a layer would usually be stronger than is represented by this cut. This is of suitable size and age, however, for planting out. Cut back to one or two buds at time of transplanting in spring, and allow but one shoot to grow. Tie up to a stake from time to time, and, if laterals make much growth, check them by pinching off the tender ends occasionally. The vine should present the appearance at the close of the second season as represented in Fig. 49. Before growth commences the next spring (see best time to prune hereafter), this cane, as it is now called, is to be cut back to two buds, and a cane grown from each, tying up and pinching in laterals as before. The vine at the end of

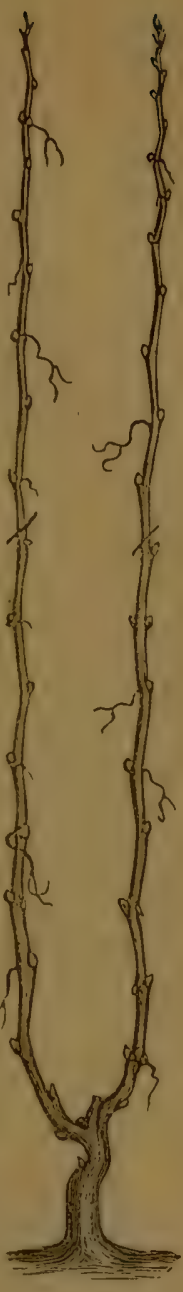

Fig. 50.

the third season is shown by Fig. 50 , divested of its foliage. T'wo marks of cancellation will be observed, showing where each cane is to be cut back at time of pruning. The length of the canes should be as nearly equal as possible, and three or four feet long, for reasons that will soon be obvious.

This vine is intended to be fixed to a permanent trellis at the 
commencement of its fourth year. It is of the utmost importance that the wood forming these canes should be mature, and the buds well developerl, and that they remain uninjured during the winter. In the spring the canes are to be bent in opposite directions, in line with the rows, and retained in the position represented in Fig. 51 till the buds have expanded and growth

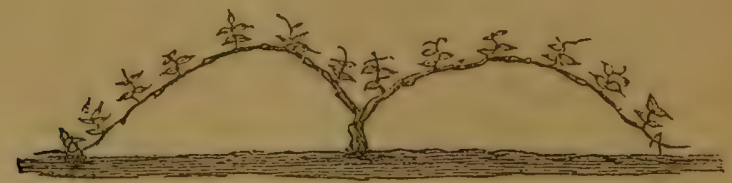

Fig. 51.

has fairly commencerl. The question will be asked, "What occasion is there for this treatment at this particular season?" The answer is, that the buds at the end of the cane will always push earlier and stronger than any others; in fact, those lower down on the cane will often remain perfectly dormant. Bending the vine will check the rush of sap to the top; this causes the buds to "break" uniformly. As soon as this object is assured, the canes are extended horizontally, as in Fig. 52, and tied to the lowest wire or slat of the trellis.

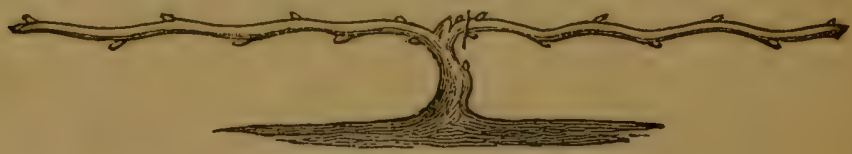

Fig. 52.

It will be found that the different varieties vary much in their manner of growth, in this, that the internodes are much greater in some kincls than in others. The wood is spoken of as short- or long-jointed, as the case may be. For example, the Hartford Prolific will have two buds where the Diana has but one. A knowledge of the habit of each variety in this particular is important, as every other bud on the horizontal arms of short-jointed canes had better be rubbed off, choosing those on the under side (see Fig. 53, $a, a, a, a, a, a$, ) to prevent too 


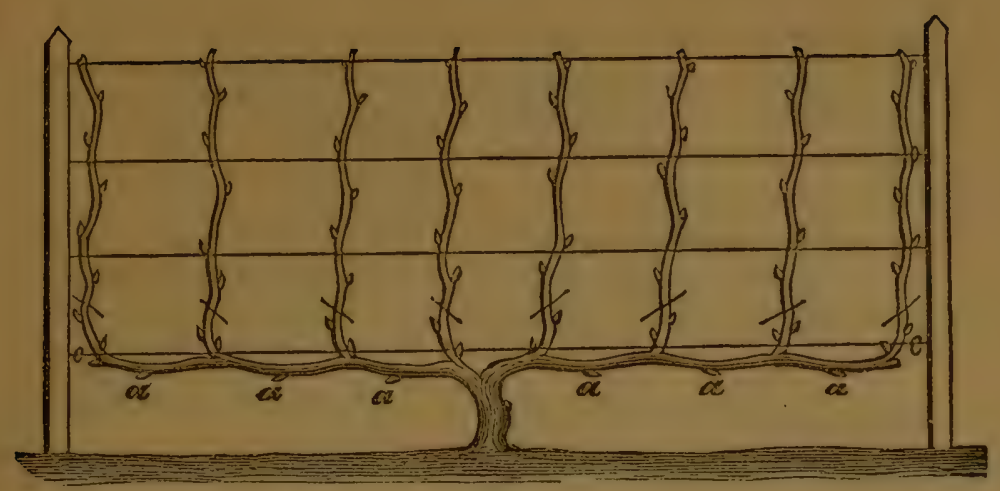

Fig. 53.

much crowding on the trellis. In Fig. $53 \mathrm{I}$ bave endeavored to represent in a single illustration what might have been better shown in three or four.

It will be understood without saying, that each cane is to be trained up, and tied as each wire is reached. It matters not what material is used for tying, whether bass-wood bark, as found in furniture mats, cotton twine, or the ravellings of an old stocking. None of these will affect unfavorably the size or flavor of the fruit. If any of the shoots grow more freely than others, pinch them back, so that all may reach the top of the trellis at nearly the same time. The marks of cancellation show where these upright canes are to be cut at the fall pruning, leaving but two buds on each spur. Another year will give us two upright canes where now there is but one; and, as each cane will set its two or three bunches, the crop of fruit, if not removed, will be doubled. The subsequent treatment of this vine will be quite simple. Cut back at each annual pruning to two healthy buds, which will give two fruit-bearing canes to each spur, cutting arvay the upper spur entirely; and this may be repeated indefinitely.

In practice it will occur that small buds will push near the horizontal arms, or the buds intended to grow will appear to be double, and two shoots will appear where but one is wanted. Let all such superfluous shoots be removed at once, and all lateral branches kept short by frequent pinching. 
Grapes are always borne on the new wood, and each upright cane of a vine of the age and condition here represented will be likely to set tro or three bunches of fruit. Not more than two bunches are allowable, unless the vine is unusually strong and vigorous, for a first crop. The danger is that too much fruit will set, and the temptation is strong to allow all to mature. When the matter of thinning is reached, this subject will be more fully discussed.

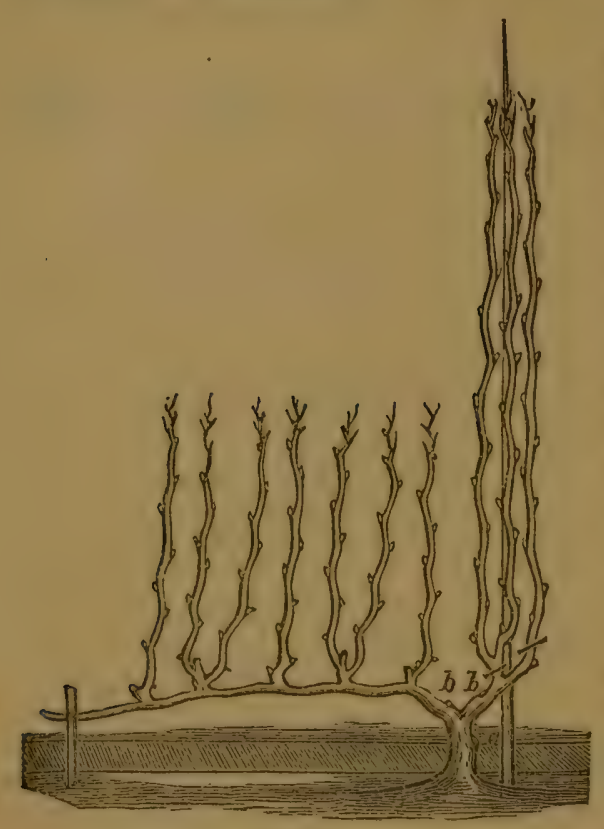

Vines trained in the way here described are to be planted out in rows, from eight to twelve feet apart, and the horizontal arms cut of such a length that those of different vines will just meet, and cover the trellis. But viues may be set as near as six feet even, and by a slight variation in the method of training give good crops. Take the vine, as represented in Fig. 50 , and instead of cutting back both canes to four or five feet, shorten one only, and cut the other back to two or three buds. Train the shoots from these buds to a stalie planted near the root, and the long arm horizontally, as in the first method. Fig. 54 will show this method without further description. V'ines thus trained may be set five or six feet apart, and this distance may do for those that inake but a feeble growth; but strong-growing varieties, such as the Concord and its seedlings, will require ten or twelve feet cach way.

A method of training having some advantages is represented in Fig. 55. A part of the canes may be tied up to a stake set 


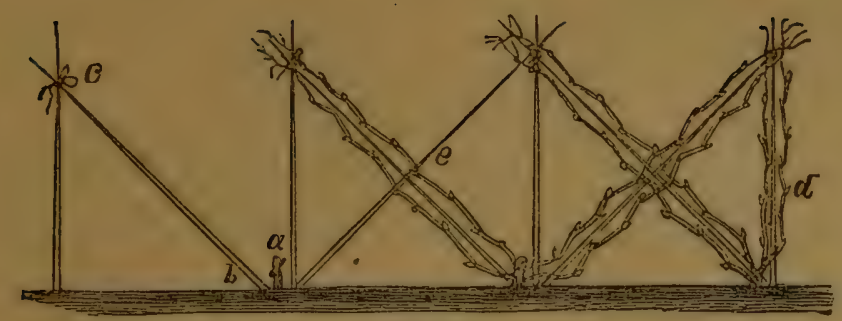

Fig. 55.

near the root $(a)$, and others trained to a pole resting one end on the ground $(b)$, and the other made fast by a slip-knot $(c)$ to the top of the next stake. This gives the fruit and foliage the full benefit of the sun and air, thereby aroiding rot and mildew, and insuring early maturity. By simply slipping the knot, the canes trained at an angle may be dropped down, and covered during winter, and taken up and placed in position again in the spring. Tender varieties require this protection, and experience has shown that the fruit of the more hardy sorts will ripen a week or ten days earlier when the vines have been thus protected. Instead of training two of the canes to upright stakes, as at $d$, poles may be placed so as to form an $\mathrm{X}$ between the stakes, as at $e$ in the cut, in which case all the canes may be dropped to the ground, and protected.

I trust that no one will conclude, from the descriptions here given, that any one of these methods of training the vine is absolutely indispensable in order to grow grapes for home use, or even for the market. Better, a thousand times, to discard them all, and plant your vines, simply tying them up to the roughest stakes you can find, and neglect pruning entirely, rather than oblige your boys to scour the hills and swamps for wild grapes that are unfit to eat after they have been stolen. There are many tons of grapes grown in the South and West every year, both for the table and for wine, where the rines are trained to stakes in the simplest manner, and some of the largest growers in New Eingland practice the same method. Just plant two stakes on opposite sides of each vine, eighteen inches from the root, and train one cane around ench stake spirally, pinching the end of the vine when the top of each stake is reached, and pinching the laterals occasionally. Vines thus trained may 
be set six feet apart. Cut back the laterals to tro buds in autumn, for bearing wood the next season.

TRELLISES AND STAKES.

Trellises may be constructed with posts and slats, or wire stretched from one post to another, and made fast by staples. Numbers 12 to 15 galvanized or annealed wire will be found of suitable size, and the staples may be readily made of the same. Cedar posts, set eight feet apart, five inches in diameter, are durable, and cheapest in the end. Stretch the bottom wire twenty inches from the ground, and three others about thirteen inches apart, making the trellis five feet high. Such a trellis will require no renewal or repairs for many years. Wooden slats soon become tender, and are almost a constant source of annoyance. Stakes are also of cedar, and may be somewhat smaller, and should be, when set, at least six feet high.

BEST TIME FOR PRUNING THE VINE.

The annual pruning may be done at any time from the fall of the leaf till early spring. Pruning vines or trees when frozen is not thought to be a good practice, and hence the autumu and pleasant days in winter are to be preferred. If the wood removed is to be used for propagating, let the pruning be done and the cuttings planted out in the fall, as before described. Winter pruning will be very inconvenient, if not impossible, where the rines are dropped on the ground, and covered with evergreens or snow, as is strongly recommended where practicable.

I am fully aware that some successful vine-growers say, "Prune at any time," and claim that bleeding, which is sure to follow spring pruning, is not injurious. It is quite certain, however, that bleeding can do the vine no good, and equally certain that wounds made when the wood is frozen do not readily heal. Because the sugar-maple is not seriously injured by the escape of sap from a small hole made with a bit, it does not follow that the same tree would not be injured by cutting away numerous large branches at the same season. This is precisely the treatment that is given the vine when the grower cuts back to one or two buds annually. 
There is but a short time in spring, just before the buds unfold, when a vine will bleed. There is little or no movement of the sap in winter, nor when the ground is frozen; aud, as soon as growth commences, the sap is absorbed and evaporated through the leaf in large quantities. Why, then, choose the spring, the worst time in the whole year, for pruning? There is no objection, however, to pruning at transplanting, as the roots having been cut or broken in ligging, there is not a sufficient flow of sap to result in bleeding. Severe pruning cluring the growing season will give the vine a shock from which it will take a long time to recover, but the pinching in of laterals and the ends of canes, to check a too rampant growth, is always in order.

\section{MANURE FOR THE VINE.}

Some extensive grape-growers have contended in the past that vines require little or no manure; that land in good condition for any of the hoed crops is quite rich enough to insure the best results. 'They outgrow this notion after a few years' experience. The removal of a large growth of wood at the an. nual pruning, with a crop of fruit in addition, will exhaust the fertility of the soil as rapidly as most other crops. While this is true, caution should be exercised in the use of unfermented nitrogenous manures. The tendency of all such applicatious would be to cause an excessive and late growth of wood, entirely unfit to endure the extreme temperature of our winters. Fine old compost, say half muck, is much to be preferred. Rather coarse ground bone, mixed with wood ashes or commercial potash, will give good results on most soils. Such a mixture contains very little nitrogen, while the percentage of phosphoric acid, potash, and lime is large. It seems to meet the wants of the vine perfectly. An application, once in tro or three years, of three hundred pounds of bone, one hundred pounds of potash, or fifty bushels of wood ashes to the acre, will be suflicient to maintain the vines in a thriving, healthy growth, and, other conditions being farorable, insure an annual yield of the best fruit. The boue and ashes should be mixed and moistened some weeks before using. This may be done on the stable floor, where it can remain till the odor arising from the mass iudicates 
the presence of heat, when it should be shovelled over, and, if too dry, more water applied. This may be done two or three times, at intervals of a few days, using caution in applying water, as, if the mixture once becomes pasty, it cannot he properly or conveniently applied. Gypsum, or dry soil, will effectually check and preserve the ammonia that will otherwise be lost during the process of fermentation.

The application of clas, or well seasoned muck, will be useful on very light, sandy land, by absorbing and retaining moisture in a dry seasou. The grape, however, seldom suffers from drouth. Southern California is reported to have but two inches of rain annually, and there the grape is perfectly at home. The preference of our American grapes for rather dry situations is well known and recognized by all successful vineyardists.

Cultivation OF THE GRAPE.

After what has been said relative to the growth of roots near the surface, it would seem unnecessary to cantion the grapegrower against deep tillage in the vineyard after the vines have become established. The surface soil being filled with a perfect network of roots, it follows that the cultiration must be of the most shallow kind. The vineyard is no place for the plow or the spade, and the common cultivator, even, may do a vast amount of mischief in unskilful hands. A light barrow with numerous small teeth, set sloping backwards, may be used without detriment; but the best implement I have ever seen for this purpose is a cultivator from which all the tecth have been removed, run simply with the wheel and a broad knife attached, from which not a weed can escape. The depth of cultivation may be regnlated with perfect ease. There should be no piling of the soil, or throwing it into furrows, but let it be simply raised, loosened, and left as mellow as possible. The harrow may be run through the vineyard every week, or as often as small weeds appear, or the surface becomes crusted, till August, when all cultivation should cease. Late mauring or late tillage causes late growth of immature wood, which is always to be avoided. The harrow, scarifier, slide hoe, and the steel rake are the only implements required to keep the soil of the vine- 
yard in perfect condition. The best time to kill weeds is the day they are born.

\section{AMOUNT OF FRUIT.}

"How much fruit can a vine safely be permitted to carry?" This is a question often put by the novice, and suggests a matter of vital importance. The answer depends on a variety of circumstances. Be careful never to ask too much of your vines, especially when young. An overcrop is sure to be followed by no crop at all, as in the case of the apple, pear, and other fruits. The most successful growers never allow their vines to ripen more than a few bunches (say four to six) before they are four years old, the number depending upon the vigorous character and strength of each vine. As the vine attains age, the quantity may be gradually increased, till six or eight pounds are reached, and this crop may be repeated every year. Some allow their-vines to retain trielve or fifteen pounds, or even more, without serious injury ; but, as a rule, excessive cropping will work ruin in the end.

Thinning the fruit cannot be done too early. The best time is as soon as the berries have formed. Remove all small clusters, and with small pointerl scissors take out all inferior berries from the bumches that are to remain. Some varieties set their berries too closely on the bunch, and may be improved by thinning, both in size and quality. Fruit thus carefully grown will give much greater satisfaction to the consumer, and command a ready sale at a high price in the market. The effect of premature, excessive bearing is often to destroy or greatly to impair the vigor, health, and productiveness of whole vineyards. It should also be borne in mind that reducing the crop by thinning insures early maturity.

It may be suggested that the number of pounds to a rine above named, will gire but a light crop to the acre; but vines planted six by eight feet will give more than nine hundred plants to an acre, and more than three tons of fruit. This would give a profitable return if failures were not too frequent. From two to four tons to an acre is regarded as a fair crop of grapes, while ten tons, it is said, have been grown. But the grower must bear in mind that the larger the crop a vine is allowed to 
bear, the poorer the quality is likely to be, and the later it will be in maturing. Hence the more unfavorable the locality or the season, the greater the necessity for thinning the fruit.

\section{WHAT VARIETIES SHAIL, WE PLANT?}

The list of profitable market grapes that can be grown in a northeru latitude is very short. We can only select varieties ripening about the same time, as the earliest will be none too early to escape our autumn frosts. Till the Worden, Moore's Early, and other new varieties have been more extensively grown, so as to lower the price of vines within our reach, the list must begin and end with the Concord. I know of but few instances in New England where any other grape is being extensively grown for market. If the expectations of those engaged in bringing out new seedlings are realized, we shall not long be limited to two or three varieties. When we recall the fact that in other sections of the country, where the brevity of the season is no obstacle, there are very few profitable market grapes grown, we shall be more content with our lot and locality.

For the table, we may extend the list almost indefinitely. New candiclates for favor are presented every year, and the disposition to give them a fair trial should be encouraged. It is not diflieult to name a dozen sorts of good quality, any one of which we may ripen, where it would have been impossible to name one fourth that number a few years ago. The demand has insured a supply, and still they come. We may name as varieties, some of which are well established in pubiic favor, and others worthy of trial, the following: Concord, Hartford Prolific, Delaware, Worden, Moore's Early, Isabella, Martha, Lady, Wilder. Brighton, Prentiss, Pocklington, Dutchess, and Agawam. Here we have a baker's dozen, and the list might easily be extended. It is by no means certain that it might not be greatly improved.

As all are not acquainted with the older varieties, and know little or nothing of the new, a brief description may be found convenient for reference. Interested parties will pardon me if I abbreviate somewhat descriptions found in their catalognes, use less expressive adjectives, and occasionally hint at the faults of their pets. 


\section{1}

Admondac. Bunch medium; berry black, round, large; skin thin; flesh tender, scarcely any pulp; sweet, but not rich. It seldom succeeds.

AGawam (Rogers' No. 15). Bunch medium, somewhat loose, shouldered; berry large, roundish oval; skin thick, brownish red; flesh tender, juicy, free from pulp; flavor rich and pleasant, having a peculiar aroma; vine very vigorous and hardy ; a hybrid between a native and a foreign species; ripens with Concord; a little subject to mildew; does not bear close pruning. Origin, Salem, Mass.

Allen's Hrbrid. Bunch medium, compact; berries medium, round; skin thin, pale, amber; fiesh tender, without pulp, excellent; early ; not hardy ; requires protection. Origin, Salem, Mass.

Barry (Rogres' No. 43). Bunch rather short, broad, compact, shouldered; berries black, rounctish, oval, large; flesh delicate, sweet, tender; skin thin; early as Concord; one of the best black grapes; vine vigorous, hardy, and productive. Origin, Salem, MIass.

Brignton. Bunch large, shouldered; berry large, Catarbacolored, but little pulp; flavor fine, rich; vine vigorous, hardy, and productive; a week earlier than Concord; a cross between Concord and Diana Hamburgh. Origin, Brighton, N. Y.

Concord. Bunch large, compact, shouldered; berries black, round; skin thin, tender; flesh juicy, sweet; pulp tender when fully ripe; vine very hardy and vigorous; leaves thick and enduring; very productive; ripens from 10 th to 20 th of September; the most popular and profitable grape grown. Origin, Concord, Mass.

Crevintrag. Bunch loose, straggling, shouldered; berries medium, black, sweet, and juicy, good; vine hardy and healthy, and good grower; ripens with Concord. It is not very valuable or reliable; fertilizes imperfectly.

Delaware. Bunch small, compact, often shouldered; belries small, round; color red; skin thin; flesh tender and juicy; scarcely any pulp ; sweet, with a brisk, viuous flavor ; vine hardy, 
slender grower when young; requires good soil and cultivation; moderately productive; ripens in September; a standard in quality. Origin, New Jersey.

Ducriess. Bunch medium to large, shouldered, compact; berries medium, round, greenish white; skin thin; flesh tender without pulp; quality good; rots and mildews in some localities; ripens with Delaware. Origin, New York.

Exprese State. Bunch medium, long, narrow shouldered, compact; berries round, green, sweet, juicy, and nearly free from pulp. It has a distinct Frontignan flavor, and is free from any foxy quality. Vrine said to be hardy, healthy, productive, and a vigorous grower; early; a cross between Hartford and Clinton. Origin, New York.

Haitrond Prodrfic. Bunch medium, compact, shouldered; berries black, unedium, roundish oval; skin rather thick; flesh sweet, juicy; pulp somewhat fory ; vine vigorous, short-jointed, and productive; berries of ten drop if not thinued ; ripens early in September. Origin, Hartford, Conn.

Hayes. Bunch medium to large; berries medium, round, greenish white, changing to amber yellow when fully ripe; skin firm; flesh tender, juicy, of fine flavor, and free from foxiness; vine moderately vigorous, hardy, and productive ; a week earlier than Concord, of which it is a seedling. Origin, Massachusetts.

Isiratela. Bunch medium, shonldered; berries black and slightly oval; skin thin; flesh tender, sweet, nearly free from foxiness; vine a good grower, hardy, healthy, and productive. Season, September 1. It fails in many localities. Origin, New York.

Jefrersox. Bunch large, compact, shouldered; berries large, roundish, oval ; light red, with lilac bloom ; flesh meaty, tender, juicy, sweet, and spicy ; vine vigorous, hardy, and productive; wood short jointed ; a little later than Concord ; a cross of Concord with Iona. Origin, New York.

Lady Washington. Bunch large, compact, shouldered ; berry medium, round, deep yellow; white bloom; flesh soft, tender, juicy, sweet, and good; vine vigorous, hardy, productive; 
leaves large lobed; ripens later than the Concord. Origin, New York.

Lady. Bunch medium to large; berries round, large; color white; quality good; hardy and healthy; skin tender; vine a moderate grower at first, but becomes as strong a grower with age as the Concord, of which it is a seedling; ripens two weeks before the Concord. Origin, Ohio.

Martia. Bunch short, compact; berries white, large, round, sweet, juicy, a little foxy and pulpy; quality good; vine a strong grower, healthy, hardy. A seedling of the Concord, and two weeks earlier. Origin, Pennsylvania.

Merrinack (Rogers' No. 19). Bunch short; berries round, large; skin black; flavor sweet and rich; quality good; vine very vigorous; a good bearer. Season, medium. Origin, Salem, Mass.

MInore's EArLx. Bunch and berry large; black, with hervy bloom; quality better than Concord; vine healthy, hardy, vigorous, and productive. A seedling of the Concord, and nearly two weeks earlier. Popular and profitable. Origin, Concord, Mass.

Niagara. Bunch large and compact; berries large, round, light greenish-white; skin thin and tough; quality good; little pulp, melting and sweet; vine a strong grower, hardy and productive; ripens early, with Hartford Prolific. Origin, New York.

Pocklington. Large and showy; skin white, thin, but tenacious; a little foxy, but as good or better than the Concord; keeps a long time. Not as early as the Concord, of which it is a seedling. Healthy and productive; a fair grower. A promising new variety in some localities. Origin, New York.

Prentrss. Bunch large, not often shouldered, compact; berry medium, tencler, sweet, melting, juicy, with pleasant aroma; free from foxiness; little pulp; seeds few and small; vine hardy and a good grower; very productive; foliage not always healthy; color yellowish green; a good keeper; ripens about with the Concord. Origin, New York, from seed of Isabella. 
Salem (Rogers' No. 22 or 53). Bunch rather large, broad; berry inclined to oval; skin thin, black; flesh tender, sweet, and delicate; vine vigorous and productive. As early as the Concord. Origin, Salem, Mass.

Vergennis. Bunch medium to large; berries large, round, light amber; flesh meaty, tender, rich; vine vigorous, hardy, productive; a good keeper. Early as the Hartford Prolific. Origin, Vermont.

White Ann Arbor. Bunch and berry very large, white; quality good; vine hardy and productive; ripens earlier than the Concord, of which it is a seedling. Sometimes drops from the stem. Origin, Michigan.

Wilder (Rogkrs' No. 4). Bunch large and showy, resembling Black Hamburgh ; berries large, round ; color black ; flesh tender, with a slight pulp ; very good; vine hardy and productive. Later than Concord. Origin, Salem, Mass.

Wonden. Bunch large and compact; berries black, larger than Concord, and of better quality; less pulp; ferw and small seeds; vine hardy, healthy, vigorous, and productive; a seedling of the Concord, and a week or ten days earlier. Becoming very popular. Origin, New York.

I have here given a description of trenty-five varieties of the grape, embracing most of the kinds claimed to be hardy, and early enough for a Northern latitude. Some that might well be included may have been inadrertently omitted, while others may have been named not entitled to consideration. I have had under cultivation at different times more than fifty varieties, foreign and native, highly recommended, but most of them proving of no value. The vines and foliage of some varieties, otherwise desirable, prove tender; the fruit of others is spoiled by rot and mildew; and still others require too long a season to mature. It may be well to name the faults aud virtues of some kinds here omitted.

Champron (Talian, Beaconsfield). The same grape sailing under different names. The Champion is quite early, and for this alone is it to be commended. The average tree agent will urge you to purchase one of each kind. Profitable for market, but unfit to eat. Iron clad. Origin, New York. 
Dians. Too late; vine tender; ripens, if at all, very unevenly, and often has a musky flavor, and odor exceedingly offensive; sometimes excellent. Origin, near Boston.

Iona. A very showy grape, of the best quality where it will ripen; too late for New England, except in very favorable localities. Origin, New York.

Blood's Purple. Early, sweet, but a shy bearer, and does not set its fruit well on the bunch. Origin, Massachusetts.

ISABELLA. A good grape when ripe, but requires a favorable locality and long season; tender. Origin, South Carolina.

Catawba. Has been a famous grape; too late for the East; rots badly. Origin, District of Columbia.

Rebecca. Vine a feeble grower, and tender; leaves mildew; fruit very good.

The Man Gkape. The Concord under another name. Price as the "Main," three dollars; as the Concord, twenty-five cents.

Cotrage. Early; succeeds well in some localities, and fails in others; inclined to drop from the stem. A seedling of the Concord.

Essex (Rogers' No. 41). Excellent quality, poor bunch; otherwise almost identical with Barry, Wilder, and Herbert.

Herbert (Rogers' No. 44). Recommended for trial. Large, black, very good.

Monroe. " "Early and delicious," says Mr. Wilder.

Eumelan. One of the best in quality, but does not always succeed. A poor grower, and sets its fruit poorly owing to imperfect blossoms.

Hiland. One of Rickett's seedlings, not fully tested; later than Concord.

Lindly (Rogers' No. 9). One of the best of Mr. Rogers' hybrids-" the best of the reds." "I denominate it the Muscat of America. It is a most valuable grape every way." So says Col. Wilder.

Massasott (Rogers' No. 3). Seems to succeed with all who have tested it. The earliest of Rogers' hybrids. 
Early Daws. A new grape recommended by reliable parties, who have tested it in Massachusetts and Connecticut.

EARLY Victor. Good in Massachusetts, and promising in other states.

\section{FOREIGN GRAPES UNDER GLASS.}

The number interested in foreign grapes is small ; still there are occasional inquiries by those about to erect glass structures. I have hat no experience with such as require a long season and artificial heat, only having grown about twenty varieties in a common cold grapery. The Black Hamburgh is the standard foreign grape, and its progeny is about as numerous as that of the Concord. Among these the Gros Blue, Victoria Hamburgh, and Wilmot's Black Hamburgh, have given good satisfaction. The Golden Hamburgh is a shy bearer, and not recommended. The Sweetwaters, both the Buckland and the White, have failed to set their fruit evenly, and hence have given very imperfect bunches. The Lady Downes and White Nice require fire heat to bring them to perfection. White and Grizzly Frontignan both succeed well, and the same is true of Bidwell's Seedling and Bowker. Directions for preparing borders, the erection of cold graperies, and for the training and management of vines under glass, are here omitted for obvious reasons.

\section{DISEASES-ROT AND MILDEW.}

The rot and mildew are the worst enemies in the form of disease with which the grape-grower has to contend; and yet, like diseases in animal life, they are to a certain extent under his control. I have only been troubled by milderr. It often destroys both the folinge and fruit, as the fruit cannot mature in the absence of healthy foliage.

I have not been careful to keep the date of its appearance, and doubt whether it is governed by any time-table. Dr. Fisher, of Massachusetts, says, - "It usually appears about July 10 , after a wet June. A wet June followed by a dry July causes mildew, while a dry June followed by a wet July gives us freedom from this disease." Dry, powdered sulphur, though not a specific for mildew in the open air, is perhaps the best remedy at present known. Half an ounce volatilized on a warm sur- 
face in a grapery checks the mildew without fail. Sulphur scattered on the ground on the sunny side of a grape trellis will sometimes ward off mildew, or retard its progress.

If rot and mildew are of fungus origin, as is generally admitted, it is easy to understand why they become more prevalent and fatal under certain climatic and other conditions. Of course no one can control the elements, and we can only escape the consequences of adverse conditions of the season by planting out such varieties as are usually exempt from mildew, and by the selection of a soil and location best adapted to a healthy growth of the vine. We want a warm, well-drained soil, with a "south side" exposure, and so far elevated as to admit of a free circulation of air ; and in this way we may escape the fogs and frosts that are peculiar to and prevalent in the valleys.

Mr. William Saunders, a very intelligent horticulturist, says the best grape climates are those where there are least dews, and wherever we find specially favored localities we will find this partial or total exemption from heavy dews. This has long ago been demonstrated, and new grapes emanating from favored regions will fail to give entire satisfaction when grown in localities less favorably situated, and thus lead to disappointment. This is the reason for so many seemingly conflicting opinions regarding the merits of varieties, and it is unfortunate that these considerations are not better understood and recognized. When a young grape-vine loses its foliage by midsummer, and the green shoots remain unmatured till frost, that variety might as well be discarded at once. No known methods of pruning, fertilizing, or care in cultivation will help it. The only known remedy is shelter, arranged so as to arrest radiation of heat from the folinge during nights.

The next most important matter will be to supply plant-food of a kind and in such quantity only as will produce a moderate, healthy, annual growth. This subject has been sufficiently discussed on another page.

Frequent and rather close pruning of laterals will cause a more full and healthy development of foliage on the lending canes, and such foliage will be usually able to withstand the attacks of disease. Dry, hot days, succeeded by cool, foggy nights, are trying to all varieties having delicate leaves. A vine 
badly located, badly pruned, and improperly fertilized, whether starved or overfed, will be in a condition to invite rather than ward off disease and mildew.

The microscopist has discovered that mildew, rust, and other fungi are vegetable growths, propagated by spores, and the practical observer has learned that these will only germinate at a certain temperature, and under other favorable conditions. The wild, thick-leaved, native vine is usually exempt from mildew, while the delicate folinge of the foreign species, and many of the hybrids, and some others that have been "bred too fine," cannot, owing to their susceptibility, be grown successfully except under glass.

Now there is no donbt that at certain seasons the air is filled with the spores of fungoid growths, unobserved because so minute. The common "puff-ball," which is a species of fungus, when compressed fills the air with its spores as with smoke, and if each one should find a favorable lodgment, would seed a whole township. These and other spores are not likely to adhere to dry, smooth surfaces, but are caught up by leaves moistened by rain, fog, or dew. It has been found that vines, the folinge of which is kept dry by a coping, are almost entirely exempt from mildew and rot. This protection may be given, without great expense, by boards or cloth fastened to the tops of the trellis posts.

The rotting of the grape has within a few years, in some seasons and localities, nearly ruined the crop. We know little of the cause, and less of the cure. It is believed by most growers of the grape to be of fungus origin. One vineyardist, who has suffered severely' by this disease, says he has found out the cause, and that " it is all cussedness, every bit of it." He does not claim to have found any remedy.

"Bagging the grape" has proved to be a preventive wherever practised. This is simply enclosing the clusters in rather thin paper bags when the berries are about the size of pease. Perforated bags have been invented for this purpose, but the common two-pound bag used by grocers answers every purpose. The end of the bag may be folded around the stem of the cluster, or brought up over the cane and fastened with a pin. The fruit thus protected is secure from attacks of birds and insects, 
and also from mildew and the rot. But the practice in large vineyards would require an almost endless amount of labor, and is not likely to be generally adopted.

\section{INSECTS}

There are but few insects that give us much trouble. That scourge of the Freneh vineyardist, the phyllosera ( $P$. vastatrix), bas not yet favored us with a call. It may be advisable for congress to pass an act suspending its immigration for twenty years.

Prof. Riley says,__"The insect presents itself under several different forms, all of which belong to two types. One of these is the Leaf-gall type (gallicola, $R$.), and the other is found upon the roots of the vine (radicola, $R$.).

The first form of the insect produces a gall or excrescence on the under side of the leaf of the size of an ordinary pea. On carefully opening one of them, we shall find the mother louse diligently at work surrounding herself with pale yellow eggs of an elongated oval form, scarcely .01-inch long, and not quite half as thick. She is about .04-inch long, generally spherical in shape, of a dull orange color, and looks not unlike an immature seed of the common purslane. The eggs begin to batch when six or eight days old. The number of eggs in a single gall averages about two bundred, and every egg brings forth a fertile female. Laying and hatching continue during the summer, until the fifth or sixth generation. The insects and galls multiply to such an extent that the leaves become completely covered. The autumnal insects, gallicola, descend to the roots, and there hibernate.

"As to the phylloxera (Radicola) that destroys the roots of the vine, little need be said, as it is now admitted to be identical with the type already described. Galls may be produced upon the leaves by the same insects that work such mischief to the roots. The puncture of the roots produces enlargement, that usually commences at the tip of the rootlets, resulting in decay, as the supply of sap to the plant and the entire root system eventually wastes away, and the vine dies. There are but slight indications of the presence of the insect the first year of the attack, and not until the second year are the outward mani- 
festations of the disease observed. At this stage the leaves assume a yellowish, sickly appearance, and the canes make but little growth. The vine usually dies the third year, when circumstances are favorable for the multiplication of the insect. The lice desert the plants before they are dead, and of course are not found on examination of the roots.

"The phylloxera spreads from one county and from one section of the sarne county to another, by the sale and transmission of vines from infected districts, and great care should be taken in the purchase of vineyard stock on this account. At particular stages of their development the winged insects are able to fly to considerable distances, and undoubtedly spread in this way from vine to vine and from vineyard to vineyard, but proper precautions will do much to retard their progress.

"As in case of mildew and rot, some varieties are peculiarly susceptible to the attacks. The slow-growing and tender varieties are more likely to suffer than those that are hardy and vigorous. The Southern Fox-grape (Vitis vulpina) is said to be entirely free from attacks in any form, and many of our Northern varieties are but little affected. For this reason thousands of vines and cuttings have been exported, to be used as stocks on which to graft foreign kinds that are more susceptible. Roots of our native vines otherwise worthless become valuable for the purpose bere indicated.

"There has yet been discovered but one remedy for this insect-drowning out by irrigation."

The steel-blue beetle (Haltica chalybea) causes some damage by eating the buds just as they are stwelling, making a hole in the bud so that it does not develop. The iusect lays an egg on each leaf, and that produces a slug which feeds upon the foliage. Examine your vines when the buds are swelling, and warn them off. They are not very numerous, and can be quickly seen and destroyed.

Then we have the leaf-roller, a few of which turn up every year. They roll themselves up in the small, tender leaves at the end of the growing shoots. Pinch off the end of the shoots containing the small caterpillar, about half an inch long, and rub it beneath your foot.

The rose-chifer, or rose-bug (Melolontha sub-spinosa), has 
been seen in some parts of New Hampshire in small numbers, and occasionally may be seen on the grape-vine when in flower. Their visits are often quite sudden and informal. Harris, in his work entitled " Insects Injurious to Vegetation," says " they are common in the vicinity of Boston," and hence we may regard them as emphatically Boston bugs. The writer also says, "It is, or was a few years agro, unknown in the northern and western part of Massachusetts, in New Hampshire, and in Maine." Dr. Harris does not claim to be the author of this interesting little insect, simply its biographer and natural historian. It moves out into the country in June, to avoid the bay fever, undonbtedly, and, like other summer boarders, takes a great interest in sinall fruits. Dr. Harris says the Melolontha lives forty days, but its habits of fasting are not in the least like those of Dr. Tanner.

I am confident that those writers who tell us that the rosechafer attacks the flower-buds just before they expand are mistaken. I have never seen them on the vine except when in full flower. They are undoubtedly attracted by the delicate odor of the blossom. This insect does not trouble flowers that are destitute of fragrance. The fragrant varieties of the rose may be alive with them, while the Prairies by their side will be unmolested. The beetle abandons the grape as soon as out of flower. I think a smudge, or neighborhood slander, well circulated and supported in a vineyard during the flowering season, would overcome the odor of the vine and repel attacks.

My practice has been to jar the insect into a shallow basin having a small quantity of kerosene at the bottom. This must be done early in the morning, or when the weather is very cool. At such times they drop at the slightest touch, but in the middle of a sunny day they are both lively and shy.

\section{GRAFTING THE VINE.}

The vine comes so soon into bearing from cuttings or layers, and young vines are so cheap, that grafting on to large roots of inferior varieties is little practised. Still we may gain a point by grafting the feeble-growing linds on to the roots of hardy, strong-growing, native vines. 'The extra root power of the stock will insure a more rapid and healthy growth than can be 
otherwise obtainer. Grafts will often make from ten to twenty feet of wood the first season, and are quite likely to bear the next year.

Practical vineyardists disagree as to the best time for grafting the vine, but all agree that cleft-grafting below the surface of the ground is the most successful method. Husmann, of Missouri, grafts about the middle of March ; others prefer May, after the leaves have expanded. Fuller performs the operation in the fall, covering the graft with an inverted flower-pot, and then with litter, to prevent freezing. He claims that the scion and stock will form a junction during winter, and will start sooner in spring. I have had no experience in grafting the vine.

RINGING THE VINE.

This process cousists merely in removing a ring of bark from a cane early in June, when it parts readily from the wood, below one or more branches of fruit. The effect is to check the return of sap from the leaves, and cause an enlargement of the caue and fruit above the ring, and hasten maturity. The clusters will be so changed in size and season as hardly to be recognized, unless the cause should be suspected. Fruit thus produced is always ruled out on the exhibition table, and ringing is seldom practised, except as a matter of curiosity. It seems now to be admitted, though formerly denied, that the quality of the fruit is equal to that grown in the ordinary way. A similar effect may be produced by winding the cane below the cluster tightly with a wire or strong cord, or even bending the vine back on itself, making the bow as short as we may without breaking. The effect of ringing is said to continue for several years, causing no injury to the vine.

\section{GRAPE-VINES FROM SEED.}

There is no skill requirer in groming vines from seed, but whoever embarks in this business will find it a lottery, where the prizes are extremely rare. As in case of other fruits, not one seedling in a thousand will prove superior to its parent; but prizes have occasionally been drawn, and it may pay for any one taking an interest in grapes to invest a little time in this scheme.

The question will arise as to the best method to pursue in 
growing seedlings. Of course no sane person would think of sowing the seeds of our wild frost and fox grapes, when we have varieties greatly superior from which seeds may he obtained. The Concord has produced more good seedlings, probably, than any other hardy variety known. It counts among its descendants the Cottage, Worden's Seedling, Lady, Moore's Early, Martha, Pocklington, Hayes, and White Ann Arbor. Other new varieties of good repute are the result of crossing or hybridlizing with the Concord, namely,-Brighton with Diana Hamburgh ; Hiland with Jura Muscat ; Irving with White Frontignan; Triumph with a foreign variety; Jefferson with Iona; and the Duchess, a cross of a white seedling of the Concord, with the Walter; Monroe, a cross of Concord and Delaware. Here we have a family of children of which any father or mother might well be proud. Why not erect a monument at Concord, Mass., the place of its origin, to the Concord grape, and E. W. Bull, who introduced it?

Dr. Fisher, of Fitchburg, in an address on Grape Culture before the Massachusetts Board of Agriculture, says, - "I last year set two thousand vines-nineteen hundred and seventyfive Concords, and twenty-five other varieties for playthings. If the Concords were blotted ont, after twenty years' experience I would not grow a grape to sell." J. F. C. Hyde agreed with Dr. Fisher, and stated that he had never made a dollar on any grape except the Concord. It is undoubtedly a grape which, more than any other, adapts itself to a great variety of soil, and to all situations and conditions. Notwithstanding its fruit ranks as only second or third rate in quality, yet it is more popular and profitable than any other variety grown in the country. This is owing to the healthy, hardy, and vigorous character of the vine, enabling it to bear neglect, ill treatment, and no treatment at all, and still yield an abundance of good fruit. It is a better grape for the table or for wine West aud South than at home. Worden and Moore's Early are pressing the Concord hard for first place.

After what I have written, I will only suggest that in planting seeds of the Concord we may have a reasonable expectation of obtaining new varieties of high merit. The fruit should be well ripened, and selected from perfectly healthy vines. Crush the 
berries, wash out the seeds, and pack them array in damp sand, in a cool cellar. Be sure and guard against mice, otherwise the seeds will come up before they have germinated. Plant ont the seed early in the spring, in fertile, well drained soil, sowing in drills from one to two inches deep. Others prefer to plant the grape whole, as soon as it is perfectly ripe. Either method may be adopted, the latter requiring the least trouble and care. Always select the best berries from the best clusters, and from well ripened wood. It will be noticed that sometimes a vine produces much finer and earlier fruit than most others of its kind, and no matter whether this is owing to its locality, better cultivation, or any other cause, it is likely to transmit its superior merits to its offspring.

Give the young plants partial shade till they have made two or three leaves, when they may be safely exposed to the sun. In some cases not more than half the seeds will germinate the first season. These are the strongest growers, but of ten prove sterile and of no value; while those that grow the second year will give a larger percentage of valuable seedlings. For this reason it is advisable to disturb the seed-bed as little as possible in taking up the vines in the fall, and take good care of such as grow the second year. If the ground is saturated with water, seedlings may be pulled up without using a fork or spade. They require no tying up to stakes the first year, aud only the usual cultivation of a garden crop need be given.

The young vines are likely to be injured by the action of frost on the roots and tops, if allowed to remain in the ground over the first winter, and for this reason had better be taken up and heeled in, in a safe place, where there is no danger from standing water. The second spring, shorten the roots and top by a clean cut of the pruning-knife, and plant out in good soil, two feet apart in the rows, with rows wide enough to admit a horse and cultivator. Tie up to a stake set by each vine, - a lath will answer, -and cultivate as occasion may require. As the vine reaches nearly to the top of the stake, pinch it off. It will cause the cane to "stock up," and the leaves will thicken up and enlarge. By closely observing the foliage and wood, you may judge of the future character of the seedling. Let the vines stand exposed during the second winter, because, if any are likely to prove tender, the sooner we know it the better: 
they should be condemned at once. Look out for milder the second year as well as the first, and, unless the season and locality are peculiarly unfarorable, reject all those that show unhealthy foliage.

Cut back the vines the following spring to two buds, and tie up the shoots, as they grow, to the stakes. Some of the stronger vines may show fruit, and a single cluster may be permitted, as, if it prove worthless, we wish to spend as little time on that particular specimen as possible. But do not condemn hastily, as the fruit of the vine often improves as it attains age. Cut back one of the canes in antumn to two buds, and shorten the other to three or four feet, to be layered in the spring. The object of layering before we know more about the seedling is to obtain vines for early fruiting, as the plants from lavers will often fruit before the parent vine. Seedlings rill fruit in from three to ten year's, and any that are slow must be hurried up. The treatment need not vary much from year to year, till we learn what is the measure of our success. If in ten years we could produce a single vine in all respects better than the Concord, our reward would be ample. If one or more seedlings of value should be obtained, the manner of pruning and training them in the vineyard will be found explained on another page.

\section{CROSSING AND HXBRIDIZING.}

The seedlings above described are not what may properly be called chance seedlings; for we have been careful in selecting good seed from a good variety. But we may do better than this, there being a shorter road to success. 'There are numerous varieties of marked excellence, now well known, that are purely the result of skill in crossing and hybriclizing. These terms are often used indiscriminately; but crossing properly applies to the union of two varieties of the same species, while bybridizing is the mixture of two species. For example, our native grape (Vitis Labrusca) and the foreign grape (Vitis vinifera) are distinct species; and it was contended till within a few years that species could not be mixed. But there is no longer any cloubt of its entire practicability. Allen's Hybrid, Rogers' hybrids, Rickett's seedlings, and many others, are the results of successful efforts in this direction. No one pretends to doubt that varieties may be crossed, and most of the so-called chance seed- 
lings are the result of crossing without our aid. It is now well known that all perfect flowers have what are termed male and female organs. As these are found in the same flower, selffertilization is constantly taking place. But in crossing we must prevent self-fertilization, by removing the male organs and impregnating the germ by a flower of another variety.

Now the flower of the grape is very minute; so minute that its several parts can hardly be seen without the aid of a microscope of small power. As this subject is of so much importance and so exceedingly interesting, I here present magnified views of the grape flower, so that the operation of crossing may be clearly understood.

In Fig. 56, 1 represents the flower-bud before it has expanded, and just at the time when crossing must be attempted if we would be successful. The calyx $(A, 1)$, forming as it does a sor't of cap to the organs beneath, is being raised up by the elongation of the stamens as seen fully expanded at $B, 2$, and is just ready to be thrown off, leaving the pistil, which is the large central organ, exposed. That part of the pistil resembling a blunt perforated point, as seen at 2 or 3 , is the stigma. The fine, small organs projecting from every side of the pistil are the stamens, and consist of the anthers $(B)$ and the filaments $(D)$ by which they are supported. The anthers are filled with an exceedingly fine powcler called pollen, which is shaken

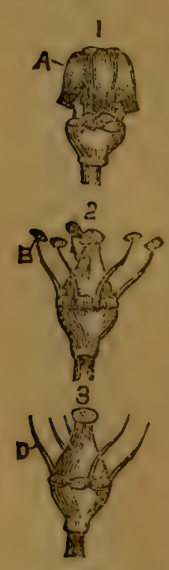
out by every movement of the wind, and carried by insects from flower to flower. It finds its way to, and lodges on, the stigma, which contains a viscid substance, by which the pollen is made to adhere. The pistil contains the rudimentary seeds, and, when fertilized, enlarges and becomes the fruit.

I do not propose to go at length into botany, but suffice it to say, that, in the absence of pollen, no such thing as fertilization could occur, and no fruit could be formed. In a few days the entire flower would drop off, - " blight," as it is termed,-and the vine would be barren. The pistil is fertilized by the pollen from the anthers $(B)$ through the stigma (3). Now if the anthers are removed as at Fig. 56. (D), no fruit would form for want of fertilization, 
unless pollen was received from some other flower. This might occur, as insects are constantly flitting from flower to flower with their downy coats covered with pollen, and, as it is very subtile, the air is filled with it when the vine is in flower. Crossing is constantly taking place in fruits, flowers, and vines, when two or more varieties are in blossom at the same time. The effect is not manifest in the fruit the same year, but only when we plant the seed and grow fruit therefrom.

Now, unfortunately, we have no perfect fruits or flowers. Some are very near perfection in one or two particulars, but fail to fill the bill in others. We find another variety that excels, and fails in just the opposite requisites. If we can but unite the surpassing excellence of both in one variety, we shall bave arrived almost at the end of our journey. We want a grape as large in bunch and berry as the Black Hamburg; as bardy, healthy, and productive as the Concord; at least two weeks earlier than the Hartford Prolific; that will bear handling as well and keep as long as the Diana; and in quality, equal to the Delaware in its best condition. This would not give us a perfect grape; but to enumerate other requisites might tend to discourage all efforts for improvement.

If the ideal grape is ever produced, it is likely to be by crossing or hybridizing varieties and species having the characteristics that we wish to combine. The desired result may be attained when least expected. But, while in crossing we may hope to unite the best qualities of two varieties, it may happen that we get only the faults of both; yet our chances of success are eubancerl by breeding from ancestry having the best blood.

The question, How shall we proceed in crossing so as to obtain a new variety having the characteristics of both parents? has already been hinted at, but may require a more minute explanation. The cut (2, Fig. 56) shows a perfect flower after the calyx has been removed. The pollen from stamens surrounding the pistil will be sure, under favorable conditions, to fall upon the stigma, when fertilization will occur. We say that such a flower is self-fertilized; but, if we remove the calyx as soon as it can be done, before the flower expands, and clip off the anthers with pointed scissors, as shown at $D$, Fig. 56 , self-fertilization cannot occur. Then gather the pollen from 
some other variety on a small crmel's-hair brush and apply it to the stigma of the flower to be fertilized. If the pollen and the stigma are in the right condition, we are reasonably certain of success, and this will be indicated in a few days by the swelling of the fertilized berry. It may happen, that, owing to difference of a few days in the time of flowering, the pollen may be in its best condition before the variety to receive it is sufficiently advanced. In this case we have only to collect and "bottle up" the pollen, as a physician treats his raccine matter, till wanted for use. It may, in this way, be preserved for many days, and sent long distances-perhaps around the world-by mail. It may, at no distant day, become an article of commerce, along with Irish potatoes, or olcomargarine and other soap-grease. To make sure that the prepared flower is not fertilized by insects, or pollen floating in the air, it should be covered with gauze or oiled silk for a few clays, both before and after the pollen is applied.

Of course, no one will confine his efforts to a single cluster, or a single cross; but the bunches shonld be carefully labelled, and a record kept for future reference. The seeds or berries are to be preserved and planted, and the seedling vines treated and trained according to the directions before given. It will be found in plant as in animal life, that the offspring resulting from a cross will in some instances resemble one parent more than the other, that having the strongest blood, or a character more firmly fixed, prevailing. Here we have the doctrine of prepotency in vegetable life.

It is well known that the foreign grape (Vitis vinifera), while it is of superior quality, cannot endure exposure in our climate. Our native vine (Vitis Labrusca) is as hardy as an oak, sour, pulpy, and foxy to the last degree. To unite the hardiness of our native grape with the almost perfect quality of the foreign species is what Mr. Rogers and others have attempted; and the numerous seedlings they have given us, which are almost if not quite equal to the best foreign varieties, attest their wonderful success.

In 1852 the American Pomological Society only recommended two varieties of grapes - the Catawba and the Isabella-for general cultivation; and in 1858 , three others-the Diana, Concord, 
and Delaware-were added. Now, purchasers are confused by the long lists in the catalogues from which to select. This shows what science and skilful practice, when working in harmony, accomplish.

\section{GATHERING AND KEEPING GRAPES.}

The grape is not, like most of the small fruits, a luxury that can be enjoyed only for a few days. However early it may ripen, it will improve by hanging on the vine till there is danger of severe frosts. It will not improve after being gathered. Some varieties keep for months, retaining their flavor to the last, while others become insipid in a short time; a few dry into a raisin.

The grape should be gathered when in its best condition, on a perfectly dry day, and handled with the utmost care. Look over each bunch, and remove all unsound and imperfect berries. Pack in clean boxes, in layers, between sheets of cotton batting, and store in a cool room or dry cellar. The Diana is one of the best keepers, while the Concord and its seedlings soon become worthless. This is undoubtedly owing to their thin, tender skin, that is easily ruptured in handling. Some pack in leaves, and others in dry hard wood saw-dust. Avoid any substance that will impart an unpleasant flavor to the fruit.

\section{A FEW LAST WORDS.}

I wish to impress upon the mind of whoever may take the trouble to read what is here written, some of the most important conditions in successful grape-culture in our northern latitude.

Never set a vineyard except with hardy varieties, such as will endure the extreme changes of our climate in winter on the stake or trellis, without protection.

Plant out only the best vines, not more than trro years old, grown from well ripened wood, of vigorous and healthy parents.

Select rather light but warm soil, naturally or artificially drained, having an inclination to the south, southrest, or southeast. Avoid heavy clay or muck on the one hand, and a hungry sand on the other.

Plow not more than one foot deep, and never turn the sub-soil to the surface. 
Manure with fine old compost, as for a good crop of corn,say ten cords to the acre. This preparation may be followed by mineral manures-ashes, ground bone, and gypsum-once in two or three years.

The Delaware and other slow growers will endure and require higher fertilization.

High manuring with rank nitrogenous manures canses a luxuriant growth of immature, spongy wood, in no condition to withstand disease and exposure, or to produce the best results in fruit. You want fruit, not barren canes.

Never select a spot for a vine where the soil or the foliage will be shaded. What is wanted is heat, especially at the root. Ten degrees of heat will hasten maturity at least ten clays.

Plant in situations protected by buildings, belts of evergreen trees, hedges, or high fences, when practicable. These will break the sweep of violent winds, that wonld otherwise drive off the heat so important to the vine. A hill-side is preferable to a valley.

Heavy, wet soil is to be avoided, as the temperature will be reduced by constant evaporation. The vine seldom fails for want of moistme.

Do not plant too many kinds for the market; but for the garden, let the varieties be such as to suit all tastes, and the quantity abundant.

Be cautious how you invest largely in new, high-priced varieties. Wait a little, and such vines will be as cheap as any, and you are not likely to want them at any price. They will have proved their entire worthlessness, or that they are no better than the old standard kinds.

Never direst a vine of its leaves to let in the sun, thinking thereby to hasten ripening. The exposure of the fruit to our hot suns by day, and cold winds and foggy air at night, will result in mildew and all manner of mischief. The foliage affords a natural shade and protection to the fruit; and the more luxuriant the foliage, other conditions being equal, the larger the fruit and the richer the flavor. 


\section{INDEX.}

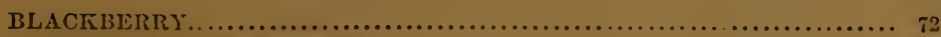

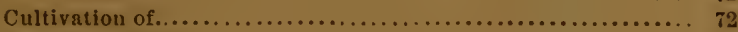

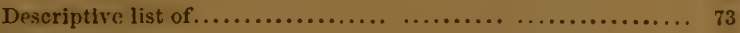

Diseases of . . . . . . . . . . . . .

Distance of plants.................................. 72

Hardy varieties................................. 72

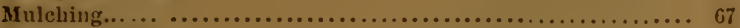

Picking the fruit..................................... $7_{2}$

Pinching back....................................... 72

Red or Orange rust................................ is

Remedies for rust................................... 74

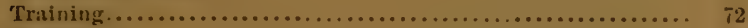

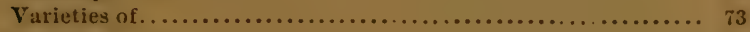

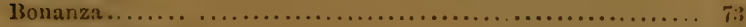

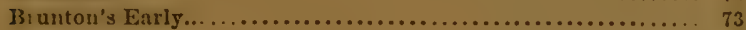

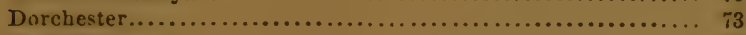

Early Harrest......................................

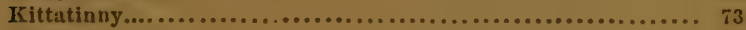

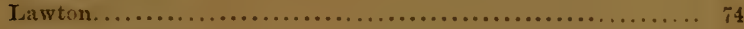

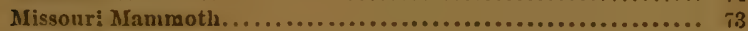

New Rochelle.................................... it

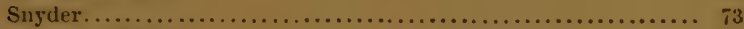

Stayman's Early .....................................

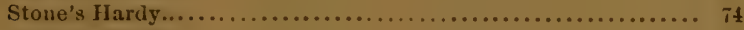

Taylor's Prolific......................................

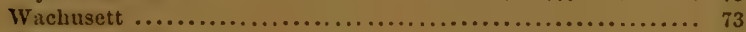

Western Triumph................................. T3

Wilson's Early.................................. 74

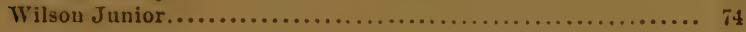

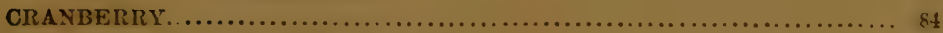

(oloring and cleaning................................ 90

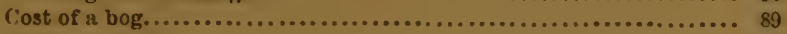

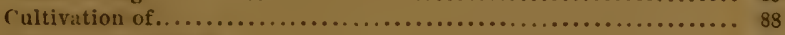

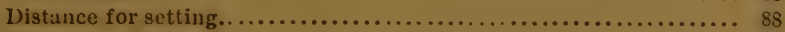

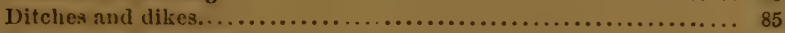

Duration of meadows.................................... 84

Flooding bogs............................................ 85

Insect enemies, .......................................... 87

Picking the fruit.......................................... 89

Preparing the bog............................................... 85

Profits of the crops........................................ 89

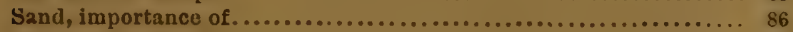

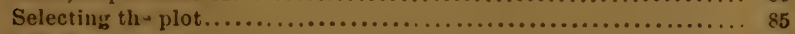

Selecting plants............................................. 87

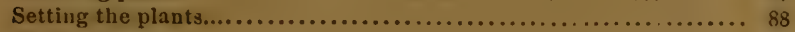

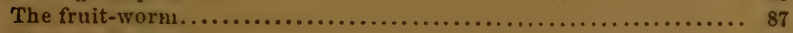

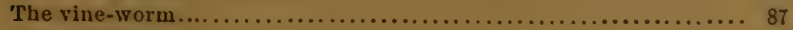

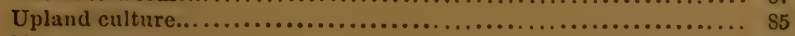

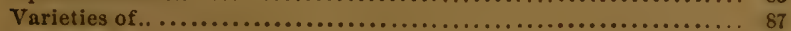

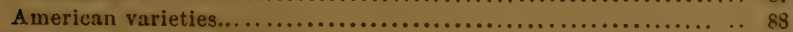

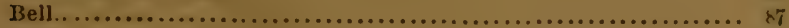

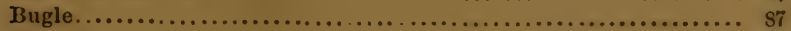

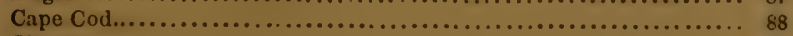

Cherry......................................... 87 


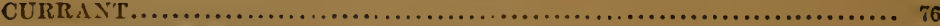

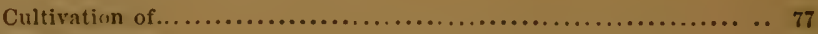

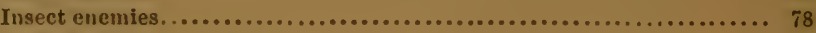

Mulchiug........................................... 77

Propagation by seeds....................................... 82

I'ropagation by cuttings.................................. i7

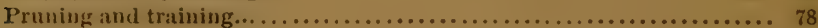

Shade for.......................................... 78

Soll for.................................................. 70

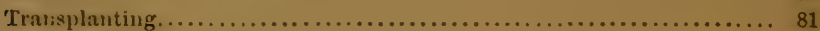

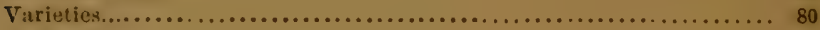

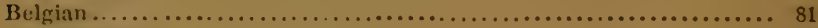

Black Naples.......................................... 81

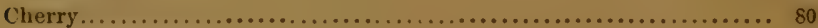

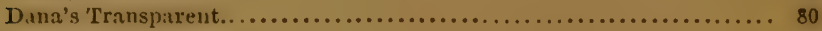

Fay's Prolific....................................... 81

Lee's Prolitic............................................ 81

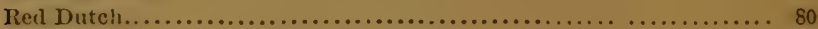

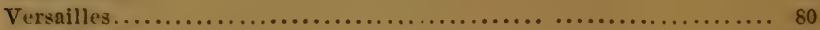

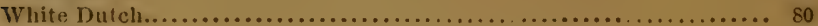

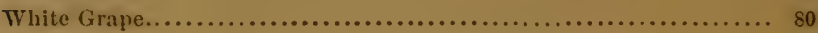

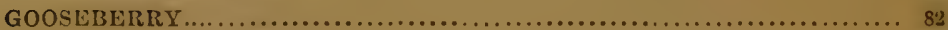

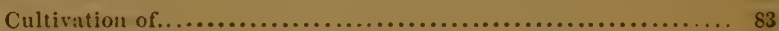

Close pruning.......................................... 84

Distance for planting.................................. 84

Grow in the shade....................................... 83

High manuring. ..................................... 83

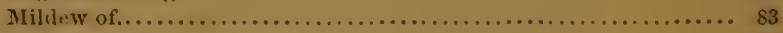

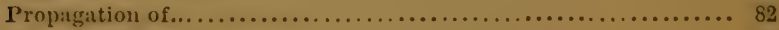

Native varieties...................................... 83

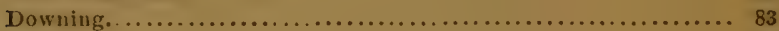

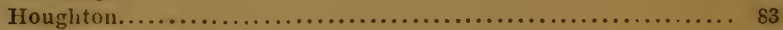

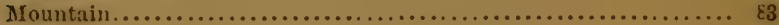

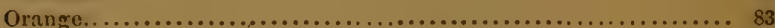

Pale Red........................................... 83

Smith's.. ....................................... 83

English varieties................................... 84

Crown Bob............................................. 84

Glenton Green............................................ 84

Roaring Lion........................................ 83

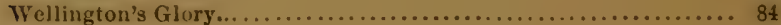

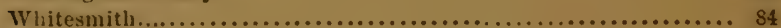

Yellow Amber........................................ 84

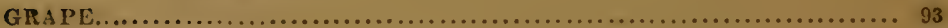

At the North........................................ 93

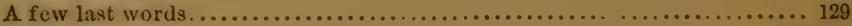

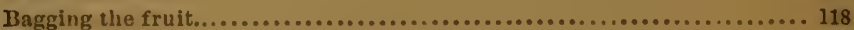

Bleeding of vines............................................. 106

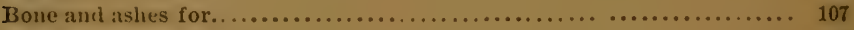

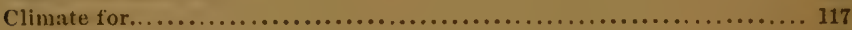

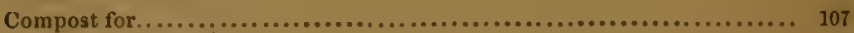

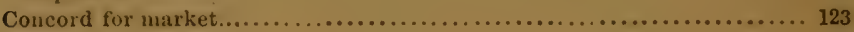

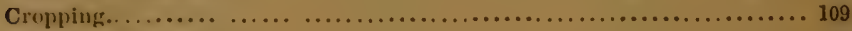

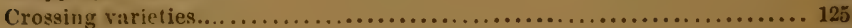

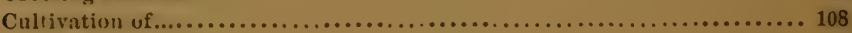

Cuttings........................................................... 96

Descriptive list. ............................................ 111

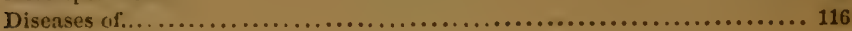


Distance to plant............................................ 104

Exposure................................................ 93

Foreign vines.................................................. 116

Fungus, bow spread......................................... 118

" protection froma........................................... 118

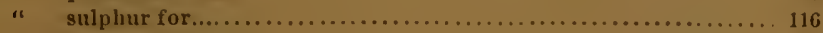

Grathering and keeping....................................... 12y

Grafting the vine............................................. 121

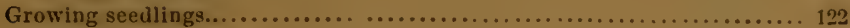

of in waste places........................................ 94

Heeling in.................................................. 98

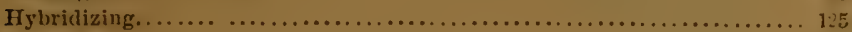

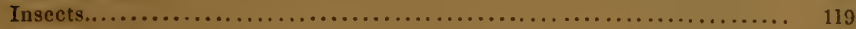

"Lenf-roller.......................................... 120

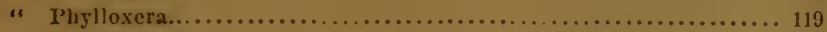

" Rose-chafer.................................................. 120

"s Steel-blue beetle........ ............................... 120

"remedies................................................... 120

Layering the vine................................................. 97

Mantures for................................................ 10 i

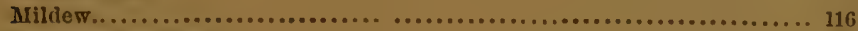

Northern limit of......................................... 93

New from seeds.................................................. 122

Over-cropping.................................................... 109

On fences and ledges............................................. 94

Pinching in................................................... 97

Planting cuttings............................................. 97

Propagation.................................................. 96

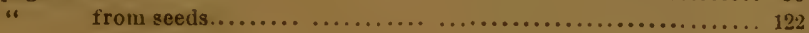

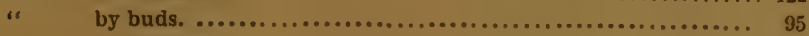

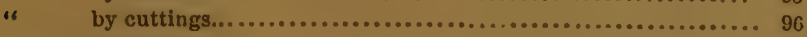

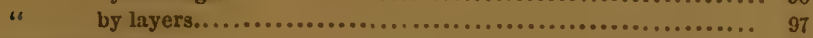

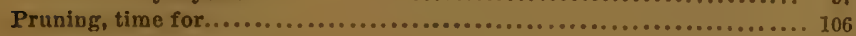

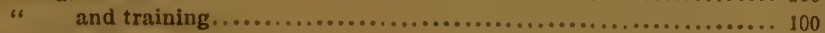

Ringing the vine.................................................. 122

Rot and mildew............................................... 116

Selection of varieties........................................... 110

Seedlings of Concord......................................... 123

Soil for...................................................... 93

Starting under glass.......................................... 95

Sulphur for mildew......................................... 116

The ideal grape............................................. 127

Thinning fruit. .................................................. 109

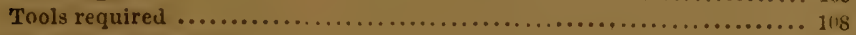

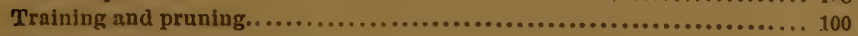

Transplanting............................................. 98

Tying to stakes.............................................. 97

Trenching.................................................. 94

Trellises................................................... 113

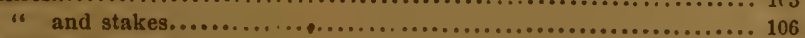

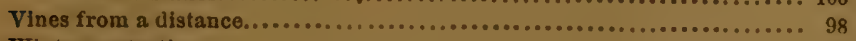

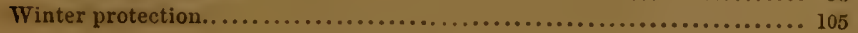

DESCRIPTIVE LIST, $\quad 111$

Adirondac. ........................................ 111

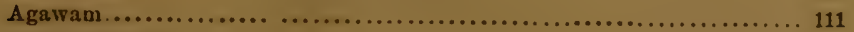

Allen's Hybrid.................................................. 111

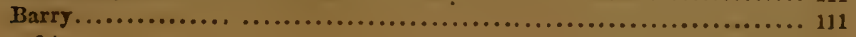




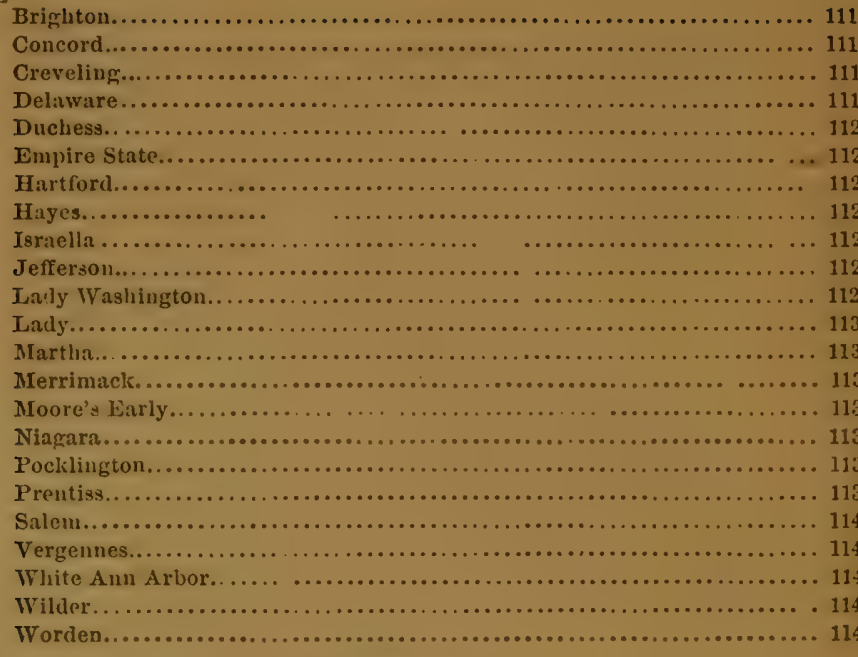

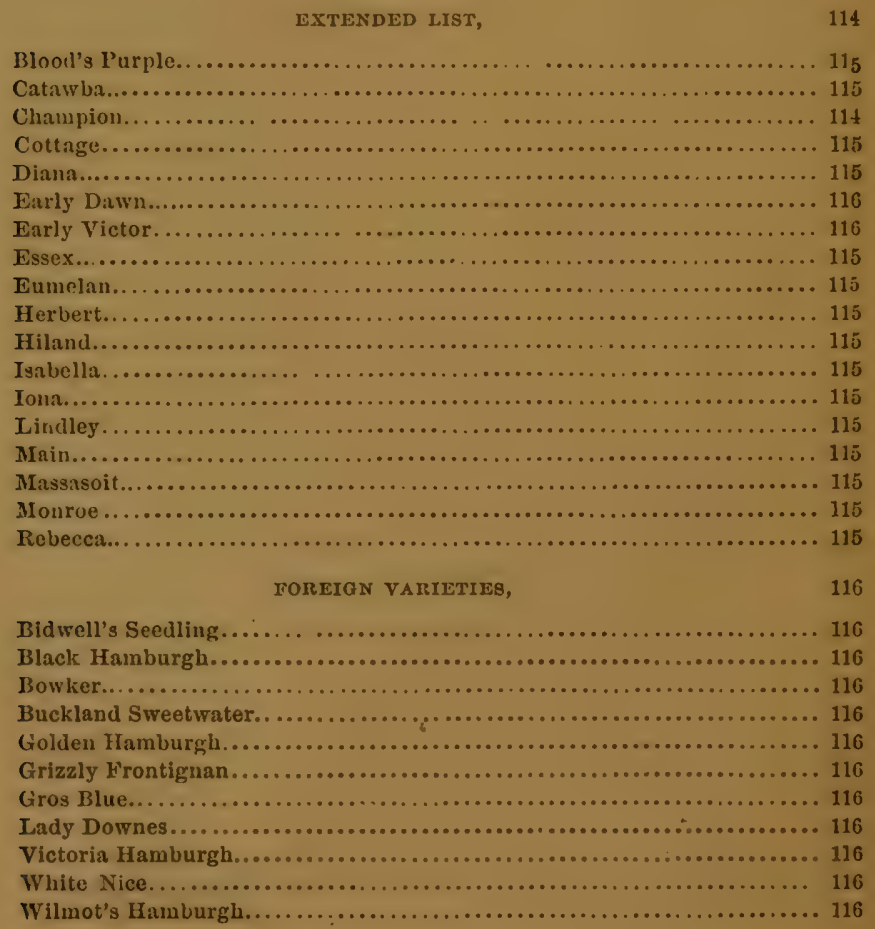




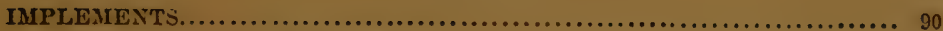

Acme and disc harrows................................ 90

Digging fork..................................... 91

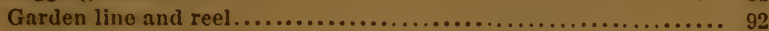

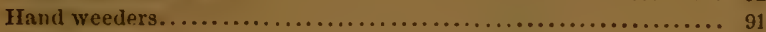

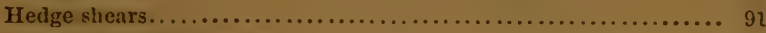

Kemp's manure spreader................................ 91

Pruning slears, ..................................... 91

Pronged hoe........................................ 91

Scuflle hoe........................................... 91

Spading fork......................................... 91

Steel rake.............................................. 91

Strawberry forks................................. si

Transplanting trowel................................ 91

MULBERRIES.............................................. 75

As ormamental trees....................................... 75

Downing's Ever-bearing............................... 75

Food for birds........................................ 76

Long in bearing.................................... 76

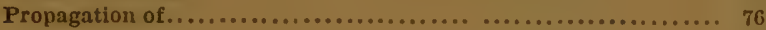

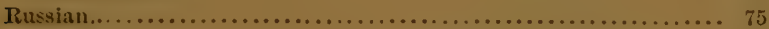

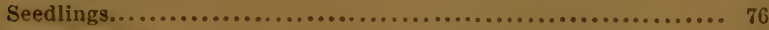

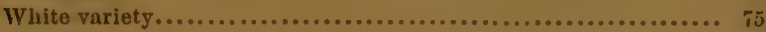

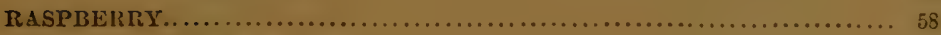

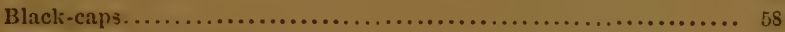

Distance for plantiug. ................................. 59

Green sucker plants.................................. 61

Growing new varieties.................................. 65

Growing in hedge-rows. ................................. 63

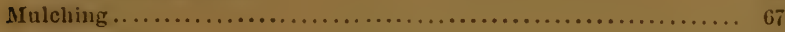

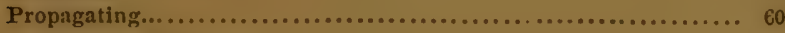

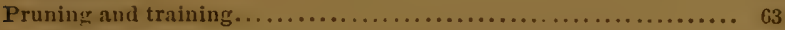

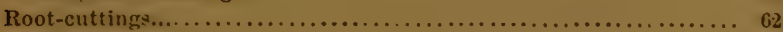

Soil and preparation. .................................... 59

Sucker plants...................................... 61

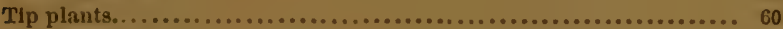

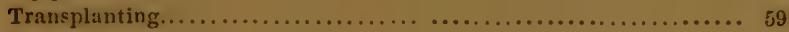

Winter protection..................................... $6{ }^{4}$

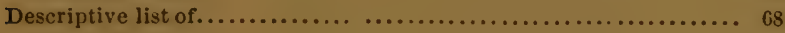

American 13 lack. ........................................ 70

Brandywine........................................ 68

Caroline................................................ 68

Centennial. ........................................... 71

Chapman................................................ 71

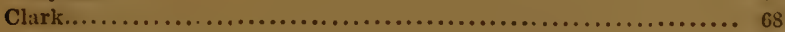

Crimson Beauty...................................... 69

Cuthbert........................................... 69

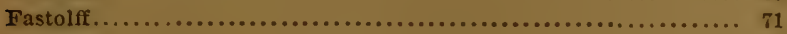

Florence......................................... 71

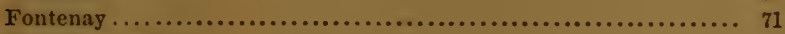

Four Seasons Red..................................... 71

Frauconia................................................ 69

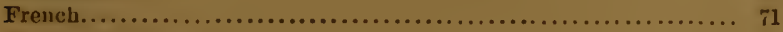

Golden Thornless....................................... 71

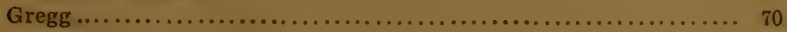

Hansell.. .................................................. 69

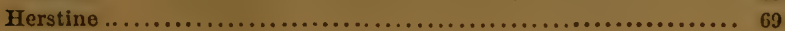




\section{RASPBERRY}

Hiland Hardy.................................... 71

Hopkins.......................................... 71

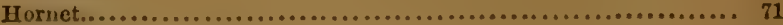

Hudson River Antwerp.................................. 71

Imperial Red............................................ 71

Ienevett......................................... $\tau_{1}$

Lost liubies....................................... 71

Marlboro .............................................. 69

McCormick.................................................. 70

Miami. ...........................................

Miller's Woodland.................................... 71

Nemalı............................................. 71

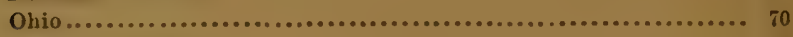

Ohio Everbearing........................................ 72

Orange (Brinckle's)........................................ 72

Philadelphia .............................................. 72

Pride of the Iudson......................................... 72

Purple Cane.......................................... 72

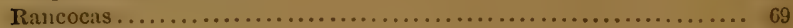

Reliance........................................... 69

Shaffer's Colossal..................................... 71

Smith's. . ............................................ $7_{2}^{2}$

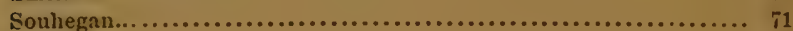

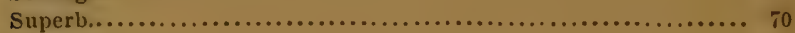

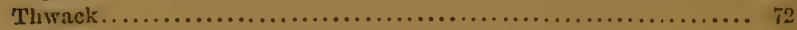

Turner.............................................. $7_{0}$

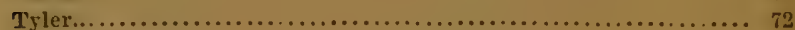

Wilson's Early........................................... it

Wilson Junior.................................... 74

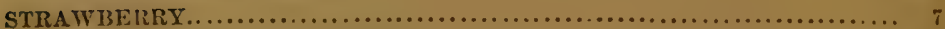

Advice to the novice..................................... 10

Adaptation of soil.................................... 24

Adaptation of varieties.................................. 24

Crossing and hybridizing............................... 32

Crossing, method of ....................................... 35

Crates and baskets.................................. 50

Cultivation.......................................... 38

Cutting rumers....................................... 39

Drahage............................................ 14

Distance for plants.................................. 22

Directions for planting.................................... 19

Early and late flowering................................. 43

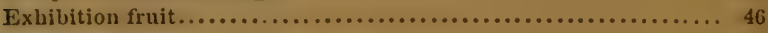

Fertilizers.......................................... 15

Field notes......................................... 43

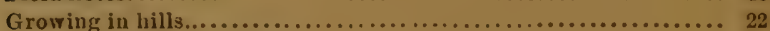

" in matted rows............................. 21

" in beds........................................ 22

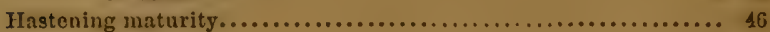

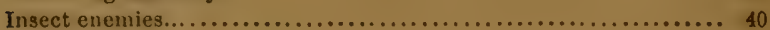

Imperfect flowers..................................... 3

Leaf-roller......................................... 41

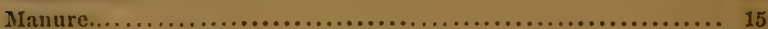

Mistakes in planting.................................... 21

Mulching....................................... 39

New varieties from seed............................... 30 


\section{STRA WBERRY -}

Ordering new varieties.................................. 25

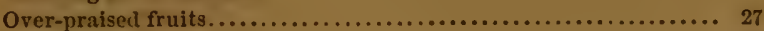

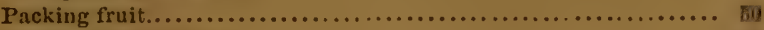

Picking and pickers.................................... 48

Packing plants.............................................. 37

Plants by mail........................................ 37

Plants from 8 distance.................................... 36

Protecting from frosts..................................... 42

Planting for home use..................................... 47

Planting on sod........................................ 14

Perfect fluwers........................................ 32

Potted plants............................................ 18

Preparation of soil...................................... 12

Rapid propagation................................... 29

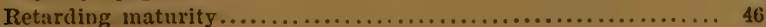

Runner plants........................................ 20

Sexuality of flowrers..................................... 32

Size of berries......................................... 45

Season for setting....................................... 16

Shipping plants........................................ 37

Substitutions......................................... 26

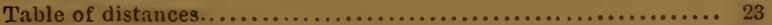

Treatment of seedlings................................ 31

What to plant.......................................... 23

White grub............................................ 40

Winter protection ................................... 39

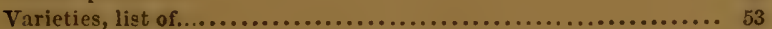

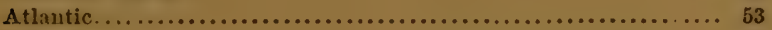

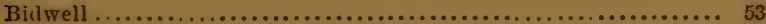

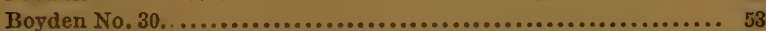

Captain Jack...................................... 54

Champion......................................... 54

Charles Downing. .......................................... 54

Crescent. . . . . . .

Cumberlaud........................................... 54

Downer's Prolific....................................... 55

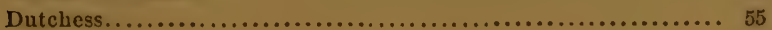

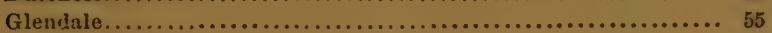

Great American....................................... 55

Hervey Davis......................................... 55

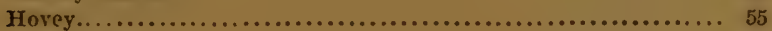

James Vick........................................... 55

Jersey Queen............................................ 56

Kentucky.......................................... 56

Mranchester.............................................. 56

Miner's Prolific..................................... 56

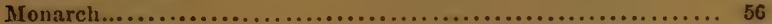

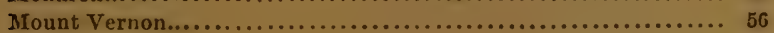

Mrs. Garfield......................................... 56

Pioneer.......................................... 57

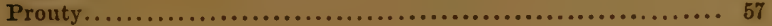

Sharpless................................................... 57

Triomph de Gand..................................... 57

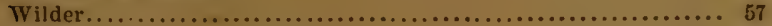

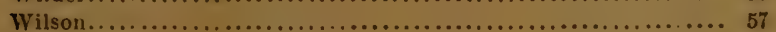

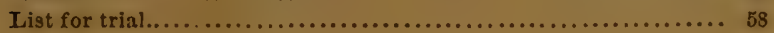


Black Defiance.................................. 58

Col. Cheney.................................... 58

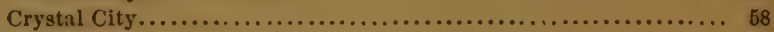

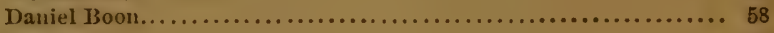

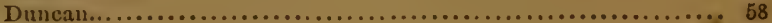

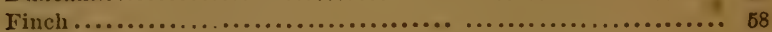

Forest Rose......................................... 58

Green Prolific.................................... 58

Golden Deliance..................................... 58

Jumbo.............................................. 58

Jucunda........................................... 58

Longfellow ........................................ 58

Park Beauty................................................ 58

Old Iron Clad. ....................................... 58

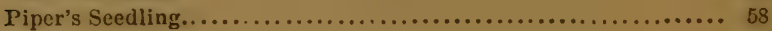

Primo............................................... 58

Ray's Prolific......................................... 58

Russell's Advance................................... 58

Senecr Queen ..................................... 58

Shirts.............................................. 58

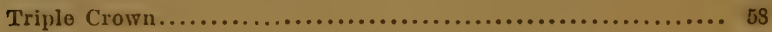

Warren............................................. 58 


\section{SELECTIONS}

FKOM

\section{THE CATALOGUE}

oF

CUPPLES, UPHAM \& CO. 



\section{A MER I C A N A.}

PEABODY. Esthetic Papers. Edited by Elizabeth P. PEÁody. I vol. 8vo.' Pamphlet. pp. 248 : Boston, 1849 . . \$2.00

A rare American pamphlet. It contains early papers by Emerson, Hawthorne, Parke, Godwin, Thoreau, and others.

PARKER. The Battle of Mobile Bay and the Cap'ture of Forts Powell, Gaines, and Morgan: By Commodore Foxhall A. PArker. Svo. Cloth, elegant. pp. 136. Portrait and two colored charts . . . . . . . . . . .

LONGFELLOW AND EMERSON. THE MASSACHUSETS Historical Sóciety's Memorlal Volume: Containing the addresses and eulogies by Dr. Oliver WeNDELI Holmes, CHARLes E. NORToN; Dr. G. E: ElLIS, and others, together with Mr. EMERson's tribute to Thomas Carlyle, and his earlier and much-sought-for addresses on Sir Walter Scott and Robert Burns. Illustrated with two full-page portraits in albertype after Mr. Notman's photograph of Mr. Longfellow; and Mr. Hawes's celebrated photograph of Mr. Emerson, taken in 1855 , so highly prized by collectors. I vol. $4^{\text {to. }}$ Boards, uncut, \$r.50; or in white vellum, cloth, gilt top, uncut edges . Limited edition printed.

"It is a marvellous piece of good printing, on exquisite paper, and illustrations superb." - Charles Deane, LL.D.

HISTORY OF THE INDEPENDENTS. Pamphlet. I vol. Square 8vo. pp. 65 ..............

This little book will be found to contain a large amount of information concerning the birth and growth of the Independent movement in Massachusetts, the cause of its establishment, and its possible influence in the future. A work of the greatest personal interest to every politician, and of the greatest general interest to every thinking man.

THE EAST AND THE WEST. Delivered in Boston, Sept. 22, 1878. By Dean Stanley. I vol. 8vo. Pamphlet . .

BOWDITCH. SUFFolk SURNAMEs. (Surnames of Suffolk County; Mass.) i vol. 8vo. Cloth. 383 pp. . . . . 3.00

FRANCIS S. DRAKE. MEMORIALS OF THE SOCIETY OF the Cincinnati of Massachusetrs. With plates. Royal Svo. Cloth. $584 \mathrm{pp}$. . . . . . . . . . . . I5.00

DE LA GUARD. The Simple Cobler of Aggavvam in America. BY Theodore de la Gúard. 16mo. Pamphlet . 0.50 A fac-simile reprint of the London edition of 1647 .

Any of the above works sent postprid to any part of the United States or Canada on receipt of the price.

CUPPLES, UPHAM, \& CO., Publishers, Boston. 


\section{A MERICA NA.}

ANTIQUE VIEWS OF YE TOWNE OF BOSTON.

Assisted by Dr. Samuel A. Green, Ex-Mayor of Boston, Librarian of the Massachusetts Historical Society; John Ward Dean, Librarian of the New England Historic Genealogical Society; and Judge Mellin Chamberlain, of the Public Library. An extensive and exhaustive work in 378 pages. Large quarto. Illustrated with nearly 200 fullsize reproductions of all known rare maps, old prints, \&c. I vol. 4 to. Cloth................. . \$7.50

FIRST CHURCH IN BOSTON. HISTORY OF, FROM I630 To I8So. By Arthur E. Ellis. With an introduction by George E. Ellis, D.D. Illustrated with plates. I vol. 8vo. Cloth. 356 pp.

SAMUEL A. GREEN, M.D., Ex-Mayor of Boston, Librarian of Massachusetts Historical Society. THE EARLX RECORDS OF Groton, MAss., 1662-1707. Illustrated, I vol. 8vo. $202 \mathrm{pp}$. .

EPITAPHS FROM THE OLD BURYing-Ground of Groton, MASS. With notes and an appendix. I vol. 8vo. Cloth. 271 pp.. . . . . . . . 3.00

Groton, MASS., DURING THE INDIAN WARS. I vol. 8vo. $214 \mathrm{pp} . . . . . . .2250$

HistoRY OF MEDICINE IN Massachusetts. I vol. 8vo. Cloth . . . . . . . . I.00

GEORGE E. ELLIS, D.D. MEMOIR OF JACOB BIgELOW, M.D., LL.D. With portrait. 1 vol. 8vo. Cloth . . . . 2.00

RALPH WALDO EMERSON. BY C. A. BARTOL. 8vo. Pamphlet. . . . . . . . . . . . .

JAMES T. FIELDS. A TRIBUTE. By C. A. BARTol. 8vo. Pamphlet . . . . . . . . . . . .

HENRY KNOX THATCHER, Admiral U. S. Navy. By Admiral G. H. Preble. With portrait. 8vo. Pamphlet . .

ALEXANDER HAMILTON VINTON. By PHILlips Brooks. 8vo. Pamphlet . . . . . . . .

DAVID PULSIFER. BATTLE OF BUNKer Hill. $16 \mathrm{mo}$.

Cloth ................ 0..75

[4 Any of the above works sent postpaid to any part of the Uniled States or Canada on receipt of the price.

CUPPLES, UPHAM, \& CO., Publishers, Boston. 


\section{A M ERICANA.}

EDWARD G. PORTER. RAMBLES IN OLD BOSTON, NEW England. By Rev. E. G. Porter, of Lexington, Mass, member of the Massachusetts Historical Society. With numerous illustrations from original drawings by Mr. G. R. Tolman. Dedicated to the Bostonian Society. (Nearly ready.) I vol. Large quarto. Handsomely bound in cloth, bevelled. . . . . . . . . . . . . \$6.00

The publishers hope to have this important work ready during the fall of 1885 . Orders received before publication will be booked at the rate of $\$ 5.00$.

E. WHITEFIELD. The Homes of OUR Forefathers. Being a collection of the oldest and most interesting buildings in Massachusetts. From original drawings in colors. With historical memoranda. I vol. Oblong quarto. Cloth, neat, gilt edges, bevelled

The Homes of OUR Forefathers. Second part. Uniform with the above, but embracing the historical homes of Rhode Island and Connecticut. 4to. Cloth . . . .

DANIEL T. V. HUNTOON. THE PROVINCE LAWS. I vol. Svo. Paper . . . . . . . . . . . . 0.25

KING'S HANDBOOK OF BOSTON HARBOR. BY M. F. SWEETSER. IVith 200 original illustrations. Second edition. 12mo. $280 \mathrm{pp.} \mathrm{.} \mathrm{.} \mathrm{.} \mathrm{.} \mathrm{.} \mathrm{.} \mathrm{.} \mathrm{.} \mathrm{.} \mathrm{.} \mathrm{.} \mathrm{1.50}$

KING'S HANDBOOK OF BOSTON. A Comprehensive, Detailed Description of Boston. Classified by subjects. $35^{\circ} \mathrm{pp}$. 200 illustrations. I2mo. Cloth, $\$ 1.00$; paper covers . . . . 0.50

KING'S DICTIONARY OF BOSTON. By EDWIN M. BACON, editor of "Boston Daily Advertiser." An elaborate history and description of the city. Cloth, gilt top, \$r.0o; flexible cloth, \$0.75; paper .............. . 0.50

PLYMOUTH, MASS. ANCIENT LANDMARKs of PlyMouth, MASSACHUSETrS. Containing historical sketch and titles of estates, and genealogical register of Plymouth families. By William $T$. Davis, former President of the Pilgrim Society. Svo. Cloth. pp. 312. With three maps............ 4.00

SWAMPSCOTT, MASS. Historical Sketches of the Town. By Waldo Thompson. Illustrated. I2mo. Cloth. $24 \mathrm{xpp}$. 1.00

155 Any of the above works sent postpaid to any part of the United States or Canada on receipt of the price.

CUPPles, UPHAM, \& CO., Publishers, Boston. 


\section{A MERICANA.}

OLD SOUTH CHURCH, BOSTON. (Third Church.) MEMORIAL ADDRESSES; viz., Joshua Scottow and John Alden, by H. A. Hill, A.M. ; Samuel Sewall, by G. E. Ellis, D.D., LL.D.; Samuel Adams, by E. G. PORTER, A.M. ; Ministers of the Old South from 1670 to $x 8 S 2$, by INCREASE N. TARBOX, D.D. With an index of names. I vol. 8vo. Cloth . . . . . . . . . \$1.co

THE SEWALL PAPERS. George E. Ellis, William H. Whitmore, Henry Warren Torrey, James Russell Lowell, Connittee of Publication. Diary of Samuel Sewall, 1674-1729. 3 vols. Large Svo. With elaborate index of names, places, and events. Cloth, $\$ 9.00$;

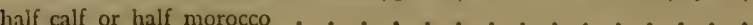

The famous diary of Chief Justice Sewall of Massachusetts, the manuscript of which is one of the treasures of the Massachusetts Historical Society. As a minute picture of the manners and customs of early colonial days, abounding in wit, humor, and wisdom, in the quaintest of English, it has hardly a prototype in the whole range of early American literature. Its publication, as an event, can be contrasted only with the deciphering of the diary of Samuel Pepys, with which it is so often compared.

Notz. - Two volumes, being the contents of Sewall's Manuscript Letter Book, are in process of anuotation for publication.

EDWARD H. SAVAGE. Boston Events. A Brief Mention and the Date of more than 5,000 Events that transpired in Boston from 1630 to 1850 , covering a Period of 250 Y'ears; together with other occurrences of interest, arranged in alphabetical order. I vol. 8vo. Cloth. $218 \mathrm{pp} . . . . . . . . . .$.

CHARLES WISTER STEVENS. REVELATIONS OF A BOSTON PHYSICIAN. 1 vol, 16 mo, Cloth . . . . . . .

GEORGE R. TOLMAN. TWELVE SRETCHES OF OLD BOSTON BuILdings. I vol Large folio . . . . . . . . 400

GEORGE E. ELLIS, D.D., LL.D. The Evacuation of BCston. With a Chronicle of the Siege. By George E. Elits, LL.D., author of "The Life of Count Rumford;" \&cc., \&c. With steel engravings, full-page heliotype fac-similes, maps, \&c. $x$ vol. Imperial 8vo. Cloth . . . . . . . . . . . .

PARKER PILLSBURY. ACTS OF THE ANTI-SLAVERY Apostles. I vol, 12mo. Cloth. pp. 503 . . . . . I.50

ए5is Any of the above works sent postpaid to any part of the United States or Canada on receipt of the price.

CUPPLES, UPHAM, \& CO., Publishers, Boston. 


\section{POETRY BY AMERICAN AUTHORS.}

EDWARD F. HAYWARD. PATRICE: HER LOVE AND Work. A Poem in four parts. I vol. I2mo. Cloth . . . . \$1.50

LEWIS. The Poems of Alonzo Lewis. New, revised, and enlarged edition. I vol. Svo. Cloth, pp. 500 . . . . . 2.00

POEMS OF THE PILGRIMS. Selected by ZII.PIIA H. SPOONER. (A handsome I 2 mo bound in cloth, bevelled edges, heavy paper, gilt edges. Illustrated in photography. The poems, about thirty in number, are selected from Lowell, Holmes, Bryant, Mrs. Sigourney, Mrs. Hemans, and other great writers) . . . . . 2.00

PAINE. BIRd SONGS OF NEw ENGLANd. Imitations in verse. By Harriet E. PAINE. 2d edition. Svo. Leaflet, tied . . . 0.50

ANGIER. Poemis. By Annie Lanman Angier. 12mo. Cloth 1.50

FRANCES L. MACE. LEGENDS, LYRICS, AND SONNETS. 2d edition, enlarged. I vol, 16mo. Cloth . . . . . . 1.25

M. F. BRIDGMAN. Mosses, and other Idyllic Poems. I vol. s2mo. Cloth . . . . : . . . . . . I.00 I vol. I6mo. White boards, gilt top, uncut ........ I.00

ALBERT LAIGHTON. POEMS. With frontispiece. $16 \mathrm{mo.}$ Cloth. $125 \mathrm{pp}$. . . . . . . . . . . 1.00

CHARLES SPRAGUE. Poetical and Prose Writings. New edition, with steel portrait and biographical sketch. 12mo. Cloth. 207 pp. . . . . . . . . . . . I.50

B. P. SHILLABER (Mrs. Partington). WIDE SWath, embracing Lines in Pleasaxt Places and other Rhymes, WISE AND OTHERIVISE. Popular edition. 12mo. Cloth. $305 \mathrm{pp}$.

JOHN BOYLE O'REILLY. SONGS, LEGENDS, AND BALLADS. 4th edition. 12mo. Cloth. $318 \mathrm{pp}$. . . . . . 1.50

JAMES H. WEST. Holiday IDLESSE. New edition, enlarged. 12mo. Cloth. $250 \mathrm{pp.}$. . . . . . . I.50

JOANNA E. MILLS. Poens. 16mo. Cloth. 94 pp. • . I.00

Ary of the atove works sent postpaid to any part of the United States or Canada on receipt of the price.

CUPPles, UPHAM, \& CO., Publishers, Boston. 


\section{POETRY BY AMERICAN AUTHORS.}

A. BRONSON ALCOTT: His Sonnets and Canzonets. Superbly printed on Whatman paper, with wide margins, gilt top, and uncut edges. Illustrated with many photographic portraits, reproduced from the author's own private collection of his illustrious contemporaries. Only 50 copies printed. 8vo. White cloth, elegant. pp. 151 . . . . . . . . . . . . \$15.00

GEORGE LUNT. The Complete Poetical Writings of George Lunt. I vol. 16mo. Cloth . . . . . . . I.50

LOUISE IMOGEN GUINEY. SONGS AT THE START. IGmo I.00

MARY CROWNINSHIELD SPARKS. HYMNS, HOME, HARVARD. Illustrated. I vol, 12mo. Cloth . . . . 2.00

CAROLINE F. ORNE. MORNING SONGS OF AMERICAN FreEdom. I vol. Square I6mo. Cloth ........ 1.00

OWEN INNSLY. LOVE POEMS AND SONNETS. With vignette. 3 d edition. 16mo. Limp cloth, gilt top, uncut edges . . I.00

ERNEST WARBURTON SHURTLEFF. EASTER Gleams. 16mo. Parchment ......... 0.35. an introduction by HezeK1AH Butterworth. 16mo. Cloth . . 1.00

CHARLOTTE FISKE BATES. RISK, AND OTHER POEMS. Second edition. 16mo. Cloth .......... 1.00

CHARLES HENRY ST. JOHN. COUNTRY LOVE AND City Life, and other Poems. r6mo. Cloth. . . . . 1.25

JULIA R. ANAGNOS. Stray ChORDS. With frontispiece. 1 vol. $16 \mathrm{mo}$. Cloth, gilt top, uncut edges , . . . . . . I.25

JAMES B. KENYON. SONGS IN ALL SEASONS. 16mo. Cloth 1.25

S. H. M. BYERS. THE HAPPy ISLES, AND OTHER PoEMS. I vol. 16mo. Cloth. . . . . . . . . . I.25

HERBERT WOLCOTT BOWEN. VERSES. I Vol. I6mo I.00 LUCIUS HARWOOD FOOTE. A RED-LETTER DAY, AND OTHER Poems. I vol. Square 12mo. Cloth . . . . I.50

DIF Any of the above works sent postpaid to any part of the United States or Canada on receipt of the price.

CUPPLES, UPHAM, \& CO., Publishers, Boston. 


\section{PRACTICAL HANDBOOKS.}

BUTTS. Tinman's Manual, and Builder's and Mechanic's HANDBOOK. Designed for tinmen, japanners, coppersmiths, engineers, mechanics, builders, wheelwrights, smiths, masons, \&c. 6th edition. r2mo. Cloth. pp. 120........... \$1.25

BOXCE. The ART of LetTering, and Sign-Painter's MANUAL. A complete and practical illustration of the art of signpainting. By A. P. BoyCE. $4^{\text {th }}$ edition. Oblong $4^{\text {to. }} \cdot 3^{6}$ plain and colored plates . . . . . . . . . . . .

MODERN ORNAMENTER AND INTERIOR DECORATOR. A complete and practical illustration of the art of scroll, arabesque, and ornamental painting. By A.P. BoxcE. Oblong 4 to. 22 plain and colored plates. Cloth . . . . . . . . . . .

THE GAS CONSUMER'S GUIDE. Illustrated. 12mo. Cloth, $\$ 1.00 ;$ paper . . . . . . . . . . . 0.75

TOWER. MOdern AMERICAN Bridge-Building. Illustrated. I vol. Svo. Cloth . . . . . . . . . . 2.00

\section{THE MODERN HOUSE-CARPENTER'S COMPAN-} ION AND BUILDER'S GUIDE. By W. A. SyLVESTER.

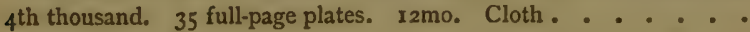

Being a handbook for workmen, and a manual of reference for contractors and builders; giving rules for finding the bevels for rafters for pitch, hip, and valley roofs; the construction of French and mansard roofs; several forms of trusses, stairs, splayed and circular work, \&c. ; table of braces, sizes and weights of window-sash, and frames for the same; table of board plank, and scantling measure, \&c. Also information for the convenience of builders and contractors in making estimates; making the most comprehensive work for the price yet published.

DERby. Anthracite and Health. By George Derby, M.D. (Harv.). 2d edition, enlarged. I2mo. Cloth, limp. 76 pp. .

POULTRY. The Raising and Management of Poultry, with a view to establishing the best breeds; the qualities of each as egg and flesh producers; their care and profit; and the great and increasing value of the Poultry interest to farmers and the country. A Phonographic Report of the meeting of Breeders and Experts held in Boston, March 7, 14, 1885. I vol. Square 4to. Paper . . . 0.50

NF. Any of the above works sent postpaid to any part of the United States or Canada on receipt of the price.

CUPPleS, UPHAM, \& CO., Publishers, Boston. 


\section{PRACTICAL HANDBOOKS.}

H. J. BARNES, M.D. Sewerage Systems. 12mo. Paper . \$0.5u

L. STONE. Domesticated Trout. How to Breed and Grow them. 3d edition. 12mo, $367 \mathrm{pp} . \ldots . . . .2 .00$

BAILEY. THE BOOK OF ENSILAGE; or, The New Dispensation for Farmers. By JohN M. BAILEy. 8vo. Cloth. 202 pp. Portrait and illustrations ................

A work of incalculable importance to the farmer, treating the new system of feeding cattle.

VILLE. High Farming without Manure. Six Lectures on Agriculture. By George Ville. Published under the direction of the Massachusetts Society for the Promotion of Agriculture. $16 \mathrm{mo}$. pp. roS . . . . . . . . . . . . .

A wonderfully cheap edition of a famous book.

\section{THE NEW BUSINESS-MAN'S ASSISTAN'T AND} READY RECKONER, for the use of the Merchant, Asechanic, and Farmer, consisting of Legal Forms and Instructions indispensable in Business Transactions, and a great variety of Useful Tables. 1 vol.

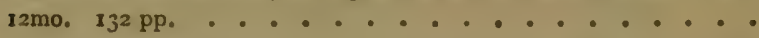

It would be difficult to find a more comprehensive compend of business forms and facts, for everyday use, than this valuable Assistant.

THOMAS KIRWAN. ELECTRICITY: WHAT IT 1S, WHERE IT COMES YROM, AND HOW IT IS MADE TO DO MECHANICAL WORK. I vol. I2mo. Paper. pp. 104. Illustrated. . . . . . 0.25

COUNT A. DES CARS. PRUNING FOREST AND ORNAMental Trees. From the 7 th French edition. Translated by Prof. C. S. SArgeNt (Harv.). 2d edition. I vol. 12mo. Cloth .

CARROLL D. WRIGHT. THE RELATION OF POLITICAL ECONOMY TO THE LABOR QUESTION. 16mo. Cloth. . . 0.75

Any of the above works sent postprid to any part of the United States or Canado on receipt of the price.

CUPPleS, UPHAM, \& CO., Publishers, Boston. 


\section{MEDICAL WORKS.}

HACKER. DiRections For THE ANTISEPTiC TREATMENT OF Wounds, aș employed at Prof. Billroth's clinic. By Dr. VICTOR R. v. Hacker. Translated by F. W. TAylor, M.D. Svo. Paper $\$ 0.50$

Williams. The Diagnosis and Treatment of Diseases of the Eye. By H. W. Williams, M.D., Professor of Ophthalmotology in Harvard University. With illustrations. I vol. Svo . . . . . . . . . . . . . . .

An important work by one of the most distinguished of living oculists. It embodies the scientific researches and the practical knowledge gained from many years' devotion to the eye and its diseases.

BROWN. The Medical Register for New England. A complete Directory and Guide. By Francis H. Brown, M.D. I vol. $16 \mathrm{mo}$. Cloth. pp. 512 . . . . . . . .

WARREN. SURGICAL OBSERVATIONS. With Cases and Operations. By J. MASON WARREN, M.D., late Surgeon to the Massachusetts General Hospital. I vol. Svo . . . . . . . . . . . .

The cases cited are mainly those which came under the author's personal charge during his practice at the Massachusetts General Hospital, and the volume contains much valuable information drawn from his surgical experience.

RUDINGER. ATLAS OF THE OSSEOUS ANATOMY OF THE HuMan Ear. By N. RUdinger. Translated and edited, with notes and an additional plate, by CLARENCE J. BrakE, M.D. 9 plates. 4to. Cloth extra . . . . . . . 3.50

BOSTON MEDICAL AND SURGICAL JOURNAL. Published weekly. Yearly subscription . . . . . . 5.00

FIRST HELP IN ACCIDENTS AND SICKNESS. A Guide in the absence or before the arrival of Medical Assistance. Hllustrated with numerous cuts. 12mo. Cloth. $265 \mathrm{pp}$. . . . . .

"A very useful book, devoid of the quackery which characterizes so many of the health manuals." - Am. Med. Ob.

"The directions given are such as may be understood by any one." New York MedicalJournal.

FISHER. Plain Talk about Insanity. Its Causes, Forms, Symptoms, and Treatment of Mental Diseases. With Remarks on Hospitals, Asylums, and the Medico-Legal Aspect of Insanity. By T. W. FisheR, M.D., late of the Boston Hospital for the Insane. Svo. Cloth . . . . . . . . . . . . . 1.50

Any of the above works sent postprid to any part of the United States or Canada on receipt of the price.

CUPPleS, UPHAM, \& CO., Publishers, Boston. 


\section{MEDICAL WORKS.}

Hunt. Some General Ideas concerning Medical ReForM. By David Hunt, M.D., Boston. Square 12mo. Cloth • \$0.75

JEFFRIES. DISEASES OF THE SKIN. The recent advances in their Pathology and Treatment, being the Boylston Prize Essay for 1871. By B. JoY Jeffries, A.M., M.D. Svo. Cloth . . . .

The Animal and Vegetable Parasites of the Human Skin and HaIr, ANd False Parasites of the HuMan BODY. By B. JOY JefFries, A.M., M.D. 12mo. Cloth . . .

LÜCKE. Surgical Diagnosis of Tumors. By A. Lücke (Strasburg). Translated by A. T. СABOT, M.D. I6mo. Pamphlet

BIGELOW. LITHOI.APAXY, OR RAPID LITHOTRITY WITH Evacuation. By Henry J. Bigelow, M.D., Professor of Surgery in Harvard University, Surgeon of the Massachusetts General Hospital. Svo. Cloth. Illustrated . . . . . . . . .

BOTH. Small-POX. The Predisposing Conditions and their Prevention. By Dr. CARL Both. 12mo, Paper. 50 pp. . .

"It has more reason as well as trore science than anything we have met." - Universalist.

"Should be read not only by the physician, but by every person." Ecl. Mfed. Fournal.

Consumption. By Dr. Carl Both. 8vo. Cloth . .

This is the first work ever published demonstrating the practical application and results of cellular physiology and pathology.

BRIGHAM. Surgical Cases, with Illustrations. By Charles B. Brigham, M.D., of Harvard University, Surgeon to the French Hospital at San Francisco, Member of the California State Medical Society, Chevalier of the Legion of Honor. I vol. 8vo. .

WHITNEY - CLARKE. A COMPENDIUM OF THE MOST IMPORTANT DRUGS, WITH THEIR DOSES, ACCORDING TO THE Metric System. By IV. F. IVuttnev, M.D., and F. H. Clarke. $32 \mathrm{mo} .40 \mathrm{pp}$. Specially made to fit the vest pocket . . . . 0.25

Any of the above works sent postpaid to any part of the United States or Carada on receipt of the price.

CUPPLES, UPHAM, \& CO,, Publishers, Boston. 


\section{BIOGRAPHICAL BOOKS.}

GRACE A. OLIVER. A Study of Maria Edgeworth. With notices of her father and friends. Illustrated with portraits and several wood engravings. 3d edition. I vol. pp. 56\%. Half calf, $\$ 5.00$; tree calf, $\$ 7.50$; cloth .......... $\$ 2.25$

A Memolr of Mrs. AnNa Letitia BARBAULD. With many of her letters, together with a selection from her poems and prose writings. IVith portrait. 2 vols. $12 \mathrm{mo}$. Half calf, $\$ 7.50$; cloth, bevelled, gilt top ....... 3.00

THe Story of THEODORE Parker.

I vol. 12mo. Cloth . . . . . . . . . .

Arthur Penriryn Stanley, Dean of

Westminster: His LiFE, Work, AND TeAchings. With fine etched portrait. $4^{\text {th }}$ edition. I vol. $12 \mathrm{mo}$. Half calf, $\$ 4.00$; tree calf, $\$_{5.00}$; cloth . . . . . . . . . . . .

E. B. CaLlender. Thaddeus Stevens (AMerican Statesmax, and Founder or the Republican Party). A MIemoir. With portrait. I vol. I2mo. Cloth . . . . . .

ANNA C. WATERSTON. ADELAIDE PHILlipts, THE American Songstress. A Memoir. With portrait. I vol. r2mo. Cloth . . . . . . . . . . . .

MARTHA PERRY LOWE. A MEMOIR OF CHARLES LOWE. With portrait. I vol, I2mo. Cloth。 pp. 592 ......

JOHN LE BOSQUET. A MEMORIAL: With REMINISCENCES, Historical, Political, and Characteristic, of John FArMer, aN AMERICAN ANTiQuarian. I vol. 16mo. Cloth .

JUDITH GAUTIER. RICHARD WAGNeR AND HIS POETICAL IVORK, FrOM "RiENZI" TO "PARSIFAL." Translated by L. S.J. With portrait, I vol. I2mo. Cloth . . . . . . . . 1.00

A. BRONSON ALCOTT. Ralph IVALdo EMERSON: His Character and Genius, in Prose and Verse. With portrait and photographic illustrations. I vol. Small 4 to. Cloth . . . 3.00

CHARLES H. BRAINARD. JOHN HOWARD PAYNE. A Biographical Sketch of the author of "Home, Sweet Home." IVith a narrative of the removal of his remains from Tunis to IVashington. With portraits and other illustrations. I vol. Svo. Cloth . . . 3.00

Any of the above works sent postprid to any part of the United States or Canada on receipt of the price.

CUPples, UPHAM, \& CO., Publishers, Boston. 


\section{WORKS OF FICTION.}

ANONYMOUS. Mr. AND Mrs. MORTON. A Novel. gth thousand. I vol. r2mo. Cloth ..... . . . . . \$1.25

GEORGE G. SPURR. THE LAND OF GOLD: A TALE OF '49. Seven illustrations. I vol. $12 \mathrm{mo}$. Cloth . . . . . . . I.50

IVAN TURGENEF. ANNOUCHKA. A Tale, I vol. $16 \mathrm{mo}$. Cloth . . . . . . . . . . . . . . . I.00

FREDERICH ALLISON TUPPER. MOONSHINE. A Story of the American Reconstruction Period. I vol. 16mo. Cloth . . . 1.00

MRS. H. B. GOODWIIJ. Christine's Fortune. A Story. I vol. IGmo. Cloth. . . . . . . . . . . . 1.00

Dr. Howell's Family. A Story of Hope and Trust. 3d edition. I vol. 16mo. Cloth . . . . . 1.00 I vol. $86 \mathrm{mo}$. Cloth .............. 1.00

PHILIP ORNE. Simply A Love-STORY. I vol. I6mo. Cloth

WILLIAM WILBERFORCE NEWTON. PRIEST AND MAN; OR, ABELARD AND HeloISA. An Historical Romance.

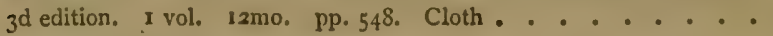

CARROLL WINCHESTER. From MADGE TO MARGARET. 3d edition. I vol. 12mo. Cloth . . . . . . . . I.25

\section{The Love of A Lifetime.}

A Story of New England. I vol. I2mo. Cloth . . . . 1.25

ANONYMOUS. WheELS AND WhIMS: AN ETCHING. An out-of-doors story, dedicated to American girls. With illustrations. I vol, x zmo. Cloth ..............

ANONYMOUS. SILKEN THREADS. I vol. I6mo. Cloth • 1.25

SALLY P. MCLEAN. CAPE COD FolKs. A Novel. Illustrated. I vol. 12mo. Cloth ........... I.50

TOWhead: The STORy OF A Girl.

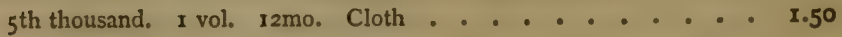

SOME OTHER FOLKS. A book in four stories. I vol. I2mo. Cloth. . . . . . . . . I.50 AfF Any of the above works sent postpaid to any part of the United States or Canada on receipt of the price.

CUPPlES, UPHAM, \& CO., Publishers, Boston. 


\section{WORKS OF FICTION.}

E. A. ROBINSON AND GEORGE A. WALL. THE

Disk: A Tale of Two Passions. I vol. 12mo. Cloth . . . \$1.00

MRS. GREENOUGH. THE STORY OF AN OLD NEw ENGLAND Town. (A new edition "The Annals of Brookdale.") I vol. I6mo. Cloth . . . . . . . . . . . 1.00

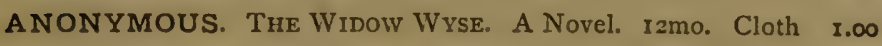

WILLIAM H. RIDEING. A LitTle UPSTART. A Novel. I vol. 16mo. Cloth ............. I.25

HEIDI: HER YEARS OF WANDERING AND LEARNING. How SHE USED WHAT SHE LEARNED. A story for children and those who love children. From the German of Johanna Spyri, by Mrs. Francis Brooks. 2 vols. in I. 12mo. Cloth. pp. 668. Elegant

This work was the most successful book for the young issued during the season. The whole edition was exhausted before Christmas. To meet the steadily increasing demand, the publishers now offer a popular edition at a popular price, namely, $\$ 1.50$, instead of $\$ 2.00$.

The Atlantic MIonthly pronounces "Heidi" "a delightful book ... charmingly told. The book is, as it should be, printed in clear type, well leaded, and is bound in excellent taste. Altogether it is one which we suspect will be looked back upon a generation hence by people who now read it in their childhood, and they will hunt for the old copy to read in it to their children."

A leading Sunday-school paper further says: "No better book for a Sunday-school library has been published for a long time. Scholars of all ages will read it with delight. Teachers and parents will share the children's enjoyment."

BY THE AUTHOR OF "AMY HERBERT." A GLIMPSE OF THE WorLd. By Miss E. M. SEWELl. I vol. 16mo. Cloth. pp. 537 ................. 1.50

AFTER LIFE.

I vol. Large I2mo. Cloth, pp. $4^{84}$. . . . . . . . . I.50

CUPPLES HOWE, MARINER: A TALE OF THE SEA.

By GeORGe CUPPLES, author of "The Green Hand." 12mo. Cloth . r.o

UFF Any of the above works sent postpaid to ary part of the United States or Canada on receipt of the price.

CUPPLES, UPHAM, \& CO., Publishers, Boston. 


\section{BOOKS OF TRAVEL.}

DANIEL E. BANDMANN. AN ACTOR'S TOUR; OR, SEVENTY THOUSAND MILES WITH SHAKESPEARE. With portrait after W. M. Hunt. I vol, 12mo. Cloth . . . . . . . . \$1.50

HATTON AND HARVEY. NEWFOUNDLAND. By JOSEPH Hatton and M. Harvey. $x$ vol. 8vo. Illus. pp. 450. Cloth .

ALFRED D. CHANDLER. A BICYCLE TOUR IN ENGLAND AND WALES. With four maps and seventeen illustrations. I vol. Square 16 mo. Limp cloth .............

J. E. L. Ten Days in The Jungle. A journey in the Far East by an American lady. With vignette. I vol. $16 \mathrm{mo}$. Cloth .

WILLIAM HOWE DOWNES. SPANISH WAYS AND BY. ways, with a Glimpse at the Pyrenees. Finely illustrated. I vol. Large Svo. Cloth . . . . . . . . . .

S. H. M. BYERS. SwitzerLANd AND THE Swiss. Historical and descriptive. By our American Consul. With numerous illustrations, I vol Svo. Leatherette ............

HENRY PARKER FELLOWS. BOATING TRIPS ON NEW ENGLAND RIVERS. Illustrated by Willis $\mathrm{H}$. Beals. I vol. Square r2mo. Cloth . . . . . . . . . . . .

THOMAS W. SILLOWAY. THE CATHEDRAL TOWNS OF ENGLAND, IRELAND, AND SCOTLAND. A description of Cities, Cathedrals, Lakes, Mountains, Ruins, and Watering Places. I vol.

8vo. Cloth ............... 2. 2. . . . . .

CHARLES W. STEVENS. FLy Fishing in MAINE LAKES; oR, CAMP LIFE IN THE IVILDERNESS. With many illustrations. New and enlarged edition. Square r2mo .......

WILliam H. PICKERING. WALKing Guide to THE Mount Washington Range. With large map. Sq. 16mo. Cloth

JoHn ALbeE. The Island of Newcastle, N. H. His. toric and picturesque. With many illustrations by Abbott J. Graves. I vol. 12mo, Cloth . . . . . . . . . I.00

WILLIAM H. RIDEING. ThaCKERAY'S LONDON. With portrait. I vol. $16 \mathrm{mo}$. Cloth . . . . . . . . . 1.00

Descriptive of the novelist's haunts and the scenes of his books, prefaced by a new portrait of Thackeray, etched by Edward $\mathbf{H}$. Garrett.

Any of the above works sent postpaid to any part of the United States or Carada
on receipt of the price. CUPPles, UPHAM, \& CO., Publishers, Boston. 


\section{RELIGIOUS BOOKS.}

JAMES R. NICHOLS. WHENCE, What, Where? A VIEW OF THE ORIGIN, NATURE, AND DESTINY OF MAN. With portrait. $9^{\text {th }}$ edition, revised. I vol. I $2 \mathrm{mo}$. Cloth ...... \$r.00

NATHANIEL S. FOLSOM. THE Four Gospels. Trans. lated from the Greek text of TISCHENDORF, with the various readings of Griesbach, Lachmans, Tischendorf, Tregelles, Meyer, ALFORD, and others, and with Critical and Expository Notes. $3 \mathrm{~d}$ edition. I vol. I2mo. Cloth. pp. $496 \ldots . . . .$. . .

E. J. H. First Lessons in the Articles of our Faith, AND Questions For Young Learners. By E. J. H. With Introduction by Rev, PHillips Brooks, D.D. 16mo. Boards . .

"A child who studies these pages, under wise directions, can hardly help being drawn into the presence of Jesus, hearing him speak, seeing him act, and so feeling, as the first disciples felt, the strong impulse to love him, to trust him, to obey him, and to give the heart and life into his care." $-E_{x-}$ iract from Introduction.

LOVING WORDS FOR LONELY HOURS. Oblong. Leaflet, tied. 22 pp. Printed in two colors. 6th thousand .. . Series. 22 pp. $2 d$ thousand . . . . . . . . . . . .

KNAPP. My WORK AND MINISTRY. With Six Essays. By Rev. W. H. KNAPP. 3d edition. 16mo. 327 pp. . . . . I.50

NEWTON. EsSAYS OF TO-DAY. Religious and Theological. By Rev. IVM. IV. Neivton, Rector of St. Paul's Church, Boston. 12mo. Cloth. $253 \mathrm{pp} . . . . . . . . . .2 .00$

"LET NOT YOUR HEART BE TROUBLED." Square 12mo. Leaflet, tied. $4^{8} \mathrm{pp}$. Printed in two colors. Illuminated covers. $4^{\text {th thousand } . . . . . . . . . . . . . . ~}$

REV. D. G. HASKINS. SELEctions From tHe ScRIPTURES. For Fanilies and Schools. I vol. 12mo. 402 pp. . . . . . I.50

G. P. Huntington. The Treasury of the Psalter. 12mo. Cloth . . . . . . . . . . . I.25

BY THE AUTHOR OF "AMY HERBERT" THOUGHTS FOR THE AGE. New edition. 12mo. $348 \mathrm{pp} . . . . . .1 .50$

Any of the above works sent postpaid to any part of the United States or Canada on receipt of the price.

CUPPleS, UPHAM, \& CO., Publishers, Boston. 


\section{BOOKS FOR THE YOUNG.}

\section{SEVEN AUTUMN LEAVES FROM FAIRY LAND.}

Illustrated with etchings, I vol. Small 4 to. Cloth. pp. I36 . . \$I 50

MRS. H. B. GOODWIN. CHRISTINE'S FORTUNE. I vol. r6mo. Cloth . . . . . . . . . . 1.00

DR. HOWELL'S FORTUNE. A Story of Hope and Trust. 3d edition. I vol. 16mo. Cloth . . . I.00 I vol. I6mo. Cloth .................... I.00

CARROLL WINCHESTER. FROM MADGE TO MARGARET. 3d edition. I vol. I2mo. Cloth .......... I.25

THE Love of A LIFETIME. An old New England Story. I vol. 12mo. Cloth . . . . I.25

MARY S. FULLER. Five LitTle Flower Songs. For the Dear Wee Folk. Large 4to. Pamphlet. Beautifully embossed pages................. . . 0.50

Contrants. - I. The Merry Sunflower. II. The Mayflower's Hiding. place. III. The Golden-rod and Purple Aster. IV. Out in the Oldfashioned Garden. V. Ragged Robin.

BY THE AUTHOR OF "AMY HERBERT." A GLIMPSE OF THE WORLd. BY Miss E. M. SEWEll. I vol. 16mo. Cloth. pp. 537 ................ 1.50

After Life.

I vol. Large r2mo. Cloth. pp. 484 . . . . . . . I.50

II CUPPLES, UPHAM, \& COMPANY keep always in stock a large line of Juvenile Books. Sunday-school and other libraries supplied at special rates. Send for catalogues and price-lists.

107 Any of the above works sent postpaid to any part of the United States or Canada on receipt of the price.

CUPPles, UPHAM, \& CO., Publishers, Boston. 


\section{BOOKS FOR THE YOUNG.}

CUPPLES. DRIVEN TO SEA; OR, THE ADVENTURES OF NORRIE Seton. By Mrs. George Cupples. Illustrated. Cloth, full gilt sides. Large r2mo. Ir th thousand. . . . . . . . \$1.00

The Deserted Ship: A Story of the Atlantic. BY GeORGE CUPPLES, author of "The Green Hand." Handsomely bound in cloth, gilt, extra. $12 \mathrm{mo}$. Illustrated . . . . . .

"In these two absorbing sea stories - "The Deserted Ship" and 'Driven to Sea' - the peril and adventures of a sailor's life are graphically described, its amenities and allurements being skilfully offset by pictures of its hardships and exposures, and the virtues of endurance, fortitude, fidelity, and courage are portrayed with rough-and-ready and highly attractive effusiveness." - Harper's Magazine.

NEWTON. Troublesome ChILDREN: Their UPS AND Downs. By William Wilberforce NewToN. With ten fullpage colored illustrations, and fifteen plain engravings by Francis G. Attwood. I vol. Thick oblong 4to. Exquisitely colored covers . .

Being wholly without cant, affectation, or any attempt to enter into the subtieties of religious creeds, the purity, sweetness, and combined teuderness and humor, together with its high moral tone, will give it an entrance to our homes and our American firesides in a way suggestive of the welcome accorded to the "Franconia" stories and "Alice's Adventures in Wonderland."

HEIDI: HER YEARS OF WANDERING AND LEARNING. How SHE USED WHAT SHE LEARNED. A story for children and those who love children. From the German of Johanna Spyri, by Mrs. Francis Brooks. 2 vols, in $\mathrm{x}$. 12mo. Cloth. pp. 668. Elegant

This work was the most successful book for the young issued during the season. The whole edition was exhausted before Christmas. To meet the steadily increasing demand, the publishers now offer a popular edition at a popular price, namely, $\$ 1.50$, instead of $\$ 200$.

The Atlantic Monthly pronounces "Heidi" "a delightful book ... charmingly told. The book is, as it should be, printed in clear type, well leaded, and is bound in excellent taste. Altogether it is one which we suspect will be looked back upon a generation hence by people who now read it in their childhood, and they will hunt for the old copy to read in it to their children."

A leading Sunday-school paper further says: "No better book for a Sunday-school library has been published for a long time. Scholars of all ages will read it with delight. Teachers and parents will share the children's enjoyment."

Any of the above works sent postpaid to any part of the United States or Canada on receipt of the price.

CUPPles, UPHAM, \& CO., Publishers, Boston. 


\section{BOOKS IN PAPER COVERS.}

CAPE COD FOLKS. A Novel. By SAlly P. MCLean. I vol. 12mo. Illustrated . . . . . . . . \$0.50

TOWHEAD: The Story of a Girl. By Sally P. McLean. I vol. 12mo . . . . . . . . . . . . . 0.50

SOME OTHER FOLKS. By SALLY P. McLEAN. A book in four stories. I vol, 12mo . . . . . . . . . .

MR. AND MRS. MORTON. A Novel. By "A New Writer." gth thousand. I vol. I2mo .............

THE DISK: A Tale of Two Passions. By E. A. Robinson and G. A. WVALL. 12mo . . . . . . . . . . .

THE NEW BUSINESS MAN'S ASSISTANT. By ISAAC

R. Butts. 49th thousand. I vol. I2mo . . . . . . .

THE WIDOW WYSE. A Novel. 4th edition. I vol. I2nıo

WHENCE; WHAT, AND WHERE: A VIEW OF THE Origin, Nature, And Destiny or Man. By James $R$. Nichols, gth edition. I vol. $12 \mathrm{mo}$. . . . . . . 0.50

THE STORY OF AN OLD NEW ENGLAND TOWN. 1 vol. $12 \mathrm{mo}$. . . . . . . . . . . . 0.50

ELECTRICITY : WHAT IT IS, WHERE IT COMES FROM, AND How IT IS MAde to do Mechanical WORK. By THOMAS KIRWAN. 12mo. Illustrated. pp, 102 . . . . . .

THE BITTER CRY OF OUTCAST LONDON. IgOth thousand. Pamphlet. 8vo ........... 0.10

AN ACTOR'S TOUR: SEVENTy Thousand MILES with SHAKESPEARE, By DANIEL E. BANDMANN. I vol. I2mo . . THE ERRORS OF PROHIBITION: AN ARGUMENT. By the late JOHN A. ANDREI, famous as the War Governor of Massachusetts. 8vo. roth edition . . . . . . . . . .

EVERY MAN HIS OWN POET; OR, THE INSPIRED SING ER'S RECIPE BOoK. By W. H. MALLOCK, author of "New Republic," \&c. Ixth edition. I6mo . . . . . . . . . . . .

THE HISTORY OF THE INDEPENDENTS. Pamphlet. I vol. Square 8 vo. pp. 65 . . . . . . . 0.50 0.50

0.50 0.50

0.50

0.25

0.75 0.50

CUPPLES HOWE, MARINER: A TALE OF THE SEA. By GEorge CUPples, author of "The Green Hand。" 12mo . . 0.50 Any of the above works sent postfaid to any part of the United States or Canada on receipt of the price.

CUPPLES, UPHAM, \& CO., PUblishers, BostoN. 


\section{MISCELLANEOUS.}

S. E. DAWSON. A STUdy, with CRITICal aNd Explanatory NOtes, OF Alfred TENNYSON'S POEM, "The PRINCESs." 16mo. Cloth ................ \$1. .

HASKINS. SELECTIONS FROM THE ScRIPTURES. For Families and Schools. By Rev. D. G. HAskins. I vol. 24mo. 402 pp. I.50

HOWE. Science of LANGUage; or, Seven.Hour System of Grammar. By Prof. D. P. Howe. Pamphlet. 3oth thousand . 0.50

WELLS. THE AMPhITHEATRES OF ANCIENT RoMe. By Clara L. Wells, I vol. 4to. Paper. . . . . . 2.00

Hall. Modern Spirttualism; or, The Opening Way. By Thomas B. Hall. r2mo. Cloth. . . . . . . 0.75

RIBBON BOOKS. Compiled by MARY S. Fuller.

LOVING WORDS FOR LONELY Hours. Oblong leaflet, tied. pp. 22. Privited in two colors. 6th thousand ......... 0.50

LOVING WORDS FOR LONELy HOURS. Second series. pp. 22. 2d thousand ...................

"Let not your Heart be Troubled." A further series. I2mo, leaflet, tied. pp. $4^{8}$............ 0.50

By the Same Author.

Five Little Flower-Songs. For the Dear Wee Folk. Large

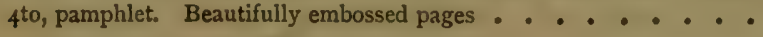

Contents. - I. The Merry Sunflower. II. The Mayflower's Hidingplace. III. The Golden-rod and Purple Aster. IV. Out in the Oldfashioned Garden. V. Ragged Robin.

HARVEY CARPENTER. THE MOTHER'S AND KINDERGARTNER'S FRIEND. I vol. 12mo. Cloth . . . . . . I.25

GEORGE PELLEW. JANE Austen's Nover: A Critical Essay. I vol. Svo. Limp cloth . . . . . . . 0.50

WALTER BESANT AND HENRY JAMES. THE ART of Fiction. 2d edition. I vol. 16mo. Cloth ...... 0.50

Any of the above works sent postpaid to any part of the United States or Canada on receipt of the price.

CUPPles, UPhAM, \& CO, Purlishers, Boston. 


\section{MISCELLANEOUS.}

IVAN TOURGUÉNEFF. POEMS IN PROSE. With portrait. I vol. 12mo. Cloth, gilt top, uncut edges . . . . . . \$1.25

E. C. WINES, D.D., LL.D. The State of PRisons and of Child-Saving Institutions in the Civilized World. I vol. Svo. Cloth. pp. 719 . . . . . . . . . . .

A vast repository of facts; and the most extensive work issued in any language, on matters relating to prison discipline and penal justice.

JAMES H. STARK. Illustrated Bermuda Guide. A description of everything on or about the Bermuda Islands concerning which the visitor or resident may desire information, including its history, inhabitants, climate, agriculture, geology, government, military and naval establishments. With maps, engravings, and 16 photo-

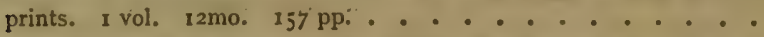

DIRECTIONS FOR SWEDISH SERVANTS, AND PHRASES TRANSLATED INTO SWEDISH. Re vised edition. Paper .............

ECRET EXPEDITION TO PERU; OR, THE PRACTICAL INFLUENCE OF THE SPANISH COLONIAL SYSTEM UPON THE Character and Habits of the Colonists. By George UlzoA. (Originaliy published in Boston, 1851. ) I vol. $16 \mathrm{mo}$. Cloth. $223 \mathrm{pp}$. . . . . . . . . . . .

GREENE. The Blazing Star. With an Appendix treating of the Jewish Kabbala. Also, a tract on the Philosophy of Mr. Herbert Spencer, and one on New England Transcéndentalism. By W. B. GREene, 12mo. Cloth. ISo pp. ......... .

Hall. Masonic Prayers. 4to. Large type. Limp cloth . ARCH. A Complete Guide to the Degrees of Mark Master, Past Master, M. G. Master, and Royal Arch. Approved and adopted throughout the United States. By JoHN K. HALL. Morocco, tuck.

Master Workmain of the Entered Apprentice Feliow-Craft and Master Mason's Degrees. By Jón $\mathrm{K}$. HAlL, P. H. P. of St. Pau's R. A. Chapter, Boston, Mass., and P. D. Gr. H. P. of the Grand Chapter of Massachusetts. Morocco, tuck .

Caf Any of the above works sent postpaid to any part of the Uniled States or Canada on receipt of the price.

CUPPles, UPHAM, \& CO., Publishers, Boston. 


\section{MISCELLANEOUS.}

4RTHUR LITTLE. NEW ENGLAND INTERIORS. A vol ume of sketches detailing the interiors of some old Colonial mansions. Thick oblong 4 to. Illustrated ............

"To those far distant, unfamiliar with the nooks and corners of New England, this work will be a revelation." - Boston Daily Advertiser.

ROLLO'S JOURNEY TO CAMBRIDGE. A TALE OF the AdVEnTURes of the Historic Holiday Family at HARVARD UNDER THE NEW RÉGIME. With twenty-six illustrations, full-page frontispiece, and an illuminated cover of striking gorgeousness. By FrANCIS G. ATTWOod. I vol. Imperial 8vo. Limp. London toy-book style. Third and enlarged edition . . .

"All will certainly relish the delicious satire in both text and illustrations." - Boston Traveller.

"A brilliant and witty piece of fun." - Chicago Tribune.

W. H. WHITMORE. ANCESTRAL TABLETS. A book of diagrams for pedigrees, so arranged that eight generations of the ancestors of any person may be recorded in a connected and simple form. $5^{\text {th }}$ edition. I vol. $4^{\text {to. }}$ Boards . . . . . . . . . . .

"Cupples, Upham, \& Co., Boston, we are glad to learn, are about to issue a new and improved edition of Mr. W. H. Whitmore's 'Ancestral Tablets.' No one with the least bent for genealogical research ever examined this ingeniously compact substitute for the 'family tree' without loriging to own it. It provides for the recording of eight lineal generations, and is a perpetual incentive to the pursuit of one's ancestry." - New York Nation, Marcle 26, 1885 .

JOHN WARE, M.D. Hints to Young MEN on the True RELATIONS OF THE SEXES. Irth edition. I vol. I6mo. Limp cloth . . . . . . . . . . . . . .

STARDRIFTS: A BIRTHDAY BooK. I vol. Small quarto. Imitation alligator, full gilt sides, $\$ 2.00$; full calf . . . . . .

An exquisitely made book, compiled by a committee of young ladies, in aid of "The Kindergarten for the Blind." Only a few copies remain for sale.

FRANCES ALEXANDER. THE STORY OF IDA. By Francesca. Edited, with Preface, by JoHin RUSkrn. With frontispicce by the author. $16 \mathrm{mo}$. Limp cloth, red cdges . . . .

The STORY OF Lucia. Trans. lated and illustrated by FrANCESCA ALEXANDER, and edited by JOHN RUskin. 16mo. Cloth, red edges . . . . . . . 0.75

[35 Any of the above works sent postpaid to any part of the United States or Canada on receipt of the price.

CUPPLES, UPHAM, \& CO., Publishers, Boston. 





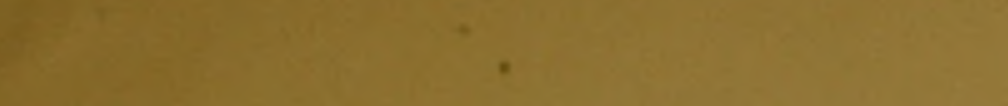

s.

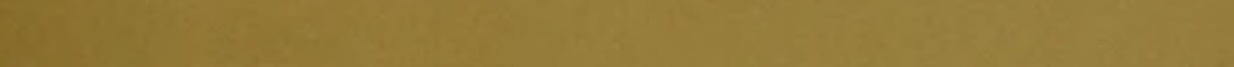

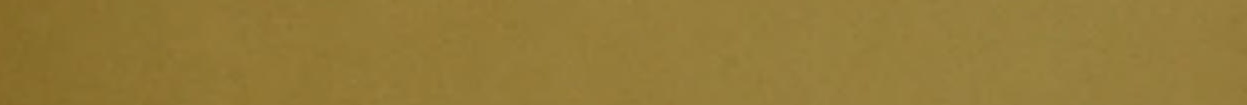

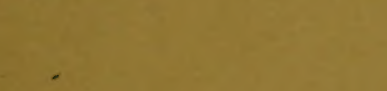

\section{$x^{2}$}

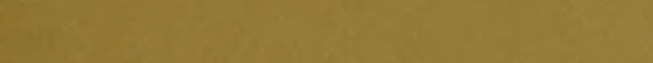

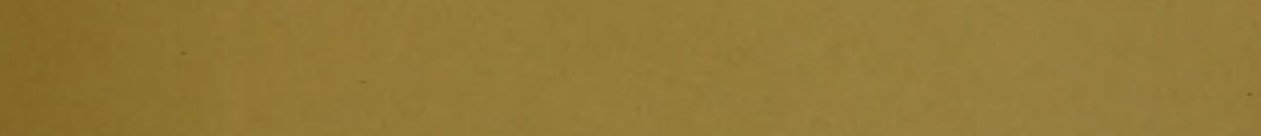

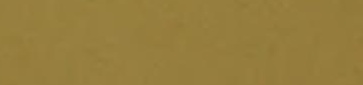

a.

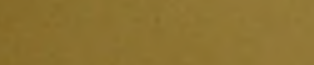

4

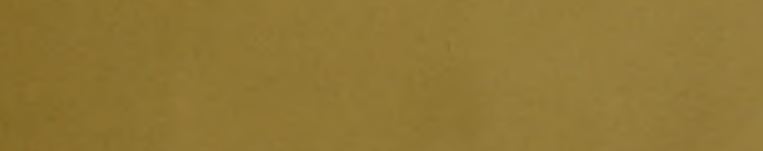

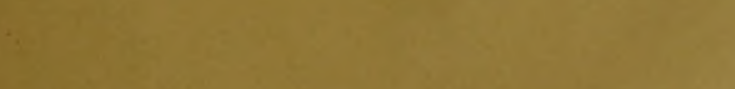

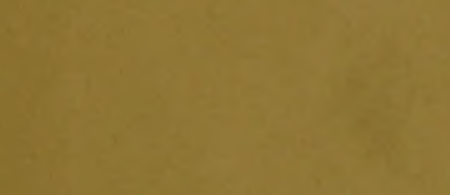

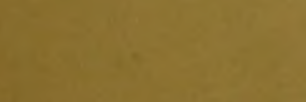

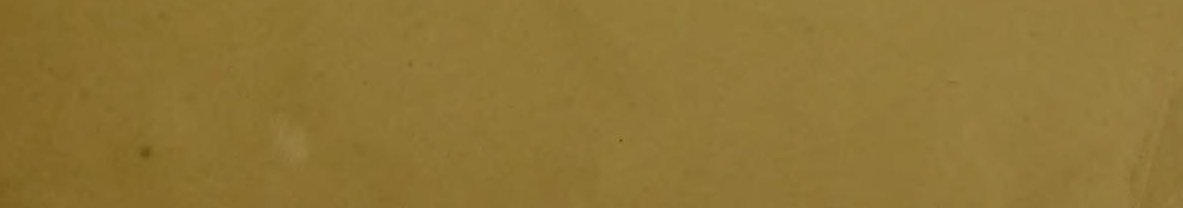



LIBRARY OF CONGRESS

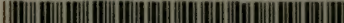

|||||||||||||||||||||||||||||||||||||||||||||||||

00009181544 